Instituto de Pesquisas Energéticas e Nucleares

Autarquia Associada à Universidade de São Paulo

\title{
ESTUDOS DO TRATAMENTO QUÍMICO DA SUPERFÍCIE DE PLACAS COMBUSTÍVEIS NUCLEARES
}

Olair dos Santos

\author{
Dissertação apresentada como parte dos \\ requisitos para obtenção do Grau de Mestre em \\ Ciências na Área de Tecnologia Nuclear - \\ Materiais \\ Orientador: \\ Prof. Dr. Adonis Marcelo Saliba Silva \\ Versão Corrigida \\ Versão Original disponível no IPEN
}

São Paulo

2014 
Dedico esse trabalho acadêmico à

À minha esposa Janice Augusto dos Santos, aos meus filhos Bruno, Olavo, Arthur e Beatriz que me incentivaram na realização de mais uma etapa vencida em minha vida. Graças à OXALÁ. 


\section{AGRADECIMENTOS}

Aos Drs. Adonis Marcelo Saliba Silva e Michelangelo Durazzo pela suas dedicadas orientações e incentivos indispensáveis que permitiram a realização desse trabalho de dissertação.

À Dra Elita Fontenelle Urano de Carvalho, ao Dr. Adonis Marcelo Saliba Silva, Gerentes do Centro do Combustível Nuclear - CCN, que facilitaram o acesso aos laboratórios do centro para experimentações desse trabalho.

Ao Dr. Lauro Roberto dos Santos, Gerente de Produção do Centro Combustível Nuclear - CCN, pela valiosa ajuda e disponibilização da estrutura produtiva para a realização das tarefas.

Ao colega Davilson Gomes da Silva, do Setor de Laminação de Placas e Montagem do Combustível Nuclear do Centro do Combustível Nuclear - CCN, pela realização das artes gráficas, tratamentos de imagem e execução de laminação dos núcleos combustíveis.

Ao M.Sc. Gilberto Hage Marcondes Centro do Combustível Nuclear - CCN pela troca de informações, discussão de dados e incentivos para a execução do trabalho.

Aos colegas Edeval Vieira, Sergio Rabello, Raimundo Rodrigues da Silva, Valdeci Aparecido da Costa e Ivo Oliveira de Jesus do grupo de Fabricação de Pós e Briquetes do Centro do Combustível Nuclear - CCN pelo apoio na preparação do pó e fabricação dos núcleos combustíveis.

Aos colegas Davilson Gomes da Silva, Eliezer Silas Bertelini e Aristeu Florêncio da Silva do Setor de Laminação de Placas e Montagem do Combustível Nuclear do Centro do Combustível Nuclear - CCN,pela execução de laminação dos núcleos combustíveis.

Sem desmerecer os colegas de laminação agradeço em especial ao amigo João Lopes de Araújo pelo sacrifício de seu trabalho em dobro para que pudesse poder terminar meu trabalho.

Aos colegas Felipe B. Jaldin Ferrufino, José Maria Fidelis, José Marcos F. da Silva e Sebastião Silva Macedo do setor de Controle de Qualidade do Centro do Combustível Nuclear - CCN, pela ajuda na preparação, execução e analise dimensional de radiografias.

Ao colega Eneas Tavares de Oliveira, pela ajuda na preparação, execução e análise das Medidas de emissão de radiação alfa e beta.

À colega Cristina Oscrovani Leandro, secretária do Centro do Combustível Nuclear CCN, por seu apoio e colaboração.

A todos que direta ou indiretamente contribuíram para que a realização do trabalho fosse finalizada.

Ao Instituto de Pesquisas Energéticas e Nucleares - IPEN/CNEN - SP, que proporcionou instalações, equipamentos e insumos para total realização do trabalho proposto. 
Por fim, agradeço aos meus familiares pela fé, apoio, carinho, atenção, disposição, e amor depositados em mim, tal como minha irmã Maria Francisca (Fia) que sempre me incentivou.

Tive na minha vida dois anjos que sempre me incentivavam e mostraram os melhores caminhos em memória Teatróloga, Atriz, Professora, Filosofa Carnavalesca e Militante pelas causas dos Povos Africanos Thereza Santos (Jaci Santos) e Engenheiro Sidney Axel Bock.

No mesmo sentido, agradeço às duas pessoas mais importantes da minha vida: aos meus pais, em memória João Camilo dos Santos e à minha amada mãe Maria Brigida dos Santos. 


\section{Sou negro}

Sou negro

meus avós foram queimados

pelo sol da África

minh'alma recebeu o batismo dos tambores

atabaques, gongôs e agogôs

Contaram-me que meus avós

vieram de Loanda

como mercadoria de baixo preço

plantaram cana pro senhor de engenho novo

e fundaram o primeiro Maracatu

Depois meu avô brigou como um danado

nas terras de Zumbi

Era valente como quê

Na capoeira ou na faca

escreveu não leu

o pau comeu

Não foi um pai João

humilde e manso

Mesmo vovó

não foi de brincadeira

Na guerra dos Malês

ela se destacou

Na minh'alma ficou

o samba

o batuque

o bamboleio

e o desejo de libertação

SOLANO TRINDADE 


\title{
ESTUDOS DO TRATAMENTO QUÍMICO DA SUPERFÍCIE DE PLACAS COMBUSTÍVEIS NUCLEARES
}

Olair dos Santos

\begin{abstract}
RESUMO
O Instituto de Pesquisas Energéticas e Nucleares - IPEN-CNEN/SP produz rotineiramente o combustível nuclear necessário para a operação de seu reator de pesquisas IEA-R1. Esse combustível é formado por placas combustíveis contendo núcleos de dispersões $\mathrm{U}_{3} \mathrm{Si}_{2}$-Al, obtidas por laminação. As placas combustíveis sofrem um tratamento químico para limpeza de sua superfície, com o objetivo de garantir a remoção de qualquer impureza presente em suas superfícies, incluindo resíduos de urânio. Nos últimos 10 anos foram constatados de forma esporádica aumentos significativos na atividade radioativa da água da piscina do reator IEA-R1. O aumento da atividade no ambiente do reator foi relacionado à entrada na piscina de elementos combustíveis recém-fabricados, entrando em operação. Apesar do processo de tratamento superficial atual estar perfeitamente estável e reprodutível, uma possível causa para o aumento da atividade da água da piscina do reator IEA-R1 é a presença de contaminação residual de urânio na superfície não retirada pelo tratamento químico superficial. Durante anos, esse problema não foi observado devido à baixa potência de operação do reator, no nível de $2 \mathrm{MW}$. Contudo, com o aumento da potência, acima de 3,5 MW, esse problema começou a ser observado. Esse trabalho verifica a hipótese da contaminação residual de urânio na superfície das placas combustíveis de forma estatística e caracteriza a adequação do processo de tratamento superficial de placas combustíveis. Utilizou-se uma metodologia estatística de avaliação do processo em três níveis: produção presente, contaminação intencional, produção histórica. A contagem de emissões alfa por contador de Nal permitiu a quantificação de urânio residual. Como resultado global, verificou-se que pode ocorrer contaminação abaixo de $1 \mu \mathrm{g}$ de ${ }^{235} \mathrm{U}$ por elemento combustível. Essa contaminação não é significante para causar eventuais acidentes de aumento de atividade no reator IEA-R1. Provou-se no presente trabalho que a metodologia de contagens de emissões alfa é segura, precisa e rápida para se analisarem contaminações superficiais de urânio nas placas combustíveis.
\end{abstract}

Palavras Chaves: elemento combustível nuclear; contaminação superficial; decapagem química; contaminação de urânio; contagem de emissão alfa. 


\title{
CHEMICAL TREATMENT STUDIES ON NUCLEAR FUEL PLATES SURFACE
}

Olair dos Santos

\begin{abstract}
Nuclear and Energy Research Institute - IPEN-CNEN/ SP routinely produces its own nuclear fuel elements, necessary for the operation of its research reactor IEA-R1. This fuel consists of fuel plates containing cores $\mathrm{U}_{3} \mathrm{Si}_{2}$-Al dispersions obtained by rolling. Fuel plates undergo a chemical treatment for surface cleaning, aiming to ensure the removal of any impurity present on the surface, including uranium residual dust. Over the past 10 years, it was found sporadically a significant increase of radioactivity emission in water pool of IEA-R1 reactor. The increased activity in the reactor environment was related to the use of newly fabricated fuel elements fed into the core. Although the actual surface treatment process to be perfectly stable and reproducible, a possible cause for the activity increase would be the presence of residual uranium contamination over the surface, which was not removed by chemical surface treatment. For years, this problem was not observed due to the low power of reactor operation, at the level of $2 \mathrm{MW}$. However, with the increase in power above $3.5 \mathrm{MW}$, this problem started to be observed. This work verifies the hypothesis of residual uranium contamination on the surface of the fuel plates in a statistical methodology and features the adequacy of the fuel plate surface treatment process. We evaluated, statistically, the process into three levels: present production, intentional contamination, historical production. The Nal alpha emission counter allowed quantification the amount of uranium residual. As an overall result, it was found that contamination may occur below $1 \mu \mathrm{g}$ of ${ }^{235} \mathrm{U}$ per fuel element. The contamination was judged as not significant to cause any activity accidents in the IEA-R1. It has been proven in this paper that the methodology to count alpha emissions is secure, accurate and fast to analyze surface uranium contamination in nuclear fuel plates.
\end{abstract}

Key words: nuclear fuel element, surface contamination, chemical treatment; uranium contamination, alpha emission counting. 


\section{SUMÁRIO}

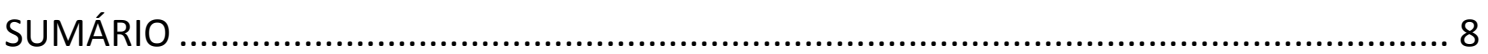

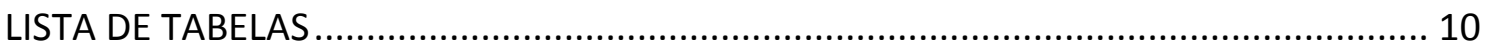

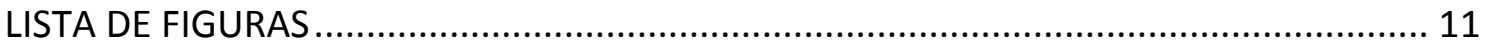

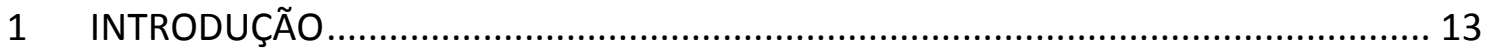

1.1 Fabricação das Placas Combustíveis ............................................................... 15

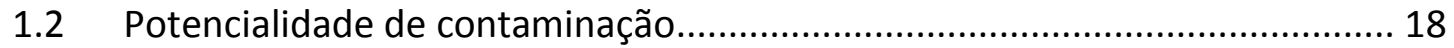

1.3 Influência de urânio livre no interior de reatores .......................................... 20

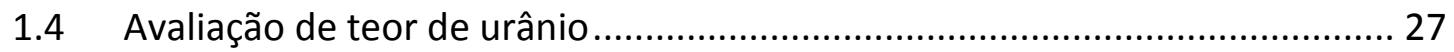

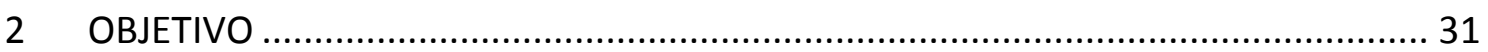

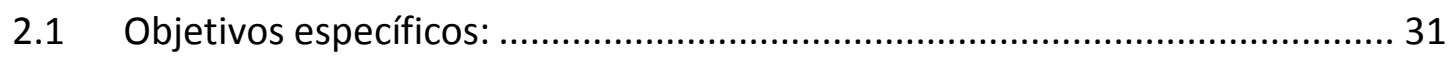

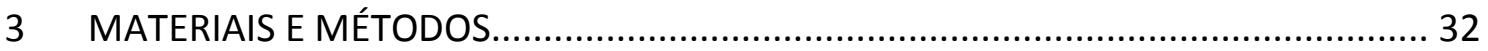

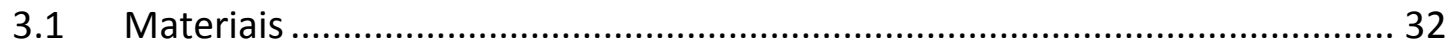

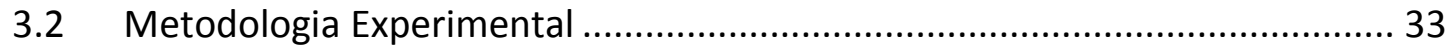

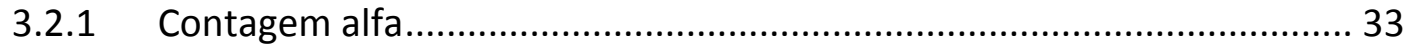

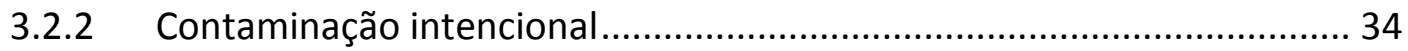

3.2.3 Preparação de amostras para contagens .............................................. 35

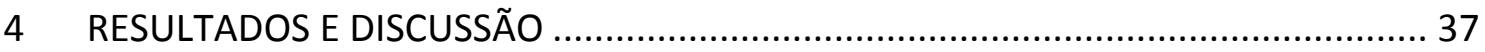

4.1 Primeira Fase Experimental: Contaminação de Rotina …............................... 37

4.1.1 Medidas de Contagem Alfa no Background ...................................... 37

4.2 Segunda fase Experimental: Contaminação Intencional ............................... 43

4.2.1 Avaliação da efetividade do tratamento químico .................................. 45

4.3 Terceira Fase Experimental: Contaminação Histórica ..................................... 49

4.3.1 Primeira Etapa: 10 amostras históricas................................................ 49

4.3.2 Segunda Etapa: amostragem maior (50 cupons) ................................5 52 


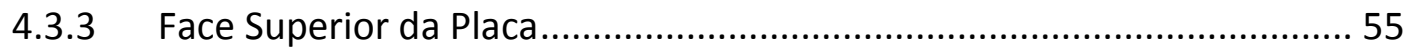

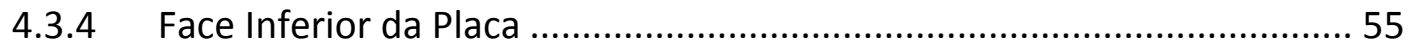

4.3.5 Possibilidade de Contaminação............................................................. 56

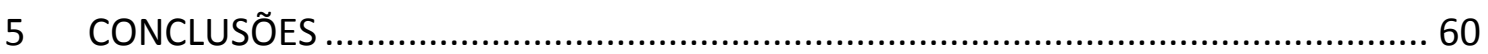

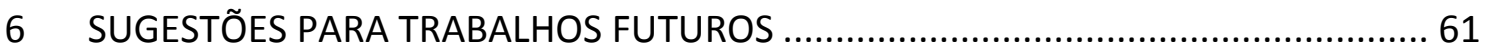

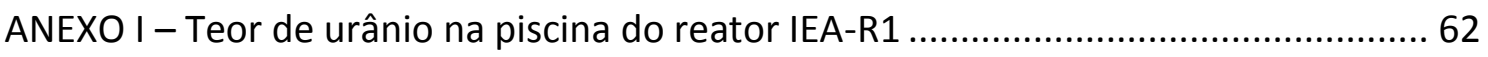

ANEXO II - Atividade Específica dos Produtos de Fissão Gasosa no reator IEA-R1 ........ 63

ANEXO III - Amostragem histórica ampliada - dados ................................................. 71

ANEXO IV - Esfregaço em placas combustíveis antes do tratamento químico .............. 77

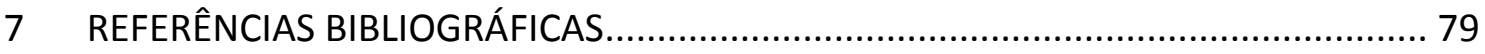




\section{LISTA DE TABELAS}

Tabela 1 - Dados de contagem alfa das placas na parte superior de laminação 39

Tabela 2 - Dados de contagem alfa das placas na parte inferior de laminação 39

Tabela 3 - Dados de contagem das placas contaminadas intencionalmente, na face superior e inferior sem tratamento superficial e na face superior e inferior com tratamento superficial. 44

Tabela 4 - Teste de Hipótese - 2a fase experimental - Eficiência do tratamento químico 46

Tabela 5 - Contagens de emissão alfa obtidas de 10 placas combustíveis fabricados no CCN. 50

Tabela 6 - Resumo dos dados apresentados na tabela 5. 50 Tabela 7 - Resumo estatístico do Anexo III da contagem alfa da amostragem histórica ampliada. Refere-se às placas combustíveis produzidas no CCN entre 1998 e $2013 \ldots 53$ 


\section{LISTA DE FIGURAS}

Figura 1 - Processo de fabricação de elementos combustíveis tipo MTR ..................... 15

Figura 2 - Vista das placas combustíveis montados no elemento combustível. ............ 16

Figura 3 - Montagem do conjunto núcleo-moldura-revestimentos para laminação.... 17

Figura 4 - Vista dos componentes da placa combustível após a laminação.

Figura 5 - Micrografias eletrônicas de varredura (elétrons retroespalhados) ilustrando incrustações de Si (A) e Fe (B) na superfície de placas combustíveis; 45X aumento [29].

Figura 6 - Micrografias eletrônicas de varredura (elétrons secundários) ilustrando a superfície de placas combustíveis após o tratamento superficial. (A) Evidências locais onde existiam incrustações; (B) A aparência superficial mostrando ataque uniforme, com ausência de corrosão localizada (pites); $1500 \mathrm{X}$ aumento. [29].............................. 20

Figura 7 - Famílias de decaimento dos isótopos de urânio 238 (A) e 235 (B).............. 22

Figura 8 - (A) Exemplo de desintegração do ${ }^{235} \mathrm{U}$ durante o processo de irradiação neutrônica. (B) Produção de ${ }^{138} \mathrm{Xe} \mathrm{e}{ }^{138} \mathrm{Cs}$ durante irradiação neutrônica [32]............. 24 Figura 9 - Níveis de atividade da água da piscina do reator IEA-R1 evidenciando aumento da atividade após a inserção de novos elementos combustíveis no caroço do reator. 26 Figura 10 - Decaimento natural de ${ }^{238} \mathrm{U}$ com níveis de energia das emissões energéticas [35]

Figura 11 - Simbologia e localização das amostras colhidas nas rebarbas resultantes do corte da placa combustível. 32

Figura 12 - Incrustação de pó de $\mathrm{U}_{3} \mathrm{Si}_{2}$ no conjunto soldado. ..................................... 34

Figura 13 - Preparação da proteção para o laminador................................................. 35 Figura 14 - Medidas de emissão de radiação alfa do ambiente (BG) no período de 1a fase dos testes de placas produzidas presentemente no CCN.

Figura 15 - Gráfico de média com dispersão mostrando o nível de contagem alfa por minuto nas diversas posições das amostras na face superior das placas laminadas \#877, \#878, \#879 e \#880. 
Figura 16 - Gráfico de média com dispersão mostrando o nível de contagem alfa por minuto nas diversas posições das amostras na face inferior das placas laminadas \#877, \#878, \#879 e \#880. O valor de BG médio com dispersão é apresentado no gráfico..... 41 Figura 17 - Resultados dos valores médios do tratamento em decapagem alcalina de $\mathrm{NaOH}$ durante 1 minuto nas amostras na forma de contagem de emissões alfa (CPM)

Figura 18 - Diagramas de caixa das médias mostrando o efeito de descontaminação com a média do background das emissões alfa. (a) face superior (b) face inferior.

Figura 19 - Gráfico ilustrando o efeito global do nível de contaminação das placas laminadas antes e após o tratamento de descontaminação. 51 Figura 20 - Diagrama de blocos contendo a média e os limites de confiança (95\%) das contagens de emissão alfa das amostras supSD e supCD. 55 Figura 21 - Diagrama de caixas contendo a média e os limites de confiança (95\%) das contagens de emissão alfa das amostras infSD e infCD. 56 Figura 22 - Histograma de distribuição das amostras da superfície inferior que foram decapadas e que apresentaram o nível de contagem alfa acima de 2,06. 57 


\section{INTRODUÇÃO}

O reator do IPEN/CNEN-SP, denominado IEA-R1, é utilizado para a produção de fontes radioativas seladas de aplicação industrial e, também, para produção de radioisótopos primários, dos quais se destaca o lodo-131. O reator IEA-R1 é um reator de pesquisa tipo piscina aberta $[1,2]$ que entrou em funcionamento em 1957 e operou até 1997 a $2 \mathrm{MW}$ de potência. A partir de 1995, foram efetuadas reformas substanciais nesse reator, o que viabilizou, com a conclusão das reformas em 1998, o aumento da potência do reator para até $5 \mathrm{MW}$ e a possibilidade de seu funcionamento durante 120 horas contínuas por semana.

Os reatores de pesquisa são basicamente empregados para a produção de radioisótopos e testes de materiais. Após a construção e operação desde 31 de março de 1952 do primeiro MTR (Materials Testing Reactor), empreendimento conjunto do ORNL (Oak Ridge National Laboratories) e do ANL (Argonne National Laboratories), os reatores de pesquisa, com elementos combustíveis tipo placa, têm sido denominados reatores tipo MTR. Os elementos combustíveis tipo MTR são montados a partir de um conjunto de placas combustíveis que são espaçadas entre si. Esse espaçamento permiti a passagem de um fluxo de água que serve como refrigerante e moderador. Cada placa combustível tem um núcleo prismático contendo o material físsil, selado completamente por placas laminadas de alumínio. Elas são fabricadas adotando-se a tradicional técnica de montagem núcleo, moldura e revestimentos e posterior laminação, técnica conhecida internacionalmente com o nome de técnica "picture-frame" [3-5]. Técnicas de metalurgia do pó são utilizadas na fabricação dos núcleos das placas combustíveis, compostos de briquetes, compósitos cerâmico-metálicos, utilizando atualmente pó de $\mathrm{U}_{3} \mathrm{Si}_{2}$ enriquecido a $20 \%$ no isótopo ${ }^{235} \mathrm{U}$ (material combustível), em conjunto com pó de alumínio (material estrutural da matriz do núcleo) $[3,6,7]$.

Assim como o reator IEA-R1, numerosos reatores de pesquisas em todo o mundo utilizam elementos combustíveis tipo MTR que, usualmente, empregavam placas combustíveis contendo núcleos de ligas urânio-alumínio fabricadas por laminação de um conjunto formado por núcleo, moldura e revestimento. Após a imposição de 
restrições na comercialização de urânio altamente enriquecido (acima de $90 \%$ em $^{235} \mathrm{U}$ ) [8], tornou-se necessário o aumento da quantidade de urânio em cada elemento combustível para que não fosse diminuída a reatividade e a vida útil dos núcleos dos reatores, abaixando-se o grau de enriquecimento para $20 \%$ em ${ }^{235} \mathrm{U}$. Essa situação conduziu ao desenvolvimento de novos combustíveis utilizando tipos diferentes de núcleos que possibilitaram a incorporação de grandes quantidades de urânio em cada placa combustível [3, 9-15]. Esta nova geração de núcleos combustíveis utiliza dispersões de óxidos e intermetálicos de urânio em alumínio, principalmente, nos dias de hoje, o $U_{3} S_{2}$, sendo este o mais recente material físsil utilizado comercialmente [6, 7].

Nesse contexto, o IPEN iniciou um programa de desenvolvimento objetivando a fabricação de combustível para suprir o seu reator de pesquisas IEA-R1, utilizando-se urânio com baixo enriquecimento $\left(20 \%\right.$ em $\left.{ }^{235} \mathrm{U}\right)$ na forma de dispersão em alumínio. Aproveitando-se a experiência anteriormente adquirida no desenvolvimento do processo de fabricação de placas combustíveis contendo núcleos de briquetes $\mathrm{U}_{3} \mathrm{O}_{8}-\mathrm{Al}$ [15-17] e, em virtude da fabricação deste tipo de combustível para o reator Argonauta do Instituto de Engenharia Nuclear, localizado no Rio de Janeiro. $[18,19], \mathrm{O}_{3} \mathrm{O}_{8}$ foi a opção inicialmente escolhida para utilização na dispersão.

Concluídos seus trabalhos de desenvolvimento visando o suprimento do seu reator, o IPEN está, desde 1989, fabricando placas combustíveis contendo núcleos de dispersões com tecnologia totalmente nacional. O IPEN, com a finalidade de operar o seu reator IEA-R1 a potências mais elevadas, preocupado em ampliar a produção de radioisótopos, iniciou em 1997 o desenvolvimento do combustível $\mathrm{U}_{3} \mathrm{Si}_{2}$-Al. A substituição do $\mathrm{U}_{3} \mathrm{O}_{8}$ pelo $\mathrm{U}_{3} \mathrm{Si}_{2}$ permitiu uma imediata elevação da densidade de urânio de 2,3 para $3,0 \mathrm{gU} / \mathrm{cm}^{3}$, possibilitando atingir-se $4,8 \mathrm{gU} / \mathrm{cm}^{3}$ [20], o qual é o combustível comercial mais avançado da atualidade, devidamente qualificado ao redor do mundo. A produção rotineira do combustível $\mathrm{U}_{3} \mathrm{Si}_{2}$-Al com densidade de $3,0 \mathrm{gU} / \mathrm{cm}^{3}$ começou no IPEN em 1999, iniciando-se a irradiação do primeiro elemento combustível nesse mesmo ano. Desde então o IPEN vem produzindo todo o combustível necessário para manter a operação do reator IEA-R1, cujo caroço de 24 elementos combustíveis é inteiramente 
composto por elementos combustíveis fabricados no IPEN. O novo combustível $\mathrm{U}_{3} \mathrm{Si}_{2}-\mathrm{Al}$ foi qualificado em 2005, quando 5 elementos combustíveis atingiram os requisitos de projeto com níveis de queima superiores a 30\%, sem apresentar problemas relacionados ao desempenho sob irradiação.

\subsection{Fabricação das Placas Combustíveis}

De modo geral, o processo de fabricação de elementos combustíveis tipo MTR, sejam do tipo óxido de urânio $\left(\mathrm{U}_{3} \mathrm{O}_{8}\right)$ ou siliceto de urânio $\left(\mathrm{U}_{3} \mathrm{Si}_{2}\right)$, apresenta as principais etapas ilustradas no diagrama de blocos apresentado na Figura 1.

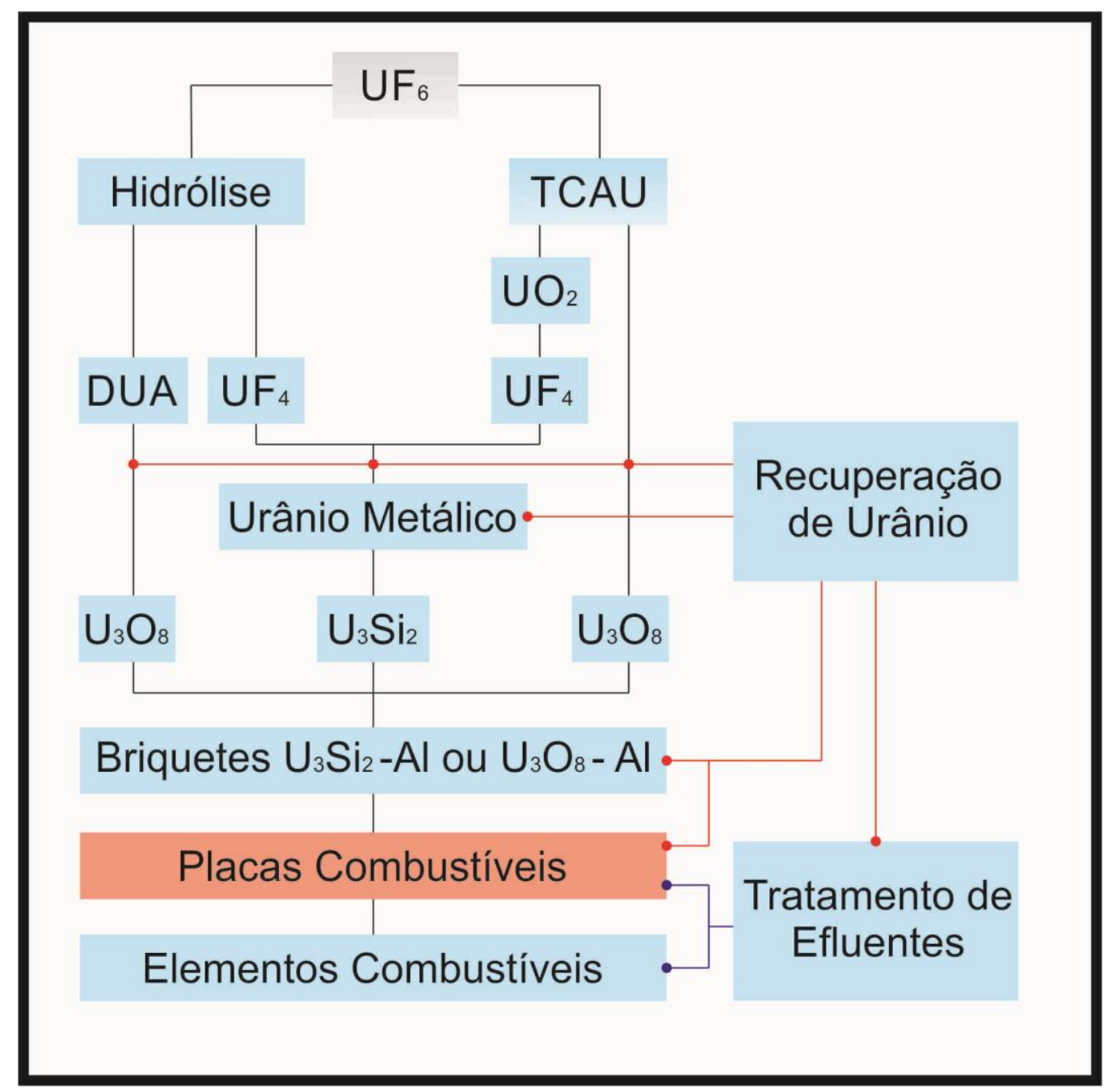

Figura 1 - Processo de fabricação de elementos combustíveis tipo MTR

A etapa do processo indicada em destaque nessa figura refere-se à fabricação das placas combustíveis, cuja qualidade superficial será o objeto de estudo deste trabalho. 
Como se pode observar na Figura 2, as placas combustíveis são as peças mais fundamentais do elemento combustível MTR, pois carrega a carga nuclear em seu núcleo. O elemento combustível consiste de um conjunto de 18 placas combustíveis, colocadas de forma paralela entre si, montadas de forma rígida. As placas combustíveis são inseridas em uma caixa prismática de alumínio, com ranhuras para contenção de cada placa individualmente. As placas são fixadas mecanicamente no interior dessa caixa fechando as ranhuras rigidamente. Assim se forma, o conjunto denominado elemento combustível.

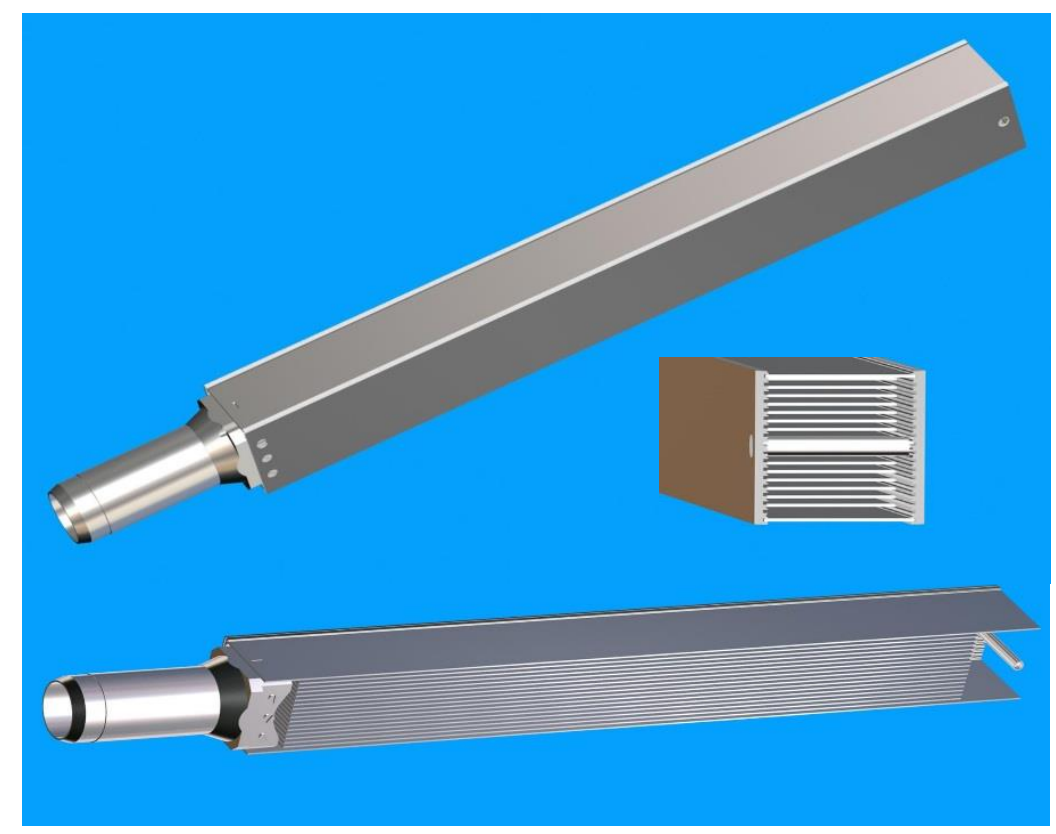

Figura 2 - Vista das placas combustíveis montados no elemento combustível.

Basicamente, o processo de fabricação das placas combustíveis do tipo MTR, baseia-se na laminação de um conjunto "Picture-frame" contendo um núcleo de dispersão $\mathrm{U}_{3} \mathrm{Si}_{2}$ $\mathrm{Al}$, atualmente utilizado pelo reator IEA-R1 e que, na tecnologia atual e operacional desse reator, contém urânio de baixo enriquecimento tipo LEU (> 20\% em ${ }^{235} \mathrm{U}$ ) com uma densidade de $3,0 \mathrm{~g} / \mathrm{cm}^{3}$. Um elemento combustível pode conter outros tipos de dispersão, tais como $\mathrm{UALx}_{\mathrm{L}} \mathrm{U}_{3} \mathrm{O}_{8}$ ou dispersões ainda em desenvolvimento comercial como o UMo-Al [21-28]. O conjunto "picture-frame" é feito encaixando-se o briquete contendo a dispersão em uma placa de moldura feita com a liga de alumínio AA6061, 
que é revestido com duas placas dessa mesma liga, formando-se um sanduíche, como ilustrado na Figura 3.

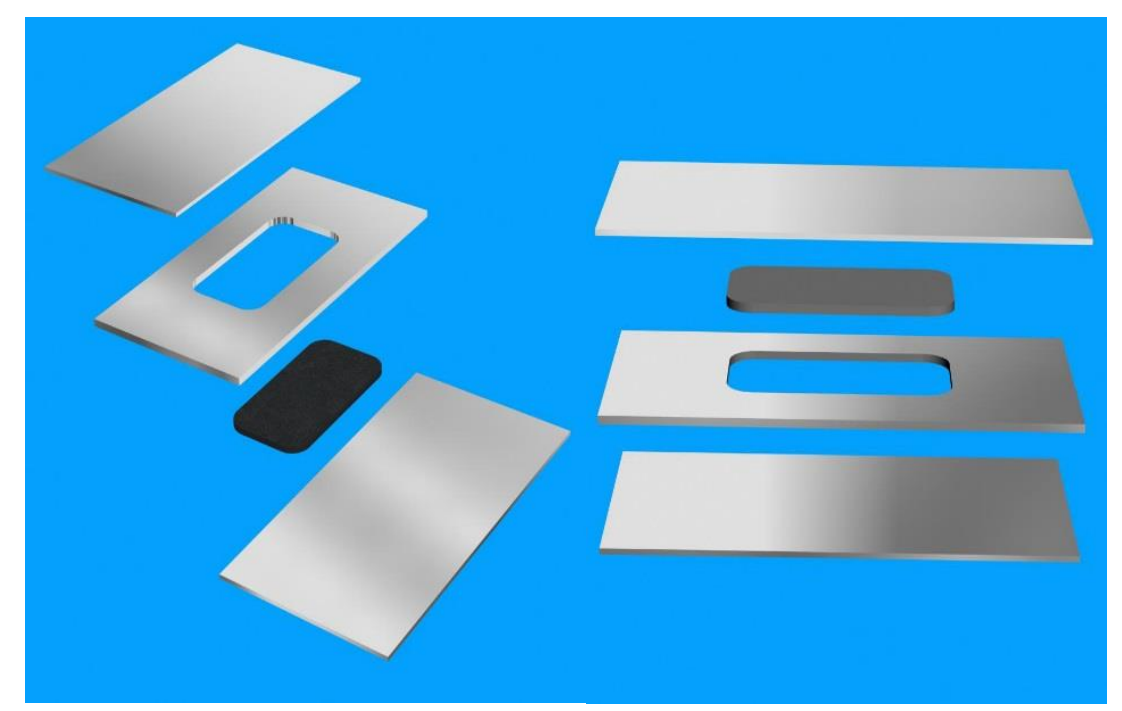

Figura 3 - Montagem do conjunto núcleo-moldura-revestimentos para laminação.

Esse conjunto é soldado e laminado a quente e a frio até a obtenção da placa combustível, como ilustra a Figura 4.

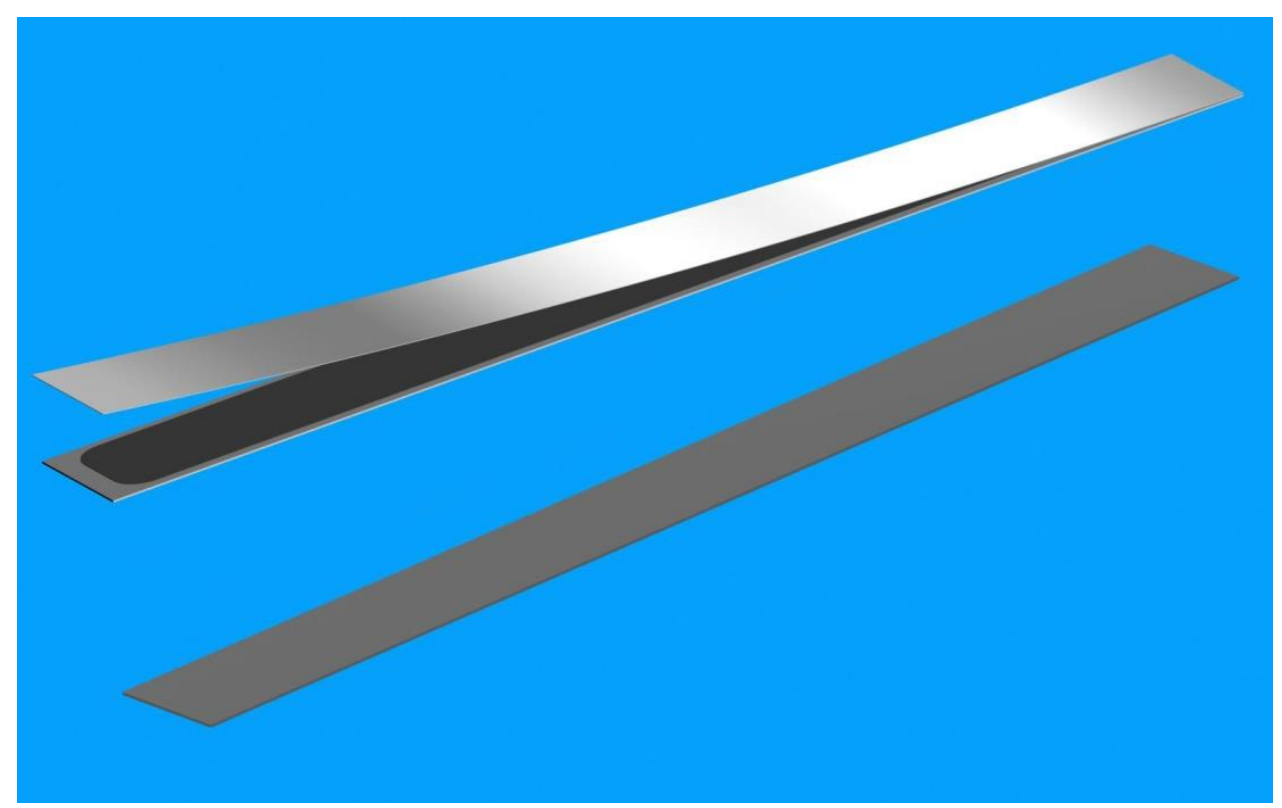

Figura 4 - Vista dos componentes da placa combustível após a laminação. 
Após a execução de todas as etapas de fabricação e caracterização metrológica, as placas combustíveis são submetidas a um tratamento superficial que objetiva efetuar uma limpeza nas superfícies das mesmas. Cada placa combustível é tratada individualmente, passando por banhos de decapagem e neutralização. Os banhos são constantemente monitorados quanto à temperatura e concentração, sendo a concentração corrigida ou o banho trocado se necessário.

\subsection{Potencialidade de contaminação}

Durante o processo de fabricação, contaminantes podem aderir à superfície das placas combustíveis. Isso ocorre principalmente durante o processo de laminação e aplainamento, ocasião em que partículas de contaminantes podem ser incrustadas na superfície. Uma inspeção microscópica da superfície de placas combustíveis revelou a presença de contaminantes incrustados na superfície da placa combustível, como ilustra a Figura 5 [29]. Observou-se a presença de incrustações ricas em silício (Figura 5A) e em ferro (Figura 5B). As incrustações podem aparecer isoladas ou na forma de agrupamentos, espalhadas na direção da laminação (Figura 5B).

Como mencionado, o processo de fabricação de placas combustíveis inclui a realização de um tratamento superficial para limpeza das mesmas. Nesse tratamento superficial, as placas combustíveis são desengraxadas em acetona e são decapadas numa solução de $\mathrm{NaOH}$ a $6-10 \%$ em peso durante 1 minuto a $80^{\circ} \mathrm{C} \pm 10^{\circ} \mathrm{C}$, contida num tanque equipado com um sistema de aquecimento e controle de temperatura. Feito isto, elas são lavadas em água corrente durante 1 minuto, neutralizadas em $\mathrm{HNO}_{3}$ a 40 \% em peso frio durante 1 minuto, lavadas novamente em água corrente por 5 minutos, lavadas em água desmineralizada corrente por 5 minutos ("spray"), lavadas por imersão em água desmineralizada fria e seca manualmente com o auxílio de um secador de jato de ar quente. 

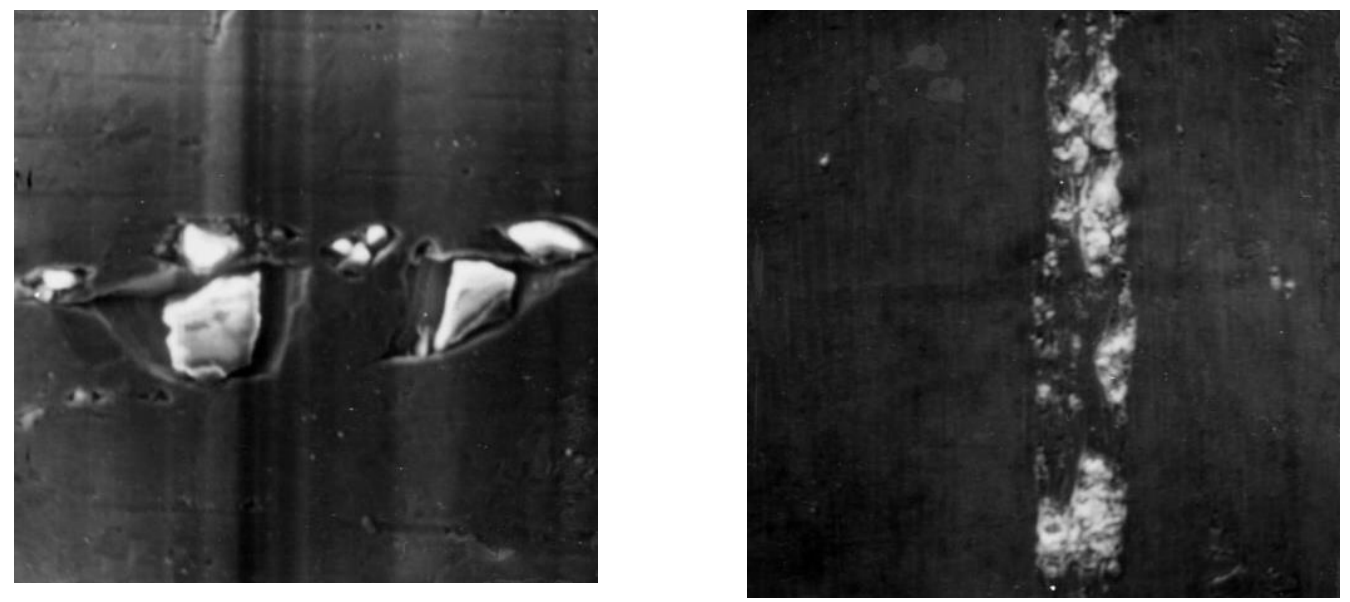

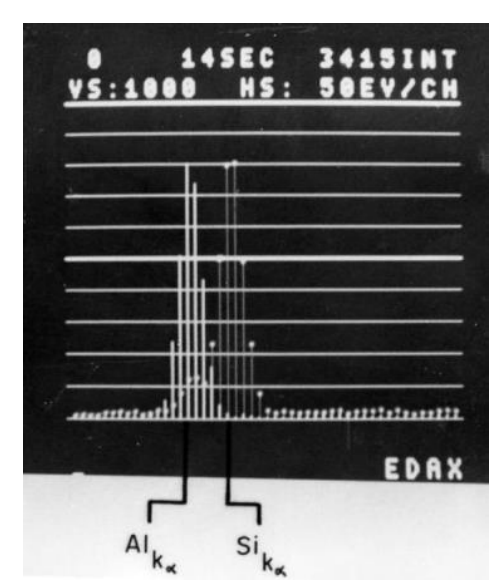

(A)

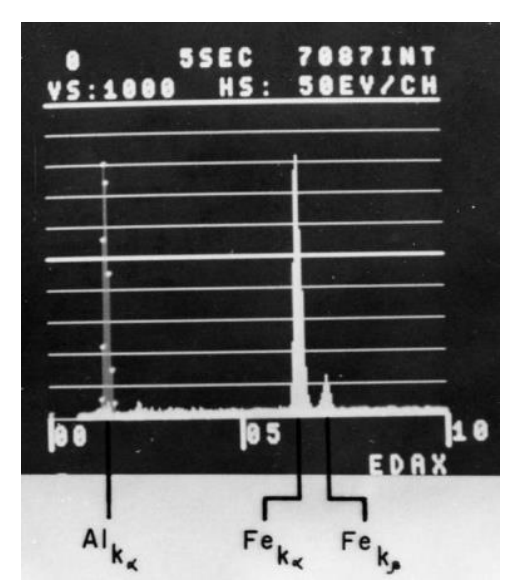

(B)

Figura 5 - Micrografias eletrônicas de varredura (elétrons retroespalhados) ilustrando incrustações de Si (A) e Fe (B) na superfície de placas combustíveis; $45 X$ aumento [29].

Uma nova inspeção microscópica da superfície das placas combustíveis após a realização do tratamento superficial revelou que as incrustações são retiradas, deixando vazios nos locais onde originalmente elas estavam alojadas [29]. A Figura 6A mostra a aparência da superfície após a realização do tratamento superficial. A Figura 6B mostra que o ataque químico é bastante uniforme, não revelando ataque localizado, ou corrosão por pites. As cavidades observadas nas micrografias são resultantes de incrustações ou cavidades preexistentes, assim como riscos também preexistentes. 


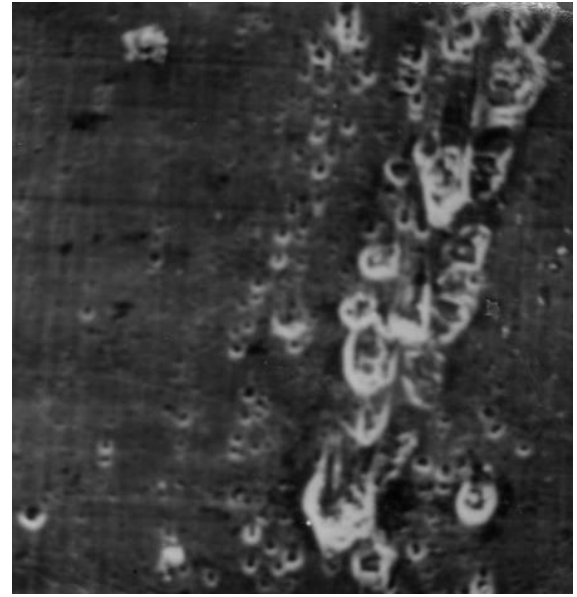

A

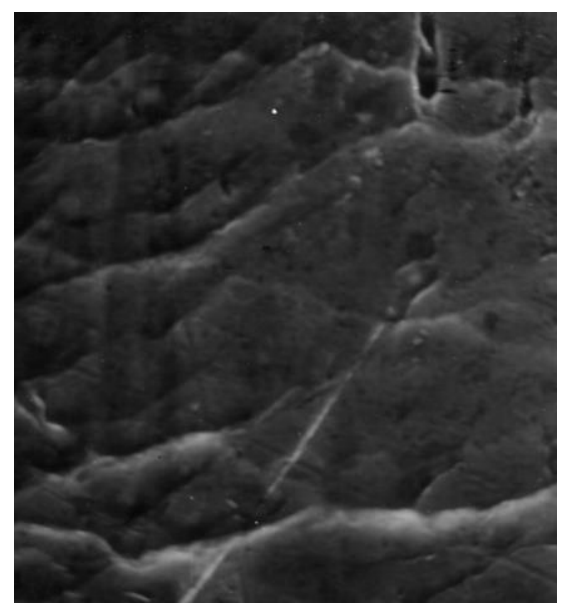

B

Figura 6 - Micrografias eletrônicas de varredura (elétrons secundários) ilustrando a superfície de placas combustíveis após o tratamento superficial. (A) Evidências locais onde existiam incrustações; (B) A aparência superficial mostrando ataque uniforme, com ausência de corrosão localizada (pites); 1500 X aumento. [29]

\subsection{Influência de urânio livre no interior de reatores}

Historicamente, observa-se um aumento no nível de atividade da água da piscina do reator IEA-R1 sempre que um novo elemento combustível é inserido no caroço do reator. Esse aumento ocorre após a inserção do elemento combustível, atinge um máximo e declina até que os valores da atividade retomam ao normal, após um período de cerca de 4 meses. Quando a potência de operação do reator estava no nível de 2 MW, o máximo de atividade que se atingia estava não era considerado fora da normalidade, sendo perfeitamente aceitável para a prática operacional. Além disso, à baixa potência, normalmente as trocas ocorriam apenas com um único elemento combustível novo em cada mudança de configuração. Contudo, ao se aumentar a potência de operação, notou-se que a inserção simultânea de um maior número de novos elementos combustíveis, o nível de aumento de atividade na piscina do reator não se tornou desprezível, passando a ser preocupante. Isso ocorreu em 2006-2007 no reator IEA-R1, quando 4 novos elementos foram inseridos simultaneamente a uma potência de 3,5 MW. 
Urânio, em princípio, deve estar totalmente contido no interior das placas combustíveis. No entanto, existe possibilidade de haver contaminação sobre as placas combustíveis, já prontas para uso. De forma genérica, essa contaminação pode ser oriunda da manipulação das placas em ambiente externo contaminado ou durante o processo de soldagem ou laminação. Certamente, essa contaminação, caso ocorra, é indesejada e não prevista, uma vez que a área de produção de placas do CCN é preparada com a devida assepsia para evitar tais contaminações exógenas.

Por outro lado, sabe-se que valores totais de urânio livre (não encapsulado) enriquecido a $20 \%{ }^{235} \mathrm{U}$ acima de $100 \mu \mathrm{g}$ já podem alterar substancialmente a atividade radioativa do sistema durante o período operacional do reator IEA-R1 em sua potência máxima $30 \mathrm{MW}[30]$.

Esse urânio livre, sob irradiação neutrônica, poderia desenvolver atividades radioativas por fissão nos isótopos de urânio 235 e 238, bem como, de todos seus filhos de decaimento natural como indicados na Figura 7. 

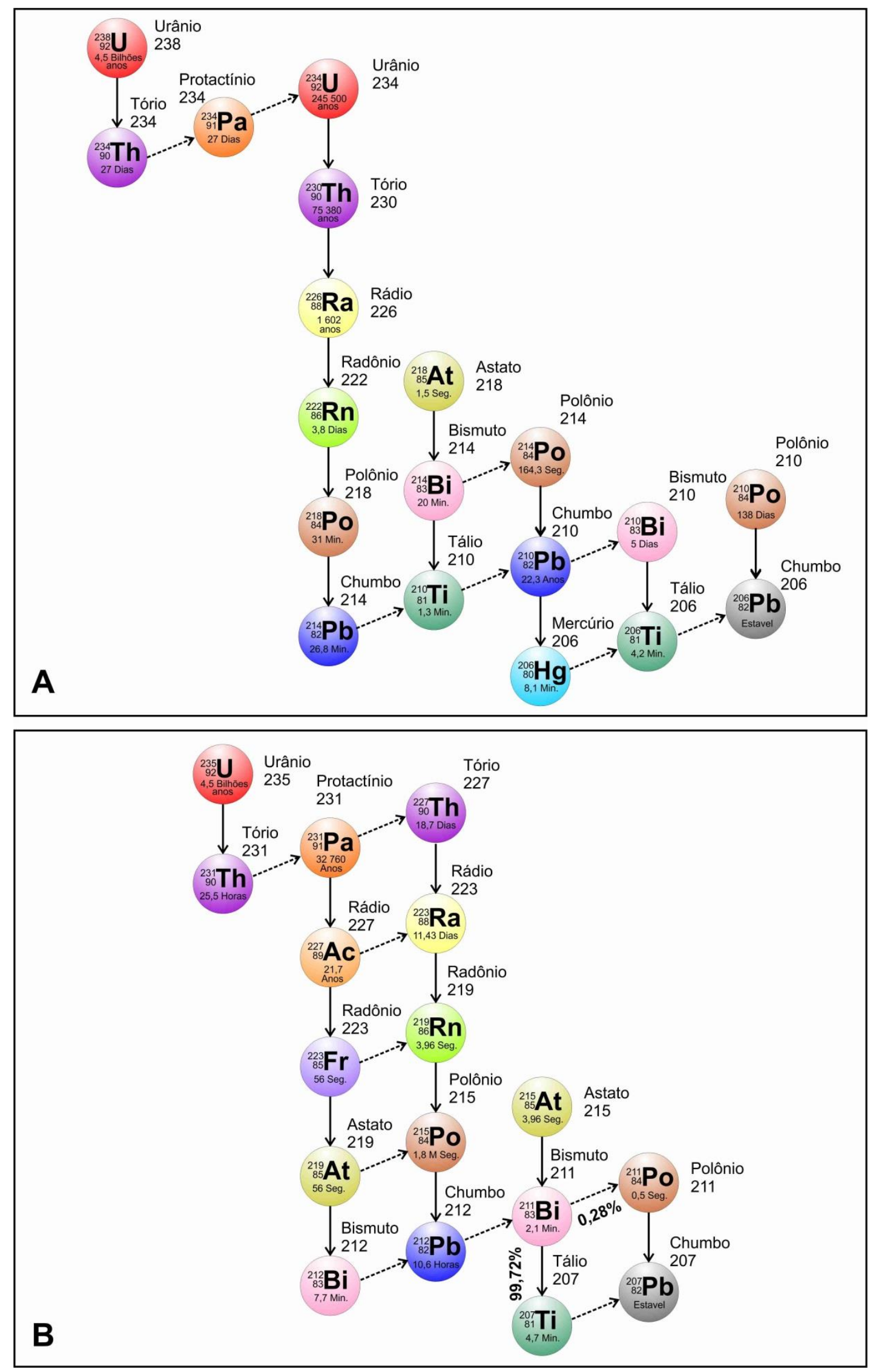

Figura 7-Famílias de decaimento dos isótopos de urânio 238 (A) e 235 (B). 
Os elementos combustíveis utilizam urânio processado quimicamente, onde a cadeia de decaimento natural com equilíbrio secular foi rompida, fazendo com que o material nuclear utilizado seja constituído basicamente de urânio puro agregado a traços de contaminação de agentes químicos utilizados no processo de produção do material nuclear [31]. O material utilizado para confecção de elementos combustíveis no IPEN tem pureza nuclear, isto é, os materiais contaminantes não passam de níveis aceitos pelo Centro de Engenharia Nuclear do IPEN. Sendo assim, todo material, que potencialmente produziriam radionuclídeos aumentando a atividade da piscina do reator IEA-R1 são filhos radioativos de urânio 235, considerando apenas fissão por nêutrons termalizados, conforme descrito no Anexo II. A Figura 8 mostra um exemplo da sequência de fissão neutrônica do ${ }^{235} \mathrm{U}$ produzindo isótopos com massa molecular 138 , exemplificação assim a produção de ${ }^{138} \mathrm{Xe}$ e ${ }^{138} \mathrm{Cs}$.

Os isótopos principais para análise de contaminações externas devido a urânio fissionado e encontradas nas amostragens da água do reator são: ${ }^{133} \mathrm{Xe},{ }^{135} \mathrm{Xe},{ }^{88} \mathrm{Kr},{ }^{85 \mathrm{~m}} \mathrm{Kr}$, ${ }^{87} \mathrm{Kr},{ }^{88} \mathrm{Rb},{ }^{138} \mathrm{Xe}$ e ${ }^{135} \mathrm{Cs}$. O Anexo II faz uma demonstração ampliada dessas possíveis fissões. Portanto, a ocorrência de qualquer um desses elementos, certamente indica que houve fissão de ${ }^{235} \mathrm{U}$ livre que contaminou a água do reator. 


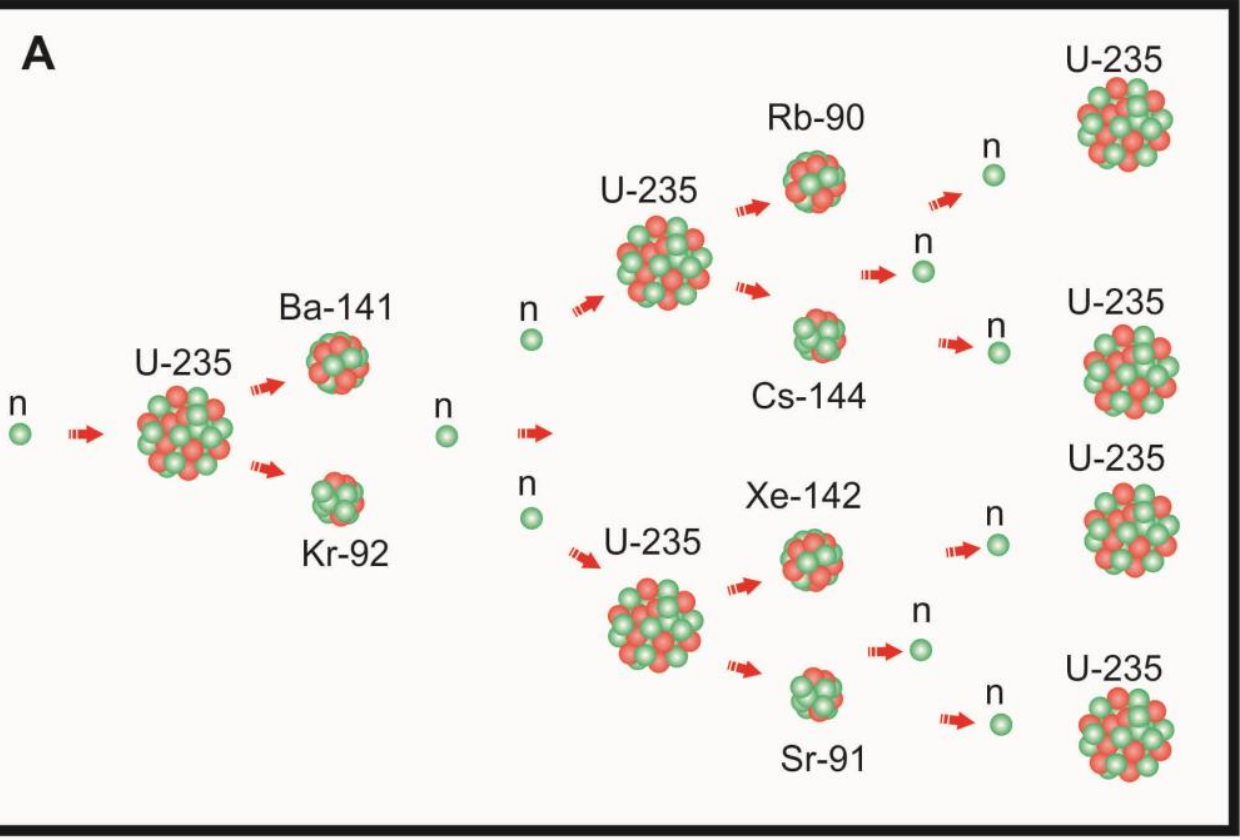

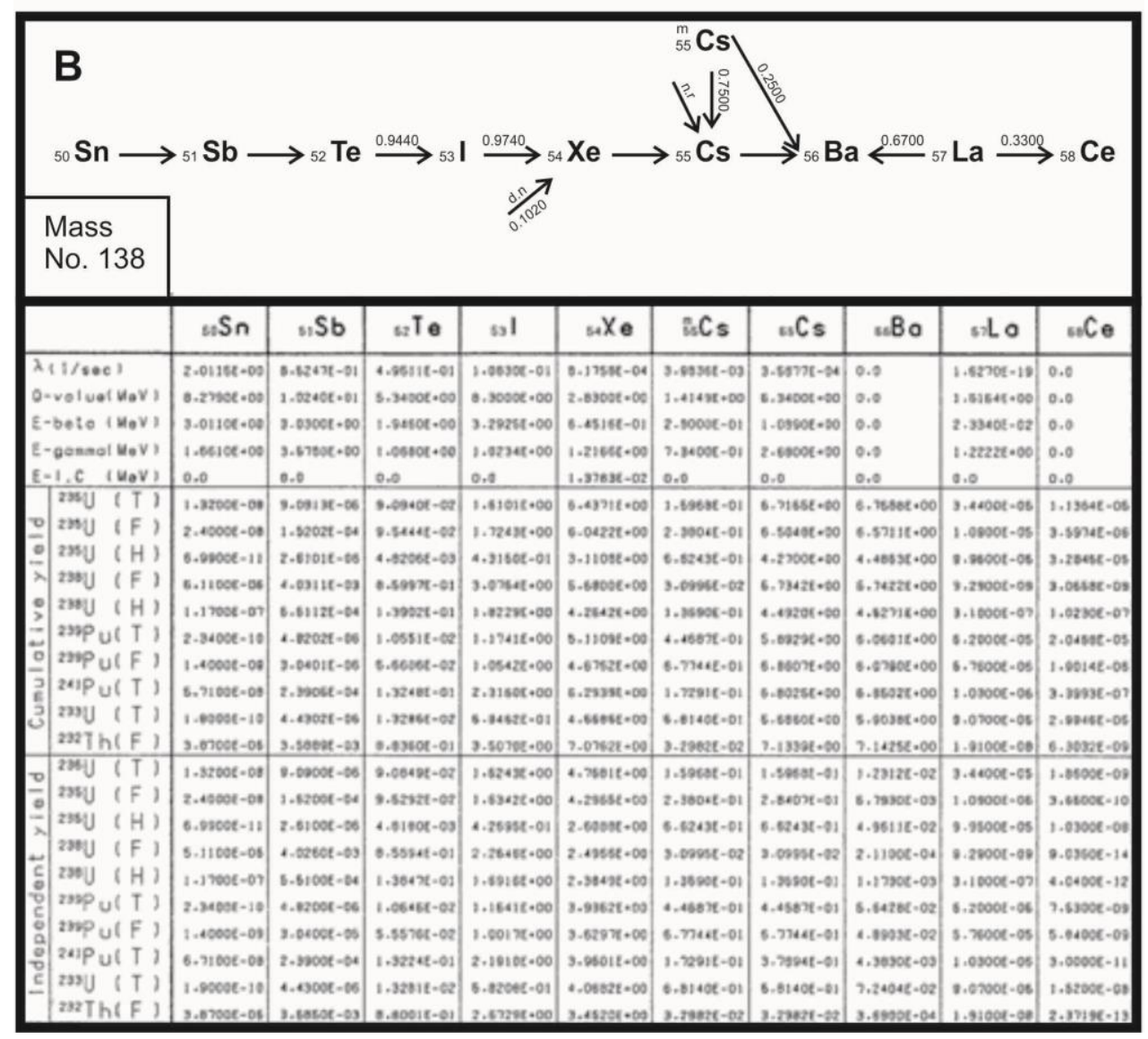

Figura 8 - (A) Exemplo de desintegração do ${ }^{235} \mathrm{U}$ durante o processo de irradiação neutrônica. (B) Produção de ${ }^{138} \mathrm{Xe}$ $e^{138} \mathrm{Cs}$ durante irradiação neutrônica [32]. 
Deve-se considerar que a água do reator também contém urânio residual. $\mathrm{A}$ água do reator, conforme análise química de amostras colhidas mês a mês em 2013 e em alguns meses de 2014 indica que a concentração máxima não passa de $50 \mu \mathrm{g} / \mathrm{L}$, conforme apresentado no ANEXO I.

Esse nível de contaminação é mantido baixo, pois essa água da piscina do reator IEA-R1 é purificada e reintroduzida no sistema. Portanto, acredita-se que todo urânio contido nessa água tem teores limites dos equipamentos de purificação.

A partir de março/2006, após a inserção dos elementos combustíveis IEA-174, IEA-175

e IEA-176, notou-se um aumento da atividade da água da piscina, crescente exponencialmente. Em meados de junho/2006 a atividade chegou a um nível inaceitável, quando se retirou o elemento combustível IEA-175. Após a sua retirada, o nível de atividade diminuiu consideravelmente, reduzindo-se a um terço dos valores anormais observados, contudo, ainda acima do nível considerado normal para o reator, ou nível de "background". No final de setembro/2006, foram também retirados os elementos combustíveis IEA-174 e IEA-176, o que resultou na queda dos níveis de radiação ao nível do "background" normal do reator. Em janeiro/2007 retornaram ao caroço do reator os elementos combustíveis IEA-174 e IEA-176, o que ocasionou a elevação do nível de radioatividade da água da piscina do reator, com um aumento exponencial dos níveis de atividade, observado a partir de junho/2006, quando houve a retirada do elemento combustível IEA-175. Esse comportamento está ilustrado na Figura 9 que apresenta o nível de contagem do ${ }^{135} \mathrm{Xe}$. Depois desse incidente, não ocorreu nenhum outro registro de aumento de atividade no reator IEA-R1, até a apresentação do presente estudo. 


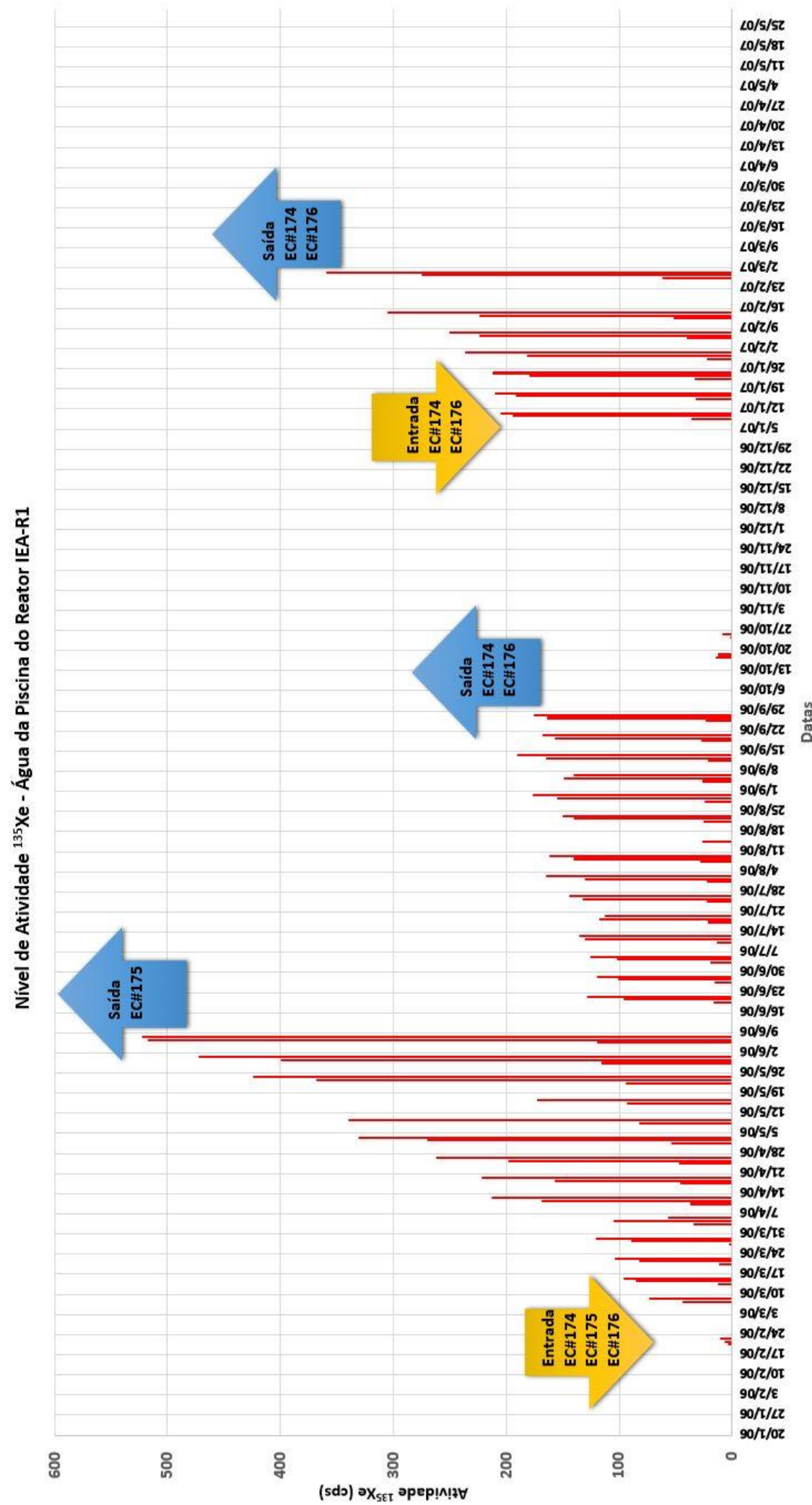

Figura 9 - Níveis de atividade da água da piscina do reator IEA-R1 evidenciando aumento da atividade após a inserção de novos elementos combustíveis no caroço do reator. 
Aumentos na atividade da piscina de reatores MTR, com comportamento semelhante a esse, foram também observados no reator holandês HOR, em junho/1997, setembro/2001 e abril/2003 [33]. A primeira causa considerada possível foi a contaminação superficial das placas combustíveis $\operatorname{com}^{235} \mathrm{U}$, o que explicaria o aumento da atividade da água da piscina e a presença de radionuclídeos derivados da fissão do urânio. Posteriormente, foi verificado que a causa foi a falha do revestimento de placas combustíveis de 3 elementos de baixo enriquecimento a base de siliceto de urânio fabricados pela CERCA, com $4,3 \mathrm{gU} / \mathrm{cm}^{3}$ [33].

Uma análise dos radionuclídeos presentes como contaminantes na água do reator IEAR1 resultou na conclusão de que os níveis anormais de atividade na água são decorrentes da presença de produtos de fissão, estimando-se ter ocorrido a fissão de $90 \mu \mathrm{g}$ de ${ }^{235} \mathrm{U}$ [34]. Foram realizados testes de "sipping" nos elementos combustíveis que haviam entrado no caroço do reator quando o aumento da atividade na água foi detectado. Os resultados desse teste mostraram que não se tratava de falha de revestimento.

Dessa forma, apesar de ter sido descartada a causa de incidente semelhante em um reator holandês, conforme relatado na literatura [33], considerou-se no caso do incidente do IEA-R1 em 2006-2007, como sendo contaminação superficial.

\subsection{Avaliação de teor de urânio}

O teor de urânio pode ser avaliado por meio de emissão de partículas alfa pelo método de contagem com cintilador de iodeto de sódio. Teoricamente, o processo segue os princípios da radioatividade.

Pela teoria básica da radioatividade, tem-se que o urânio decai de forma natural como qualquer outro radioisótopo seguindo o princípio de que a taxa de desintegração do núcleo radioativo é igual à constante de decaimento multiplicada pelo número de núcleos radioativos presentes. Essa constante de decaimento $(\lambda)$ representa a probabilidade média de que os núcleos radioativos decaiam em uma determinada unidade de tempo. As unidades de taxa de decaimento são normalmente expressas em 
"desintegrações por tempo". Convencionou-se que "desintegrações por segundo" é denominada pela unidade "Bequerel", com a abreviatura "Bq".

Essas relações convertidas em equação matemática ficam assim [31]:

$$
-\frac{d N}{d t} \propto N \quad \ldots 1
$$

Onde $\mathrm{N}$ é o número de átomos de um determinado radionuclídeo contido em uma quantidade predeterminada do material nuclear. Essa relação expressa que a taxa de decrescimento de radionuclídeos é proporcional à quantidade de radionuclídeos presente em um determinado instante.

Reescrevendo a relação tem-se:

$$
\frac{d N}{d t}=-\lambda N \quad \ldots 2
$$

Considerando-se o momento inicial como $t=0$, tem-se então $N_{0}$ que representa a quantidade de radionuclídeo presente. Integrando-se essa relação de t=0 até t tem-se:

$$
N=N_{0} e^{-\lambda t} \ldots 3
$$

Essa equação dá o número de radionuclídeos presentes em um tempo t. No entanto, em muitos experimentos, deseja-se saber a taxa de contagem em um detector como uma a função do tempo. Portanto, deseja-se conhecer a atividade das amostras. Supondo-se C, a variável que indica essa contagem de emissões em um determinado tempo e A a taxa de desintegração, pode-se dizer que elas estão associadas por um parâmetro $\varepsilon$ que indica a eficiência do aparelho de contagem:

$$
C=\varepsilon A=\varepsilon\left(-\frac{d N}{d t}\right)=\varepsilon \lambda N \ldots 4
$$

Chega-se assim à relação:

$$
C=C_{0} e^{-\lambda t} \quad \ldots 5
$$

Onde $C$ é a taxa de contagem em um determinado tempo t e $C_{0}$ é a contagem em um tempo $t=0$. Uma equação importante para os cálculos de decaimento radioativo é o tempo de meia-vida dado pela seguinte relação:

$$
t_{1 / 2}=\frac{\ln 2}{\lambda} \ldots 6
$$


Com base nessas leis da física, pode-se chegar à massa de urânio para um determinado nível de contagem de emissões radioativas tipo alfa.

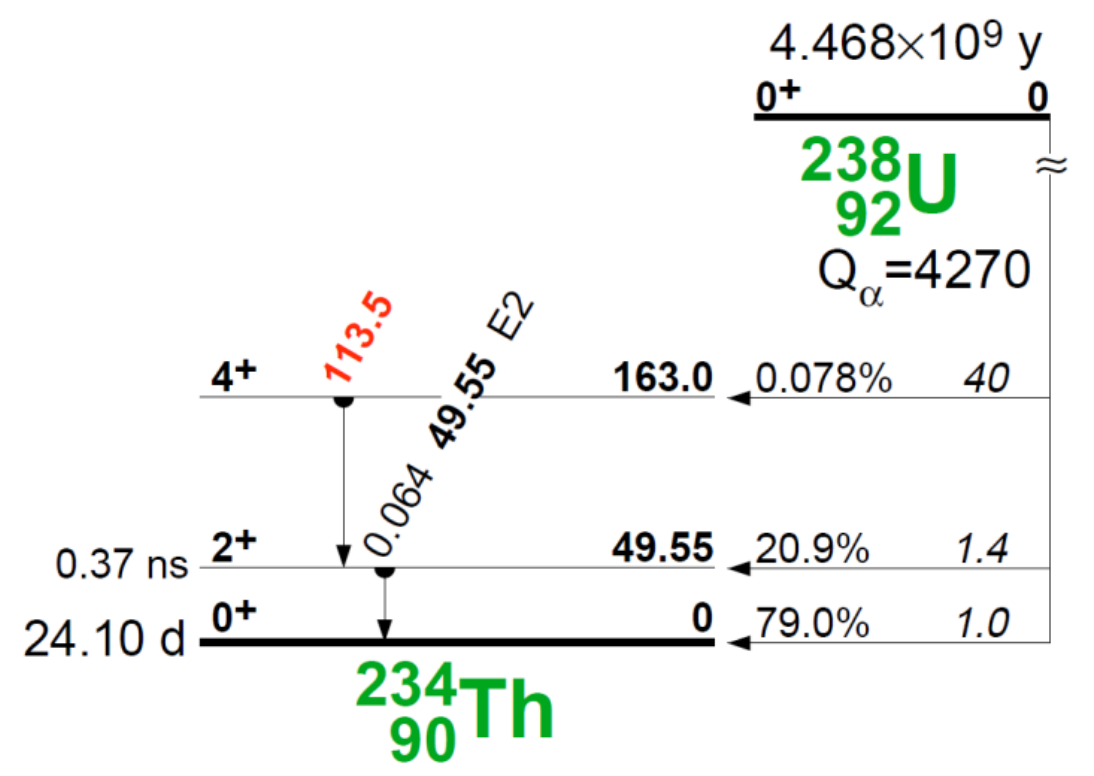

Figura 10 - Decaimento natural de 238 U com níveis de energia das emissões energéticas [35] .

Para o presente trabalho, é importante que se saiba a família de decaimento natural dos radioisótopos principais de urânio. Conforme mostrado na Figura 10, pode-se ver que 0 ${ }^{238} \mathrm{U}$ decai para ${ }^{234} \mathrm{Th}$ gerando-se uma quantidade de energia da ordem de 4,27 MeV. Exatamente essa é a energia que é captada pelo detector de contagem alfa. Apenas para referência e considerando $100 \%$ o nível de eficiência do contado, pode-se estimar as quantidades de urânio presente para um determinado nível de contagens. Fazendo-se os cálculos de decaimento, com base no tempo de meia-vida de ${ }^{238} \mathrm{U}\left(\mathrm{t}_{1 / 2}=4,468 \times 10^{-9}\right.$ anos) pode-se chegar a atividade gerada por um miligrama de ${ }^{238} \mathrm{U}$ como sendo de $12.54 \mathrm{~Bq}$.

Esse trabalho se torna relevante para evitar o aumento da atividade radioativa no reator IEA-R1 devido à eventual contaminação superficial de urânio proveniente da fabricação de placas combustíveis. O aumento de potência é necessidade operacional do reator IEA-R1, pois só assim será possível o aumento da produtividade de radioisótopos, como ${ }^{153} \mathrm{Sm}$ e ${ }^{131}$ I. Por outro lado, essa mesma fábrica de elementos combustíveis do IPEN, 
utilizado fundamentalmente a mesma rotina de produção de elementos combustíveis será a fornecedora de material combustível para Reator Multipropósito Brasileiro que trabalhará com um nível de potência bem maior do que o reator IEA-R1, podendo operar até no nível de 30MW.

O atual tratamento superficial químico das placas combustíveis tem sido adotado pelo Centro do Combustível Nuclear desde a década de 1980. Trata-se de um procedimento utilizado pela NUKEN alemã. As placas combustíveis que foram tratadas por essa metodologia sempre operaram no reator IEA-R1 com bom desempenho.

Para se avaliar o urânio residual nas placas combustíveis como potencial causador do aumento da atividade da água da piscina do reator IEA-R1, deve-se avaliar a contaminação superficial por metodologia radiológica, bem como, a eficácia do tratamento químico superficial, adotado atualmente no CCN. 


\section{OBJETIVO}

Objetiva-se, no presente estudo, obter-se a determinação de intensidade das emissões alfa remanescentes sobre as placas combustíveis produzidas atualmente no Centro do Combustível Nuclear do IPEN, bem como, sua correlação com o tratamento químico superficial adotado para efetuar a limpeza final antes da montagem do elemento combustível destinado ao reator IEA-R1.

\subsection{Objetivos específicos:}

Objetiva-se fazer uma análise estatística de potencial contaminação de urânio por emissões alfa na superfície de placas combustíveis nucleares produzidas no CCN/IPEN, executaram-se as seguintes etapas:

1. Análise exploratória de um conjunto amostral, antes do tratamento químico, obtido na linha de produção das placas combustíveis;

2. Determinação da metodologia de contagem de emissões alfa, correlacionandoo com o teor equivalente de urânio residual sobre as placas combustíveis;

3. Análise de uma contaminação intencional, com $\mathrm{U}_{3} \mathrm{Si}_{2}$, para efeito comparativo do processo antes e após tratamento superficial;

4. Análise de contaminação de uma amostragem robusta ao longo da história produtiva das placas combustíveis do CCN. 


\section{MATERIAIS E MÉTODOS}

\subsection{Materiais}

As amostras utilizadas para análise de contaminação de urânio foram obtidas a partir das aparas dos cortes da placa combustível após laminação e sem qualquer tratamento químico superficial. Foram geradas amostras de $20 \mathrm{~mm} \times 20 \mathrm{~mm}$ a partir dessas aparas, com espessura variando entre 1,47 a 1,62 mm. O material dessas amostras de contagens de emissões alfa, é a liga de alumínio AA 6061, material utilizado para fazer o conjunto da placa combustível e não contendo qualquer parte do núcleo físsil. As análises de background foram feitas sobre amostras similares da mesma liga, no entanto, sem qualquer contaminação de urânio, matéria prima virgem ainda não processada na fábrica. $O$ posicionamento das regiões de amostragem e suas codificações nas 3 fases experimentais é apresentado na Figura 11.

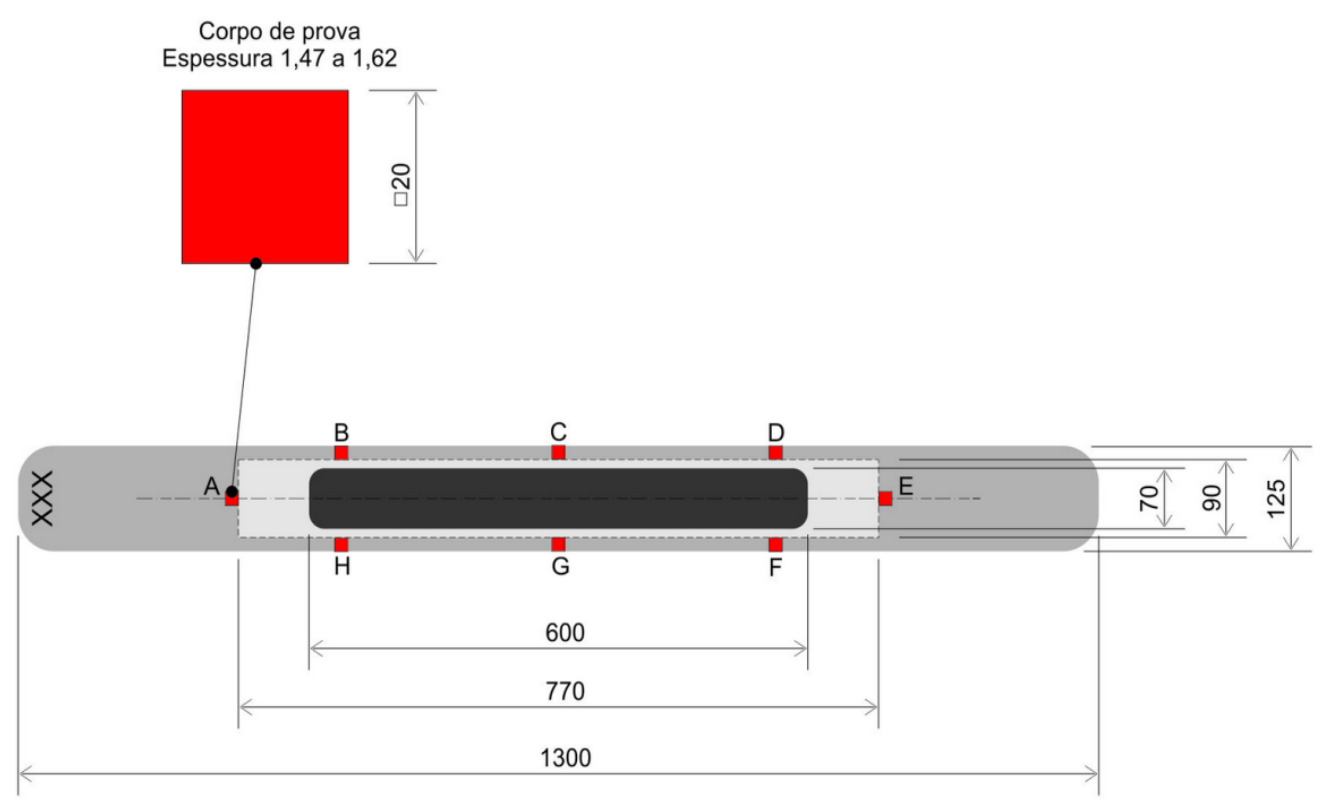

Figura 11 - Simbologia e localização das amostras colhidas nas rebarbas resultantes do corte da placa combustível. 


\subsection{Metodologia Experimental}

O processo amostral seguiu a seguinte linha de amostragens aleatórias:

$1^{\text {a }}$ Fase: Amostragem investigativa de um conjunto amostral obtido da rotina presente de fabricação das placas combustíveis.

$2^{\mathrm{a}}$ Fase: Amostragem da placa com contaminação intencional com $\mathrm{U}_{3} \mathrm{Si}_{2}$ para efeito comparativo do processo de decapagem antes e após.

$3^{\mathrm{a}}$ Fase: Amostragem aleatória da série histórica [1998-2013] de produção das placas combustíveis: investigativa (10 amostras) e ampliada (50 amostras)

A amostragem aleatória foi definida por sorteio eletrônico aleatório, após listagem de todas as possibilidades de amostras existentes. As amostras foram retiradas, conforme a fase experimental: da linha de produção (1a Fase) ou do arquivo histórico de aparas do CCN (3a Fase).

\subsubsection{Contagem alfa}

A análise de contaminação superficial com urânio foi realizada por meio de contagens de emissões alfa em um contador Ludlum 3030P munido com um cintilador de lodeto de Sódio durante um período de $600 \mathrm{~s}$ cada contagem. Essa contagem de emissões alfa do conjunto amostral foi realizada conforme as imposições de cada fase experimental, mas sempre considerando dois grupos comparativos dentro de um mesmo conjunto amostral, por exemplo antes e após tratamento químico das amostras ou na face superior ou inferior da amostra. De uma forma geral, a avaliação da contaminação de forma direta e amostral por determinação da massa de urânio foi baseada na relação de atividade em emissões alfa por massa de urânio de $12,54 \mathrm{~Bq} / \mathrm{mg} \mathrm{U}$.

Paralelamente, utilizou-se, como método alternativo, o procedimento padrão usado para determinação da contaminação de superfície de placas da GRP - Gerência de Radioproteção para verificar a contaminação com urânio. Nessa metodologia, utiliza-se um feltro com $25 \mathrm{~mm}$ de diâmetro que é esfregado em uma região com 1 metro quadrado e levado até o contador, onde se faz a contagem por 1 minuto. Nesse método, calibra-se antecipadamente o BG (background) para determinação das emissões 
radiativas de ambientes naturais, que tem uma grande variabilidade com o tempo. No entanto, esse método não se prova eficaz para avaliar níveis de contaminação baixa.

\subsubsection{Contaminação intencional}

Fabricou-se uma placa combustível com contaminação superficial intencional. Ilustra-se na Figura 12 a metodologia utilizada. Para se garantir que a contaminação equivalesse a de uma placa produzida normalmente, fez-se a incrustação do material nuclear pulverizado sobre a superfície superior do conjunto soldado, já apresentado na Figura 3.

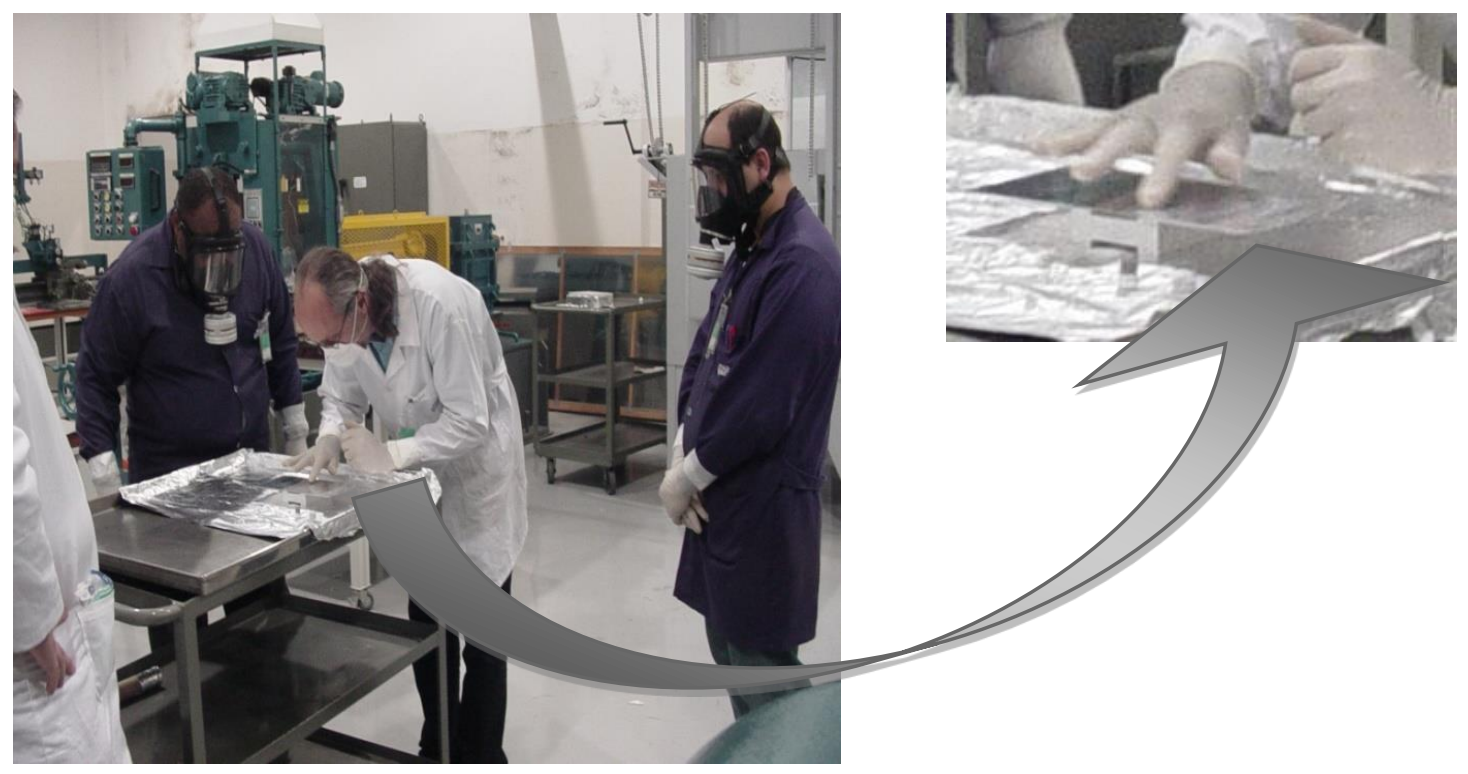

Figura 12 - Incrustação de pó de $U_{3} \mathrm{Si}_{2}$ no conjunto soldado.

A incrustação foi realizada utilizando o intermetálico $U_{3} S_{2}$, na faixa granulométrica entre $44,0 \mu \mathrm{m}$ e $150,0 \mu \mathrm{m}$, contendo até $20 \%$ de pó de $\mathrm{U}_{3} \mathrm{Si}_{2}$ abaixo de $44,0 \mu \mathrm{m}$. Utilizouse uma marcação mecânica específica para identificação da fase superior da placa. Esse conjunto foi inicialmente laminado a frio para promover a incrustação. A partir desse estágio seguiu-se uma rotina normal de laminação a quente e de laminação a frio da placa. O laminador foi protegido para evitar eventual contaminação, colocando-se um filme plástico na sua mesa para proteção, como ilustra a Figura 13. Durante todo o processamento de laminação dessa placa, que recebeu as incrustações contaminantes 
na face superior, houve cuidado para não se contaminar a outra superfície em que não houve contaminação intencional.

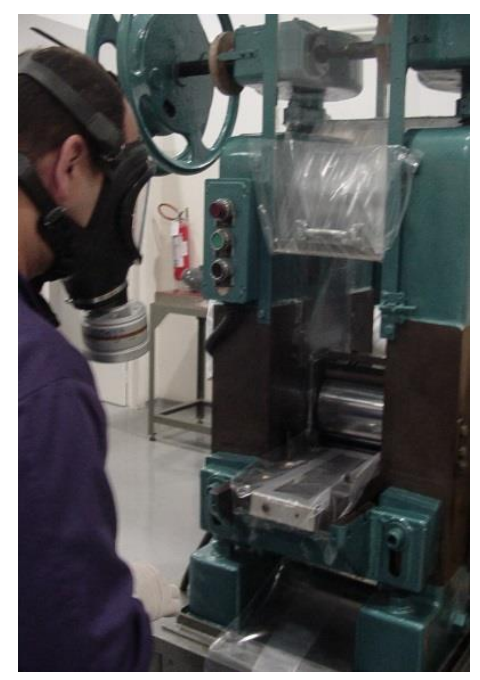

Figura 13 - Preparação da proteção para o laminador.

Nessa placa contaminada não foi realizado o pré-corte e quatro amostras foram retiradas e denominadas conforme já apresentado na Figura 11, isto é, as amostras foram identificadas por letras: (A) indicando a posição da entrada no primeiro passe de laminação e (E) a posição da saída; no lado esquerdo, em relação à entrada, foram retiradas três amostras ( $B, C$ e D); no lado direito, também foram retiradas três amostras (F, G e H).

\subsubsection{Preparação de amostras para contagens}

Em todas as fases de experimentação, as amostras foram cortadas nas dimensões $20 \mathrm{~mm} \times 20 \mathrm{~mm}$ a partir das aparas. Elas foram limpas dos resíduos de óleo da laminação com acetona e foram devidamente identificadas. Assim, as amostras estavam prontas para as contagens de emissões alfa nas duas superfícies da amostra.

Após essa etapa de contagem alfa, realizou-se, nas amostras, o tratamento químico superficial de rotina para descontaminação superficial conforme adotado no CCN, ou seja, fez-se imersão em solução de $\mathrm{NaOH}\left(10 \%\right.$ em peso) a $80^{\circ} \mathrm{C} \pm 10^{\circ} \mathrm{C}$ durante 1 minuto. 
Esse nível de variabilidade da temperatura é devido à reação exotérmica de dissociação do alumínio em soluções alcalinas $\left(2 \mathrm{Al}+2 \mathrm{NaOH}+6 \mathrm{H}_{2} \mathrm{O} \rightarrow 2 \mathrm{NaAl}(\mathrm{OH})_{4}+3 \mathrm{H}_{2}\right)$; procedeu-se com a lavagem em água fria corrente por 3 minutos; fez-se a lavagem em água desmineralizada fria corrente por 3 minutos, seguida por imersão em solução de $\mathrm{HNO}_{3}$ (50\% em peso) durante 1 minuto; repetiu-se a etapa de lavagem para retirar o $\mathrm{HNO}_{3}$ e, finalmente, procedeu-se a passivação no tanque água desmineralizada por aproximadamente 1 minuto, seguido de secagem.

Para controle, foram usadas pontas de placas para o teste de esfregaço antes do tratamento superficial e encaminhado para laboratório de análise química para determinação de teor de urânio via espectrometria de emissão por plasma acoplado (ICP-OES). Foram utilizadas como controle as placas combustíveis numeradas como placas $887,878,879$ e 880 , a serem utilizadas no elemento combustível EC-Padrão 236, destinado ao IEA-R1. Tais placas combustíveis foram submetidas às mesmas contagens de emissão alfa. 


\section{RESULTADOS E DISCUSSÃO}

Conforme descrito na metodologia, o processo experimental seguiu três fases experimentais para determinação de contaminação por contagem de emissões alfa: análise da amostragem investigativa de um conjunto amostral obtido da rotina de fabricação das placas combustíveis; análise do efeito de contaminação intencional com $\mathrm{U}_{3} \mathrm{Si}_{2}$ para efeito comparativo do processo antes e após decapagem; análise da amostragem aleatória da série histórica [1998-2013] de produção das placas combustíveis: investigativa (10 amostras) e ampliada (50 amostras).

\subsection{Primeira Fase Experimental: Contaminação de Rotina}

Nessa fase, objetivou-se avaliar o nível de contaminação em uma amostragem pequena de placas produzidas na atualidade pelo CCN/IPEN e destinadas à fabricação de elementos combustíveis. De acordo, com os resultados de análise química dos esfregaços nessas placas, vide Anexo IV, não houve avaliação química nessas placas em níveis menores do que $6 \mu \mathrm{g} / \mathrm{g}$ de urânio. Conforme já discutido na introdução, esse nível de urânio, estabelecido pelo Anexo IV. Nota-se que o nível mínimo detectado pelo instrumental de análise está 100 a 1000 maior do que a ordem de grandeza esperada para o teor de urânio livre na água do reator $(<50 \mu \mathrm{g} / \mathrm{L})$. Julga-se que essa medida avaliada pelo o teste de esfregaço tem sido ineficaz para se concluir que haja alguma contaminação na placa combustível, uma vez que o limite de detecção de urânio está insensível para o nível requisitado para operação do reator. A partir desses resultados resolveu-se estudar essa possível contaminação, utilizando-se o método de contagem de emissão alfa, descrito a seguir.

\subsubsection{Medidas de Contagem Alfa no Background}

As medidas do background (BG) das emissões radioativas do ambiente foram realizadas no mesmo equipamento de contagem das amostras das placas combustíveis. Cortaramse cupons semelhantes com as dimensões $20 \times 20 \mathrm{~mm}$ da liga AA6061, em estado virgem. 
As contagens de BG tiveram a unidade de CPM (contagens por minuto). Essas contagens foram colocadas no histograma apresentado na Figura 14. A contagem de alfa pode ser correlacionada diretamente à quantidade de urânio presente na contaminação, conforme já descrito anteriormente, pois tanto o ${ }^{235} \mathrm{U}$ e o ${ }^{238} \mathrm{U}$ são fortes emissores de radiação alfa, cujos níveis de emissão nos permitem estimar a quantidade de urânio residual que a placa eventualmente possua em sua superfície.

O valor BG foi assim devidamente computado no período de contagem das amostras das placas. O BG médio e sua dispersão basearam-se na curva normal equivalente do histograma dos dados coletados. Esses dados foram colhidos no mesmo período de contagem de emissões das amostras das placas combustíveis, feitas durante a primeira fase experimental. A média e o desvio padrão das medidas de background obtidos foram: média de contagem = 5,021 cpm; desvio padrão = 1,455 em 37 amostras, dando um erro padrão = 0,478 com 95\% de significância. Esses dados foram considerados padrões para efeito de análise de contaminação residual na primeira fase em que se avaliou de forma investigatória a produção presente de placas no CCN/IPEN.

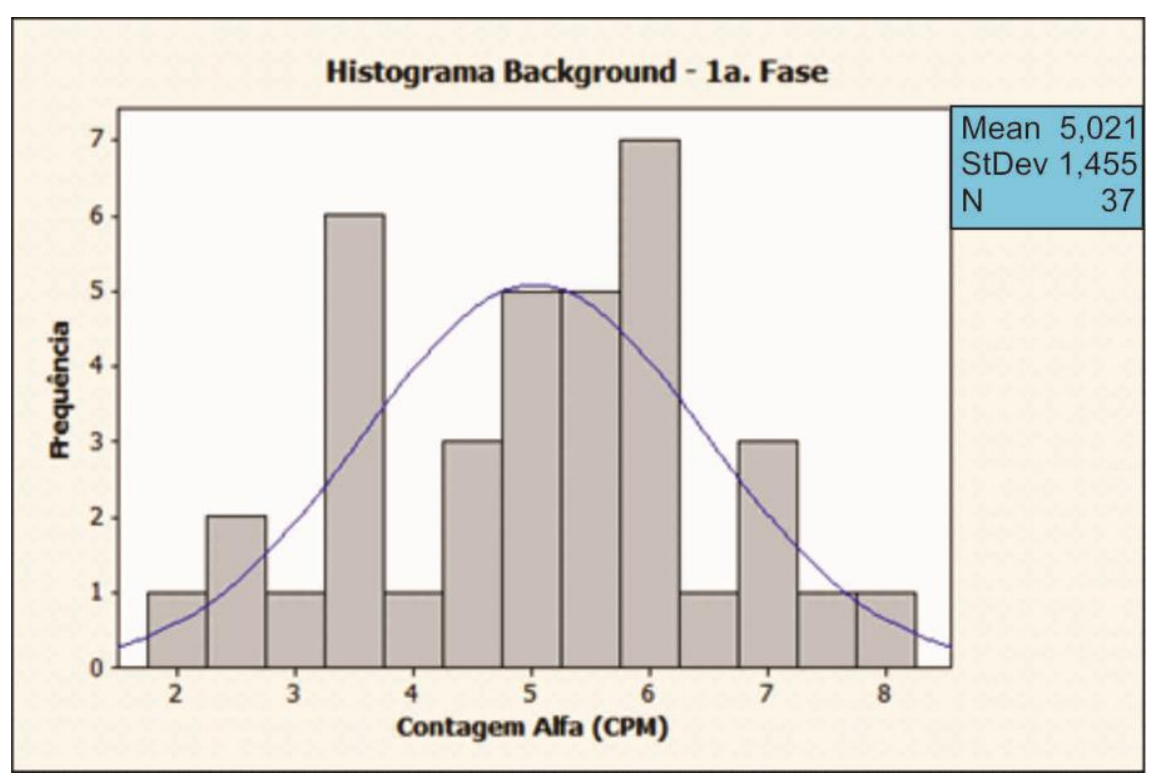

Figura 14 - Medidas de emissão de radiação alfa do ambiente (BG) no período de $1 \underline{a}$ fase dos testes de placas produzidas presentemente no CCN. 
Escolheram-se, aleatoriamente, as placas de produção 877, 878, 879 e 880 . A amostragem foi realizada após o recorte final das placas combustíveis antes de serem enviadas para a decapagem alcalina. Essa amostragem foi gerada conforme as indicações de posicionamento de amostragem dadas na Figura 11. Os resultados de contagem alfa são apresentados na Tabela 1 (superfície superior das placas) e na Tabela 2 (superfície inferior das placas). As posições (PosPI) referem às posições amostras na aparas da placa.

Tabela 1 - Dados de contagem alfa das placas na parte superior de laminação

\begin{tabular}{|c|c|c|c|c|c|c|c|}
\hline PosPI & S_I & $\begin{array}{c}\text { Placa } \\
\mathbf{8 7 7}\end{array}$ & $\begin{array}{c}\text { Placa } \\
\mathbf{8 7 8}\end{array}$ & $\begin{array}{c}\text { Placa } \\
\mathbf{8 7 9}\end{array}$ & $\begin{array}{c}\text { Placa } \\
\mathbf{8 8 0}\end{array}$ & Média & $\begin{array}{c}\text { Desvio } \\
\text { Padrão }\end{array}$ \\
\hline A & Sup & 4,80 & 5,60 & 6,40 & 6,40 & 5,80 & 0,77 \\
\hline B & Sup & 6,80 & 6,80 & 5,00 & 3,60 & 5,55 & 1,55 \\
\hline C & Sup & 5,80 & 5,40 & 7,00 & 5,40 & 5,90 & 0,76 \\
\hline D & Sup & 6,40 & 5,60 & 5,40 & 5,40 & 5,70 & 0,48 \\
\hline E & Sup & 3,80 & 4,60 & 6,00 & 6,60 & 5,25 & 1,28 \\
\hline F & Sup & 4,80 & 4,80 & 4,80 & 5,00 & 4,85 & 0,10 \\
\hline G & Sup & 5,80 & 4,60 & 5,20 & 4,40 & 5,00 & 0,63 \\
\hline H & Sup & 5,00 & 5,20 & 5,80 & 5,20 & 5,30 & 0,35 \\
\hline $\begin{array}{c}\text { Média } \\
\text { Global }\end{array}$ & & & & & & & \\
\hline
\end{tabular}

Tabela 2 - Dados de contagem alfa das placas na parte inferior de laminação

\begin{tabular}{|c|c|c|c|c|c|c|c|}
\hline PosPI & S_I & $\begin{array}{c}\text { Placa } \\
\mathbf{8 7 7}\end{array}$ & $\begin{array}{c}\text { Placa } \\
\mathbf{8 7 8}\end{array}$ & $\begin{array}{c}\text { Placa } \\
\mathbf{8 7 9}\end{array}$ & $\begin{array}{c}\text { Placa } \\
\mathbf{8 8 0}\end{array}$ & Média & $\begin{array}{c}\text { Desvio } \\
\text { Padrão }\end{array}$ \\
\hline A & Inf & 3,80 & 6,40 & 6,00 & 4,40 & 5,15 & 1,25 \\
\hline B & Inf & 7,00 & 5,80 & 5,60 & 5,60 & 6,00 & 0,67 \\
\hline C & Inf & 6,00 & 5,60 & 4,60 & 5,00 & 5,30 & 0,62 \\
\hline D & Inf & 7,00 & 6,40 & 6,20 & 5,80 & 6,35 & 0,50 \\
\hline E & Inf & 6,00 & 5,80 & 4,00 & 6,40 & 5,55 & 1,06 \\
\hline F & Inf & 4,00 & 4,80 & 6,20 & 4,20 & 4,80 & 0,99 \\
\hline G & Inf & 4,80 & 5,20 & 5,20 & 3,40 & 4,65 & 0,85 \\
\hline H & Inf & 4,60 & 5,40 & 5,80 & 4,20 & 5,00 & 0,73 \\
\hline Média & & & & & & & \\
\hline
\end{tabular}


As amostras de corte A, B, C, D, E, F, G e H revelam os níveis de contaminação contidos na fase de laminação final das placas combustíveis segundo o procedimento tradicional de fabricação utilizado presentemente no CCN.

Comentando de uma forma geral os dados encontrados, nota-se que há uma diferenciação de valores nos níveis de atividade alfa entre a superfície da placa superior no primeiro passe de laminação em relação à face inferior.

A partir dos dados apresentados nessas tabelas, geraram-se dois gráficos, mostrados na Figura 15 e na Figura 16. Além dos resultados individuais de medida da contagem alfas também estão listadas as médias entre placas e os desvios padrões globais de todo o conjunto amostral, indicado pelo tamanho dos círculos nos gráficos.

Os gráficos mostram uma variabilidade das médias de contagem ao longo dos diversos posicionamentos no conjunto, indicado por letras na Figura 11. Visualmente, essa dispersão parece indicar que há uma maior atividade alfa no lado das amostras A, B, C e D do que no lado das amostras E, F, G e H.

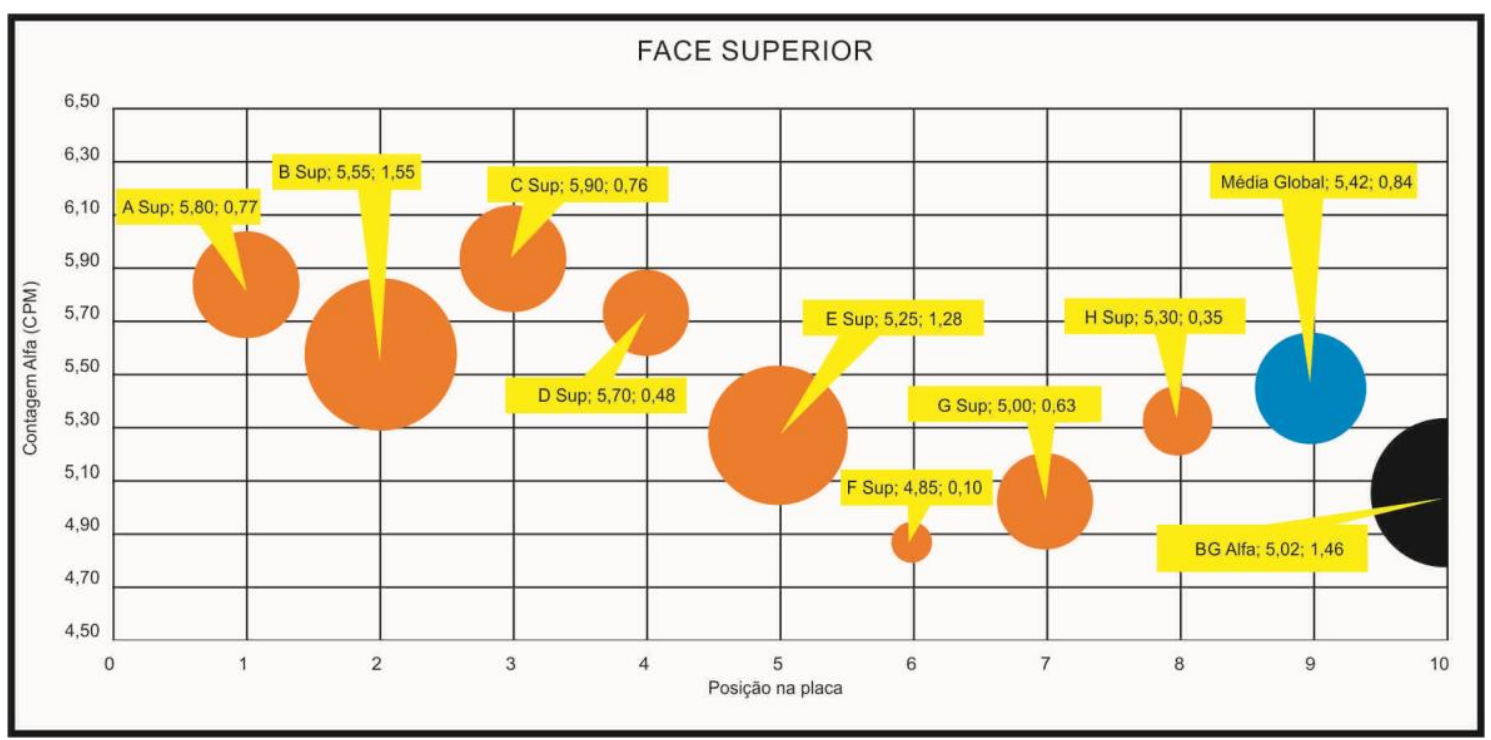

Figura 15 - Gráfico de média com dispersão mostrando o nível de contagem alfa por minuto nas diversas posições das amostras na face superior das placas laminadas \#877, \#878, \#879 e \#880. 


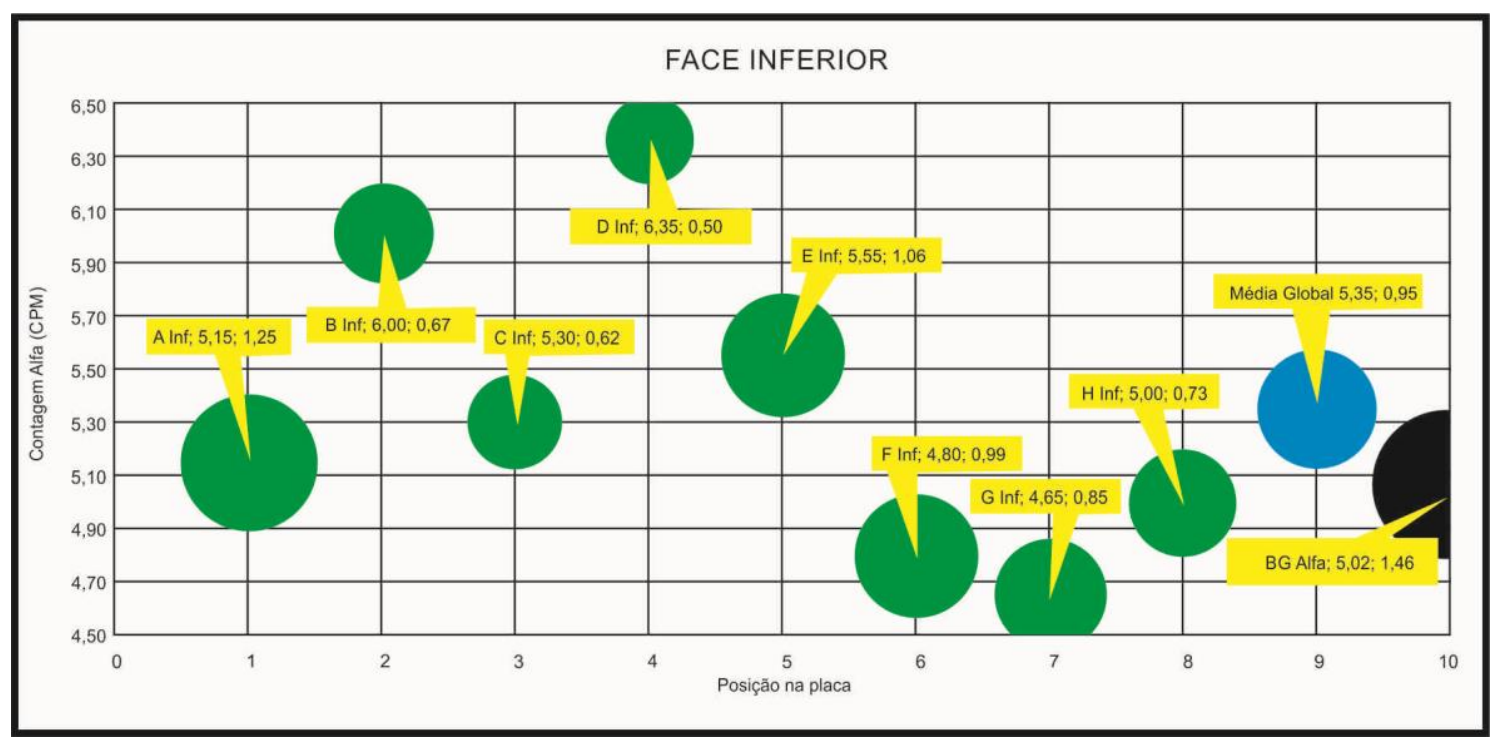

Figura 16 - Gráfico de média com dispersão mostrando o nível de contagem alfa por minuto nas diversas posições das amostras na face inferior das placas laminadas \#877, \#878, \#879 e \#880. O valor de BG médio com dispersão é apresentado no gráfico.

Mas esses dados devem ser analisados de forma mais robusta, utilizando-se os recursos estatísticos de teste de hipótese. A hipótese zero que afirma que as médias das distribuições comparadas são estatisticamente pertencentes a uma mesma população, isto é, essas médias são estatisticamente iguais. A hipótese zero é rejeitada quando se obtém um valor-p menor do que 0.05 , aceitando-se então a hipótese alternativa quando as médias são desiguais.

A superfície superior apresentou um nível de contaminação $\mu_{\text {sup }}(5.42 ; 0.84)$ e a superfície inferior $\mu_{\mathrm{inf}}(5.35 ; 0.95)$, considerando-se o teste de hipótese:

$$
\begin{aligned}
& \mathrm{H}_{0}: \mu_{\text {sup }}=\mu_{\text {inf }} \\
& \mathrm{H}_{1}: \mu_{\text {sup }} \neq \mu_{\text {inf }}
\end{aligned}
$$

Com um nível de significância de $95 \%$ (valor-p $=0.308$ ), deve-se aceitar $\mathrm{H}_{0}$ e rejeitar $\mathrm{H}_{1}$, isto é, as diversas amostras de contagem alfa das duas superfícies devem ser consideradas como pertencente a uma mesma distribuição normal, portanto, não há variabilidade entre os resultados. Esse resultado invalida qualquer inferência que se possa ter de distribuição de valores diferenciados, mesmo os assimétricos contidos nos resultados, apesar das tendências visuais. 
Portanto, não se pode afirmar estatisticamente, por teste de hipótese, que nesse quadro experimental tenha ocorrido contaminação preferencial em alguma região ou superfície considerada.

Considerando-se as avaliações de background e fazendo o teste de hipótese de todo o conjunto amostral de medidas de alfa para todas as placas, posições e superfícies (64 dados), tem-se que para a distribuição normal equivalente: $\mu_{\text {global }}(5.384 ; 0.889)$. Fazendo-se o teste de hipótese em comparação com a distribuição normal do background: $\mu_{\mathrm{BG}}(5,02 ; 1,46)$, tem-se:

$$
\begin{aligned}
& \mathrm{H}_{0}: \mu_{\text {global }}=\mu_{B G} \\
& H_{1}: \mu_{\text {global }} \neq \mu_{B G}
\end{aligned}
$$

Com um nível de significância de 95\% (valor-p = 0,175), deve-se aceitar $\mathrm{H}_{0}$ e rejeitar $\mathrm{H}_{1}$, isto é, as diversas amostras de contagem alfa de todas as amostras, posições e superfícies devem ser consideradas como pertencente a uma mesma distribuição normal, portanto, não há variabilidade entre os resultados. Logo, não se pode dizer que há significância estatística de diferenças entre médias das medidas colhidas e do background.

Resumidamente, essa fase experimental mostrou que não há um nível significativo estatístico de contaminação por urânio durante o processo de laminação, que foi apenas perceptível visualmente, mas não estatisticamente. 


\subsection{Segunda fase Experimental: Contaminação Intencional}

Após a obtenção da placa contaminada intencionalmente, fizeram-se 4 amostras das aparas em cada uma das 8 regiões especificadas na Figura 11. Foram feitas as medidas de contagens de emissão alfa nas duas faces da amostra: superior e inferior. A face superior foi a superfície que recebeu a contaminação intencional e a face inferior não foi contaminada intencionalmente. Após a medição em cada uma das faces, fez-se a decapagem das amostras em solução alcalina conforme procedimento já descrito anteriormente, mas em volume contendo um 1 litro de solução alcalina. A tabela 3 mostra os resultados experimentais de atividade alfa em cpm nas várias etapas com referência às faces ensaiadas.

Nessa tabela, evidencia-se que a contaminação foi efetiva nas amostras da face superior e não contaminou a face inferior com relação às diversas amostras nos seus diversos pontos de coleta indicados na Figura 11. Como era de se esperar, a região superior foi densamente contaminada, de forma, que o tratamento de descontaminação seguindo a rotina tradicional de fabricação de placas do CCN pode ser devidamente avaliada. Conforme, indicado na Tabela 3, o BG determinado para essa segunda fase experimental desenvolveu a seguinte distribuição normal: $\mu_{B G}=5.18 ; d p=1.82$ para 35 avaliações de contagem com amostras virgens. De uma forma apenas qualitativa, vê-se através dos dados tabelados que os níveis de contaminação caíram para o nível de BG determinado nessa 2 2 fase experimental. Dessa forma, pode-se dizer qualitativamente que houve efetividade na remoção da contaminação pelo tratamento em solução alcalina. Grosseiramente, esses níveis caíram para contagens de alfa em torno de 5 a 6 contagens por minuto e à média determinada para o BG estimado está entre essas duas contagens. 
Tabela 3 - Dados de contagem das placas contaminadas intencionalmente, na face superior e inferior sem tratamento superficial e na face superior e inferior com tratamento superficial.

\begin{tabular}{|c|c|c|c|c|c|c|c|c|c|}
\hline Pos & Suplnf & $\begin{array}{c}\text { Amostra } \\
1\end{array}$ & $\begin{array}{c}\text { Amostra } \\
2\end{array}$ & $\begin{array}{c}\text { Amostra } \\
3\end{array}$ & $\begin{array}{c}\text { Amostra } \\
4\end{array}$ & Media & $\begin{array}{l}\text { Desv } \\
\text { Pad }\end{array}$ & $\begin{array}{l}\text { Media } \\
\text { Global }\end{array}$ & $\begin{array}{c}\text { Desv } \\
\text { Pad }\end{array}$ \\
\hline$A$ & Superior & 151.20 & 67.80 & 107.60 & 131.00 & 114.40 & 35.81 & \multirow{7}{*}{\multicolumn{2}{|c|}{ Superior }} \\
\hline B & Superior & 52.20 & 80.40 & 184.80 & 62.40 & 94.95 & 61.02 & & \\
\hline C & Superior & 70.40 & 53.00 & 61.80 & 123.40 & 77.15 & 31.64 & & \\
\hline D & Superior & 151.00 & 90.40 & 136.20 & 190.20 & 141.95 & 41.23 & & \\
\hline$E$ & Superior & 133.80 & 69.40 & 91.20 & 48.40 & 85.70 & 36.52 & & \\
\hline $\mathbf{F}$ & Superior & 97.80 & 71.80 & 92.60 & 95.20 & 89.35 & 11.89 & & \\
\hline G & Superior & 81.20 & 81.00 & 188.40 & 97.30 & 111.98 & 51.52 & & \\
\hline H & Superior & 37.00 & 108.20 & 162.60 & 33.80 & 85.40 & 61.87 & 100.11 & 43.90 \\
\hline$A$ & Inferior & 4.00 & 6.20 & 5.20 & 6.80 & 5.55 & 1.23 & \multirow{7}{*}{\multicolumn{2}{|c|}{ Inferior }} \\
\hline B & Inferior & 4.20 & 7.00 & 4.60 & 5.20 & 5.25 & 1.24 & & \\
\hline C & Inferior & 6.40 & 6.20 & 8.60 & 4.80 & 6.50 & 1.57 & & \\
\hline D & Inferior & 2.60 & 4.80 & 5.80 & 5.00 & 4.55 & 1.37 & & \\
\hline$E$ & Inferior & 3.00 & 4.80 & 5.80 & 7.00 & 5.15 & 1.69 & & \\
\hline $\mathbf{F}$ & Inferior & 3.60 & 6.00 & 6.40 & 6.20 & 5.55 & 1.31 & & \\
\hline G & Inferior & 3.40 & 4.80 & 4.00 & 5.00 & 4.30 & 0.74 & & \\
\hline $\mathrm{H}$ & Inferior & 3.40 & 4.00 & 6.40 & 5.80 & 4.90 & 1.43 & 5.22 & 1.35 \\
\hline$A$ & Sup-tratada & 4.20 & 7.00 & 5.80 & 4.00 & 5.25 & 1.42 & \multirow{7}{*}{\multicolumn{2}{|c|}{$\begin{array}{l}\text { Superior } \\
\text { Tratada }\end{array}$}} \\
\hline B & Sup-tratada & 3.20 & 7.20 & 5.20 & 9.60 & 6.30 & 2.74 & & \\
\hline C & Sup-tratada & 6.20 & 4.80 & 6.80 & 9.40 & 6.80 & 1.93 & & \\
\hline D & Sup-tratada & 5.80 & 3.80 & 3.60 & 4.80 & 4.50 & 1.01 & & \\
\hline$E$ & Sup-tratada & 8.00 & 4.80 & 6.20 & 7.60 & 6.65 & 1.45 & & \\
\hline $\mathbf{F}$ & Sup-tratada & 7.20 & 4.00 & 5.40 & 6.00 & 5.65 & 1.33 & & \\
\hline G & Sup-tratada & 6.40 & 5.00 & 4.20 & 5.00 & 5.15 & 0.91 & & \\
\hline H & Sup-tratada & 6.40 & 7.00 & 5.80 & 8.00 & 6.80 & 0.94 & 5.89 & 1.62 \\
\hline$A$ & Inf-tratada & 3.80 & 4.60 & 4.80 & 7.40 & 5.15 & 1.56 & \multirow{7}{*}{\multicolumn{2}{|c|}{ Inferior Tratada }} \\
\hline B & Inf-tratada & 4.00 & 6.00 & 6.20 & 5.80 & 5.50 & 1.01 & & \\
\hline C & Inf-tratada & 6.20 & 7.00 & 4.40 & 7.80 & 6.35 & 1.45 & & \\
\hline D & Inf-tratada & 9.20 & 4.40 & 6.40 & 9.80 & 7.45 & 2.52 & & \\
\hline$E$ & Inf-tratada & 6.40 & 4.20 & 5.00 & 6.80 & 5.60 & 1.21 & & \\
\hline $\mathbf{F}$ & Inf-tratada & 6.40 & 5.20 & 7.20 & 6.20 & 6.25 & 0.82 & & \\
\hline G & Inf-tratada & 8.20 & 4.80 & 5.80 & 5.20 & 6.00 & 1.52 & & \\
\hline $\mathrm{H}$ & Inf-tratada & 6.80 & 8.00 & 4.60 & 8.20 & 6.90 & 1.65 & 6.15 & 1.54 \\
\hline
\end{tabular}

\begin{tabular}{|lll|l|l|}
\hline Background (BG) $\quad 35$ avaliações $\quad$ média $=$ & $\mathbf{5 . 1 8}$ & Dpad $=\mathbf{1 . 8 2}$ \\
\hline
\end{tabular}


A figura 17 mostra os dados médios obtidos antes e após o tratamento químico superficial. Esses dados revelam que o tratamento superficial é eficiente para retirar a camada contaminada da superfície.

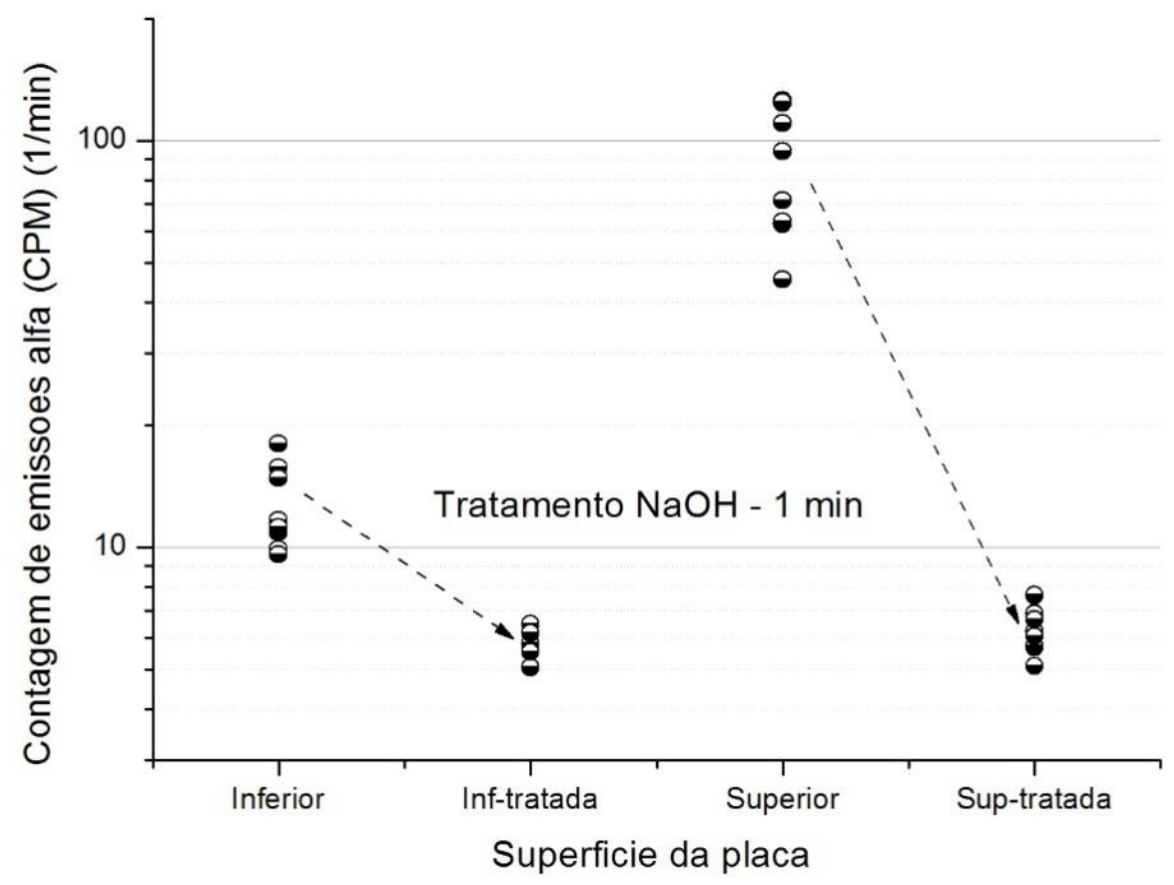

Figura 17 - Resultados dos valores médios do tratamento em decapagem alcalina de $\mathrm{NaOH}$ durante 1 minuto nas amostras na forma de contagem de emissões alfa (CPM)

No entanto, deve-se avaliar estatisticamente esses níveis de contagem de emissão alfa conseguidos após o tratamento está ainda superior ao valor do BG conforme citado na Tabela 3.

\subsubsection{Avaliação da efetividade do tratamento químico}

Para se compreender essa tabela de teste estatístico, considerou-se o seguinte plano de hipóteses:

$$
\begin{aligned}
& H_{0}: \mu_{\text {pos }}=\mu_{B G} \\
& H_{1}: \mu_{\text {pos }} \neq \mu_{B G}
\end{aligned}
$$


O teste de hipótese foi montado com base em uma hipótese zero em que as médias da contagem alfa das amostras da face superior e inferior, tratada e não tratada, são comparadas com a distribuição normal das medidas da atividade do background, consideram-se os desvios padrões das respectivas distribuições. A eficiência do tratamento químico para descontaminação da superfície contaminada intencionalmente está sumarizada na Tabela 4 e nos gráficos da Figura 17.

Nessa Tabela 4, vê-se que a hipótese zero é rejeitada em duas condições, com valores$\mathrm{p}$ bem significativos. Portanto, a superfície contaminada proporcionalmente foi devidamente confirmada pelo teste de hipótese.

Com relação à face inferior tratada, consta-se que a média de contagens ficou relativamente alta em relação ao BG, situação aparentemente ilógica, mas que pode ser explicada do ponto de vista experimental, devido uma recontaminação inadvertida durante o processo de tratamento químico feito com amostras altamente contaminadas e não contaminadas. Como se pode ver na Tabela 4, a face superior estava altamente contaminada ( $\mu=100.11$ ) e a inferior não estava contaminada $(\mu=5.22)$, basicamente com o valor de BG $(\mu=5.18)$. Como ambas faces da amostra estavam na mesma amostra a ser tratada quimicamente, o tratamento químico da amostra foi feito de forma simultânea. Isso certamente teve implicações de recontaminação da face inferior não contaminada.

Tabela 4 - Teste de Hipótese - $2^{a}$ fase experimental - Eficiência do tratamento químico

\begin{tabular}{|c|c|c|c|c|c|c|}
\hline $\begin{array}{c}\text { POS. \& } \\
\text { TRAT. }\end{array}$ & VALOR-P & DIF BG & LIC 95 & LSC 95 & $\begin{array}{c}\text { HIPÓTESE } \\
\text { ZERO }\end{array}$ & HIPÓTESE ALTERNATIVA \\
\hline SUP & $\mathbf{0 . 0 0 0}$ & 94.93 & 79.09 & 110.77 & REJEITADA & ACEITA \\
\hline SUP-TR & $\mathbf{0 . 0 9 4}$ & 0.712 & ND & 1.549 & ACEITA & REJEITADA \\
\hline INF & $\mathbf{0 . 1 1 0}$ & 0.043 & ND & 0.821 & ACEITA & REJEITADA \\
\hline INF-TR & $\mathbf{0 . 0 2 1}$ & 0.974 & 0.155 & 1.794 & REJEITADA & ACEITA \\
\hline
\end{tabular}

Obs.: POS. \& TRAT. = superfície superior (SUP) e inferior (INF), tratada (SUP-TR e INF-TR); DIF BG = diferença estimada entre a média experimental e o BG; LIC 95 = limite inferior de confiança da diferença DIF BG com 95\% de significância; LSC 95 = limite superior de confiança da diferença DIF BG com 95\% de significância. $\mathrm{ND}=$ não disponível, isso ocorre quando os valores não fazem sentido físico, por exemplo, quando se obtém valores negativos. 


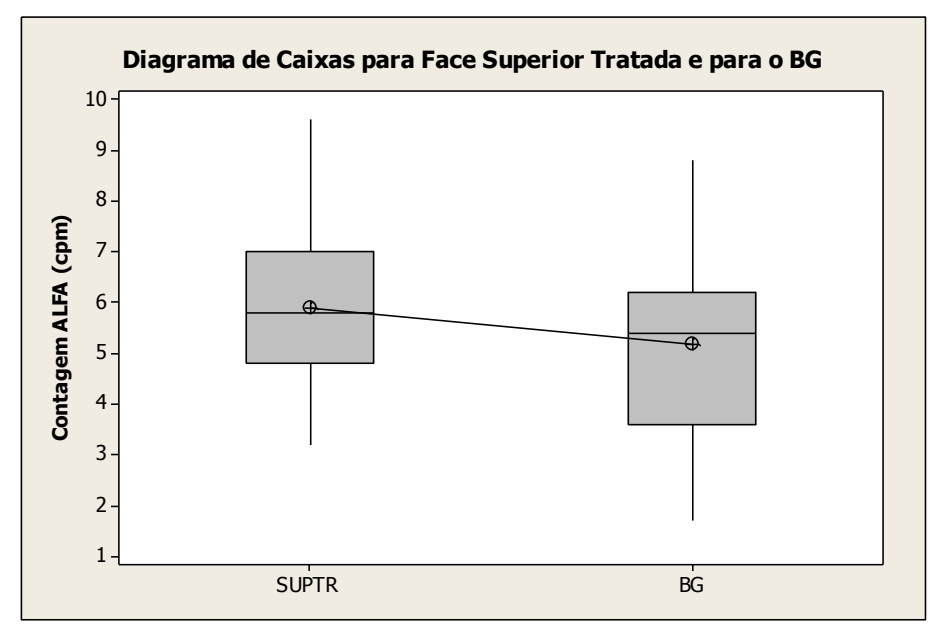

(A)

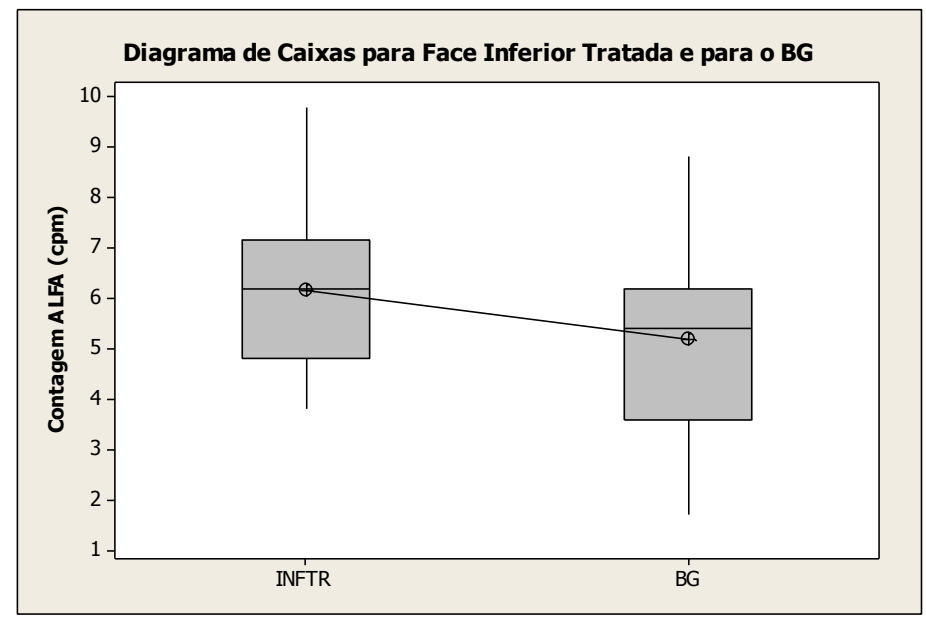

(B)

Figura 18 - Diagramas de caixa das médias mostrando o efeito de descontaminação com a média do background das emissões alfa. (a) face superior (b) face inferior.

Detalhando um pouco mais, durante o tratamento químico das amostras com contaminação ocorreu a dissolução das incrustações de urânio na forma de $\mathrm{U}_{3} \mathrm{Si}_{2}$ para íons de uranilo no banho alcalino dentro de um volume de solução relativamente baixo (1000 ml). A partir do banho químico, o urânio já dissolvido depositou na superfície inferior. Em banhos alcalinos, com presença maciça de hidroxilas $(\mathrm{NaOH})$, o urânio metálico se redissolve e oxida, transformando-se em uranilo $\left(\mathrm{UO}_{2}{ }^{+2}\right)$, que tem o estado de oxidação de urânio VI [36]. Nesse estado, o uranilo pode se redepositar como precipitado na superfície não contaminada da amostra, na forma de hidróxido/óxido de uranilo. Com base nesses dados e procedimentos não previstos anteriormente, o 
resultado das contagens na face inferior da amostra depois do tratamento $(\mu=6.15)$ não se tornou realista para se proceder a avaliação do nível de contaminação na superfície inferior das amostras.

De uma forma mais robusta estatisticamente, pode-se afirmar com base na Tabela 4 que esse o processo de contaminação intencional conseguiu produzir uma superfície contaminada antes do tratamento químico em níveis de contagem de emissão alfa 18 vezes maior do que o background.

A face superior das amostras, contaminadas previamente, gerou após o tratamento químico um nível médio de contagens ( $\mu=5.89 ; \sigma=1.35$ ), próximo aos valores do BG. Como indicado na tabela, o teste de hipótese rejeitou a hipótese zero. Caso se considerasse um risco de se errar além de 5\% (nível de significância de 95\%), mas no nível de 10\%, nesse caso, a face superior após o tratamento deveria ter a hipótese zero rejeitada, aceitando-se, assim, que haveria uma contaminação remanescente de urânio. Nesse caso, deveria se aceitar como válida a diferença de contagem alfa de 0.712 entre a superfície tratada e o BG. No entanto, como se discutiu acima a recontaminação da superfície inferior, de forma semelhante ocorreu na superfície superior também e na mesma intensidade. De forma, que se torna muito inadequada qualquer consideração de que a média de contagem da superfície superior não tenha sido a mesma do background.

Portanto, é importante que se ressalte que o tratamento químico para uma amostra altamente contaminada é certamente eficaz para promover a remoção de contaminações mais baixas do que as introduzidas deliberadamente nesse experimento. Com base nesses resultados, pode-se afirmar com segurança estatística, que o tratamento químico convencional na atual prática de produção de placas combustíveis é eficaz e não é necessário que seja alterado para promover a descontaminação do residual de urânio, que por ventura exista após o processo de laminação e corte. 


\subsection{Terceira Fase Experimental: Contaminação Histórica}

Nessa fase, houve duas etapas. Na primeira etapa, analisou-se a contaminação histórica em um nível reduzido de amostragem (10 amostras) de forma a se fazer uma primeira análise investigativa. Na segunda etapa, utilizou-se um número amostral maior (50 amostras). Em ambas etapas, dessa fase experimental, desejava-se constatar o efeito do tratamento de descontaminação ao longo do processo histórico de fabricação de placas combustíveis.

Estatisticamente, está se considerando um período de mais de 14 anos, desde 1998 até 2013.

\subsubsection{Primeira Etapa: 10 amostras históricas.}

Fizeram-se amostragens aleatórias de 10 testemunhos das placas produzidas na unidade fabril do Centro do Combustível Nuclear do IPEN ao longo de sua história produtiva. Esses testemunhos foram escolhidos aleatoriamente. Dessas placas foram tiradas amostras em duas regiões da placa, A e E, conforme mostrado na Figura 11. Cada placa teve 4 contagens de emissões alfa antes do tratamento químico convencional de descontaminação. As contagens foram realizadas no decurso de 48 horas com o BG de alfa apresentando uma média de $3,76 \pm 0.46$. A Tabela 5 apresenta os resultados das amostras. 
Tabela 5 - Contagens de emissão alfa obtidas de 10 placas combustíveis fabricados no CCN.

\begin{tabular}{|c|c|c|c|c|c|c|c|c|c|c|c|c|c|c|}
\hline Tempo & Pos & Sup-Inf & $\begin{array}{c}\text { Placa } \\
473\end{array}$ & $\begin{array}{c}\text { Placa } \\
914\end{array}$ & $\begin{array}{c}\text { Placa } \\
830\end{array}$ & $\begin{array}{c}\text { Placa } \\
835\end{array}$ & $\begin{array}{c}\text { Placa } \\
635\end{array}$ & $\begin{array}{c}\text { Placa } \\
614\end{array}$ & $\begin{array}{c}\text { Placa } \\
459\end{array}$ & $\begin{array}{c}\text { Placa } \\
882\end{array}$ & $\begin{array}{c}\text { Placa } \\
752\end{array}$ & $\begin{array}{c}\text { Placa } \\
471\end{array}$ & Média & $\begin{array}{c}\text { Erro } \\
\text { Padrão } \\
(95 \%)\end{array}$ \\
\hline 0 & $A$ & Superior & 5,40 & 3,20 & 4,40 & 5,00 & 6,60 & 5,00 & 5,00 & 3,20 & 3,80 & 4,40 & 4,60 & 0,69 \\
\hline 0 & $\bar{E}$ & Superior & 5,00 & 4,00 & 5,60 & 4,60 & 1,80 & 4,60 & 2,40 & 3,80 & 5,60 & 5,00 & 4,24 & 0,85 \\
\hline 0 & $\bar{A}$ & Inferior & 4,60 & 3,60 & 5,20 & 4,20 & 4,20 & 3,40 & 5,80 & 3,40 & 4,40 & 3,60 & 4,24 & 0,53 \\
\hline 0 & $E$ & Inferior & 3,60 & 3,60 & 4,40 & 4,60 & 4,20 & 3,60 & 3,80 & 3,20 & 4,40 & 4,00 & 3,94 & 0,30 \\
\hline 30 & $\bar{A}$ & Sup-tratada & 3,60 & 4,20 & 3,60 & 5,60 & 5,20 & 4,00 & 3,20 & 5,20 & 4,20 & 4,20 & 4,30 & 0,53 \\
\hline 30 & $\bar{E}$ & Sup-tratada & 5,00 & 4,20 & 3,00 & 5,40 & 4,40 & 3,60 & 5,00 & 5,60 & 2,60 & 4,80 & 4,36 & 0,67 \\
\hline 30 & $A$ & Inf-tratada & 5,00 & 5,60 & 3,00 & 5,20 & 3,80 & 4,60 & 5,60 & 4,20 & 1,40 & 5,80 & 4,42 & 0,92 \\
\hline 30 & $\bar{E}$ & Inf-tratada & 5,40 & 7,20 & 4,60 & 4,20 & 3,80 & 6,00 & 2,80 & 4,00 & 4,40 & 5,00 & 4,74 & 0,82 \\
\hline 60 & $A$ & Sup-tratada & 3,80 & 3,00 & 3,80 & 4,60 & 3,40 & 4,00 & 3,60 & 4,80 & 3,20 & 2,80 & 3,70 & 0,43 \\
\hline 60 & $\bar{E}$ & Sup-tratada & 4,20 & 3,80 & 3,60 & 3,40 & 3,40 & 4,00 & 3,20 & 3,80 & 3,60 & 3,00 & 3,60 & 0,24 \\
\hline 60 & $A$ & Inf-tratada & 2,80 & 3,60 & 3,60 & 3,00 & 3,20 & 3,00 & 4,00 & 3,00 & 3,80 & 2,80 & 3,28 & 0,29 \\
\hline 60 & $\bar{E}$ & Inf-tratada & 6,00 & 3,80 & 3,40 & 5,40 & 2,80 & 3,00 & 3,20 & 5,20 & 4,20 & 3,60 & 4,06 & 0,74 \\
\hline
\end{tabular}

Tabela 6-Resumo dos dados apresentados na tabela 5.

\begin{tabular}{|c|c|c|c|c|}
\hline Placa & $\begin{array}{c}\text { Sem } \\
\text { tratamento }\end{array}$ & EPad 95\% & $\begin{array}{c}\text { Com } \\
\text { Tratamento }\end{array}$ & EPad 95\% \\
\hline$\# 473$ & 4,65 & 0,89 & 4,20 & 1,54 \\
\hline$\# 914$ & 3,60 & 0,38 & 3,55 & 0,44 \\
\hline$\# 830$ & 4,90 & 0,69 & 3,60 & 0,19 \\
\hline$\# 835$ & 4,60 & 0,38 & 4,10 & 1,27 \\
\hline$\# 635$ & 4,20 & 2,26 & 3,20 & 0,33 \\
\hline$\# 614$ & 4,15 & 0,89 & 3,50 & 0,67 \\
\hline$\# 459$ & 4,25 & 1,71 & 3,50 & 0,44 \\
\hline$\# 882$ & 3,40 & 0,33 & 4,20 & 1,15 \\
\hline$\# 752$ & 4,55 & 0,87 & 3,70 & 0,48 \\
\hline$\# 471$ & 4,25 & 0,69 & 3,05 & 0,44 \\
\hline Média & 4,26 & 1,24 & 3,66 & 0,92 \\
\hline
\end{tabular}


Como os resultados obtidos não apresentaram muita variabilidade, resumiu-se a Tabela 5 em valores médios de 4 medidas de contagem, cujo resultado está apresentado na Tabela 6. Esses dados estão mostrados na Figura 19. Nota-se, nesse gráfico, o efeito global do nível de contaminação das placas logo após o corte final e as contagens alfa após o tratamento químico de descontaminação.

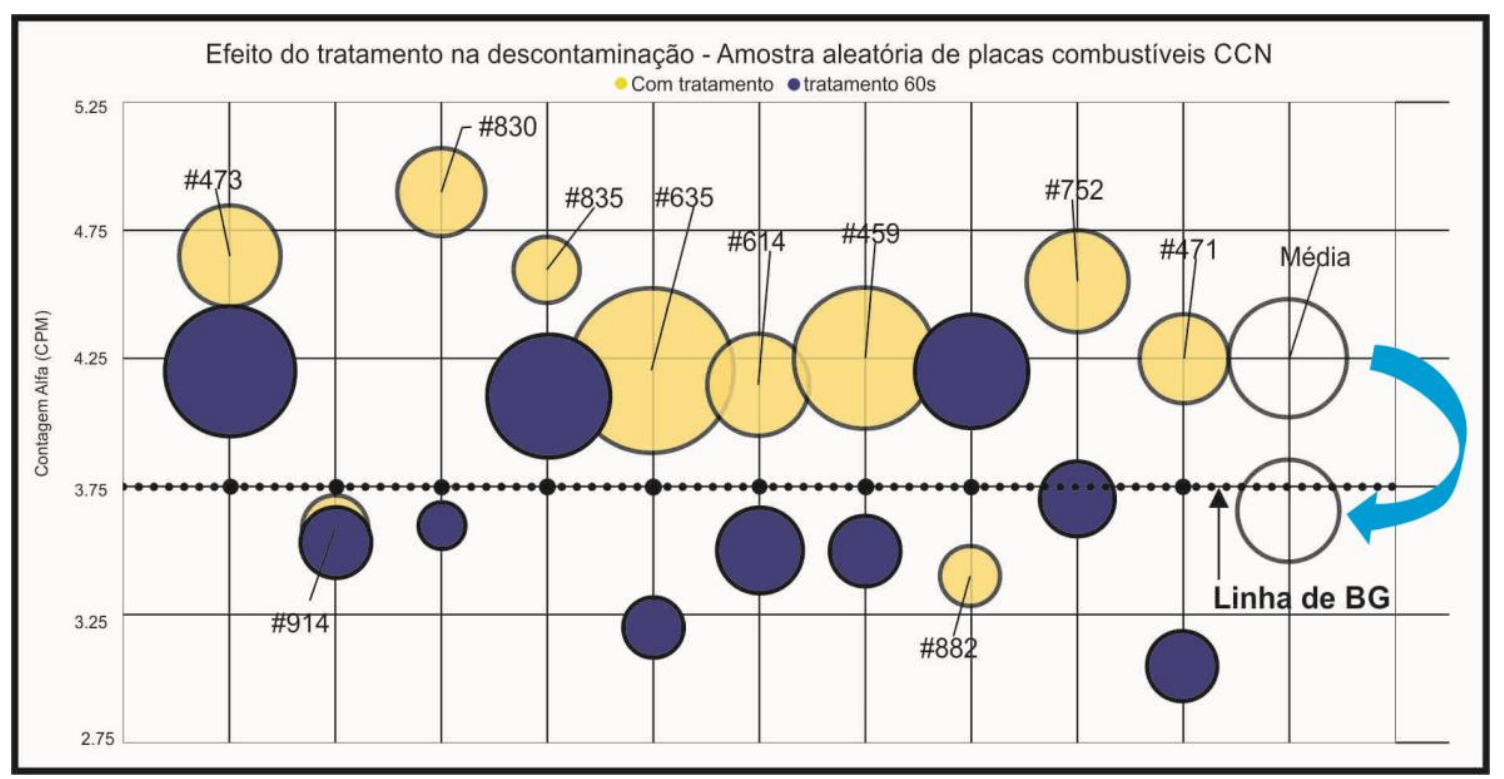

Figura 19 - Gráfico ilustrando o efeito global do nível de contaminação das placas laminadas antes e após o tratamento de descontaminação.

Como se pode ver as placas combustíveis antes do processo de tratamento estão ligeiramente contaminadas superficialmente e após o tratamento superficial em banho alcalino, elas praticamente ficam, na região do BG. Mesmo as placas antes do tratamento não diferenciaram muito do BG. Pode-se considerar o nível aproximado de $0.5 \mathrm{cpm}$.

Considerando-se que o CCN como um produtor que tem o nível de contaminação igual ao background com um desvio padrão da população de 0.5 em unidades de contagem alfa, tem-se que essa amostragem aleatória de 10 placas colhidas representam uma potência de amostragem $(\beta=0.89)$ em torno de $89 \%$, com um nível de significância de $95 \%$, podendo-se garantir que essa variação da contagem alfa das placas antes de serem descontaminadas não podem ser consideradas como não pertencentes à distribuição do 
BG. No entanto, é evidente que dentro da faixa de variabilidade, as placas antes da descontaminação foram superiores em contagem com relação às tratadas, que na média caíram na linha do BG.

\subsubsection{Segunda Etapa: amostragem maior (50 cupons)}

Os elementos combustíveis produzidos no CCN entre 1998 e 2013 foram amostrados aleatoriamente em mais de 50 amostras. Nesse processo estatístico, utilizou-se uma ampliação da faixa de contagem de emissões alfa, trabalhando-se mais na faixa do background das medidas. Para que isso ocorresse trabalhou-se com o equipamento de contagem de emissões alfa em um nível de sensibilidade 10 vezes maior. As medidas ficaram mais ruidosas, mas, estatisticamente, foi possível trabalhar com dados em uma escala maior de medida das contagens alfa.

O Anexo III traz a tabela completa de todos os dados medidos. Ela introduz uma variável calculada (DIF_Alfa) a partir da medida de contagens de decaimento alfa. Essa variável DIF_Alfa é uma diferença entre o valor medido e o BG intercalado entre as medidas, dando mais significância às avaliações das contagens e diminuindo os erros inerentes da ampliação de escala do contador.

Ao se resumirem os resultados das medidas, conforme apresentados no Anexo I, fez-se um rearranjo em 6 grupos estatísticos distintos, descritos como:

- Face Superior Sem Decapagem (supSD);

- Face Inferior Sem Decapagem (infSD);

- Ambas Faces Sem Decapagem (SD),

- Face Superior Com Decapagem (supCD);

- Face Inferior Com Decapagem (infCD);

- Ambas Faces Com Decapagem (CD)

- Amostragem Total (AT)

A Tabela 7 mostra os parâmetros estatísticos de tendência central, baseando-se no fato de essa distribuição gerar padrões de distribuição gaussiana. Esses dados foram obtidos a partir do tabelamento no Anexo III. 
Tabela 7 - Resumo estatístico do Anexo III da contagem alfa da amostragem histórica ampliada. Refere-se às placas combustíveis produzidas no CCN entre 1998 e 2013

\begin{tabular}{|l|c|c|c|c|c|c|c|}
\hline & $\begin{array}{c}\text { Sem Decap. } \\
\text { Face } \\
\text { Superior } \\
\text { (supSD) }\end{array}$ & $\begin{array}{c}\text { Sem Decap. } \\
\text { Face } \\
\text { Inferior } \\
\text { (infSD) }\end{array}$ & $\begin{array}{c}\text { Sem Decap. } \\
\text { Ambas } \\
\text { faces } \\
\text { (SD) }\end{array}$ & $\begin{array}{c}\text { Com Decap. } \\
\text { Face } \\
\text { Superior } \\
\text { (supCD) }\end{array}$ & $\begin{array}{c}\text { Com Decap. } \\
\text { Face } \\
\text { Inferior } \\
\text { (infCD) }\end{array}$ & $\begin{array}{c}\text { Com Decap. } \\
\text { Ambas } \\
\text { faces } \\
\text { (CD) }\end{array}$ & Total \\
\hline Contagens & 53 & 51 & 104 & 60 & 62 & 122 & 226 \\
\hline Média & 1,837 & 2,463 & 2,144 & 1,328 & 1,733 & $\mathbf{1 , 5 3 4}$ & 1,815 \\
\hline Erro Pad & 0,374 & 0,403 & 0,275 & 0,349 & 0,398 & 0,265 & 0,191 \\
\hline Lim.Conf (-95\%) $^{-1,087}$ & 1,654 & 1,599 & 0,630 & 0,937 & 1,010 & 1,437 \\
\hline Lim.Conf $+95 \%)$ & 2,588 & 3,272 & 2,689 & 2,026 & 2,530 & $\mathbf{2 , 0 5 9}$ & 2,192 \\
\hline Desv.Padrão & 2,721 & 2,876 & 2,803 & 2,702 & 3,137 & 2,926 & 2,880 \\
\hline Máximo & 7,385 & 10,385 & 10,384 & 7,894 & 9,894 & 9,894 & 10,385 \\
\hline Mínimo & $-3,615$ & $-6,615$ & $-6,615$ & $-4,105$ & $-5,105$ & $-5,105$ & $-6,615$ \\
\hline
\end{tabular}

Primeiramente, deve-se notar na tabela, que não houve uma grande alteração na dispersão dos diversos dados. Essa dispersão está muito relacionada com os erros gerados pelo próprio equipamento de medida, uma vez que se aumentou em 10 vezes a amplitude de medida das contagens alfa, caindo na região do background do equipamento. A dispersão, ficando em um intervalo pequeno, mostra que o erro é igual para todos os dados e não prejudicaria uma análise comparativa, que é a que se pretende fazer com esses dados experimentais.

A amostragem total AT refere-se ao total de contagens feitas nessa etapa experimental. Foram feitas 226 contagens em todas as amostras colhidas. O dado da média de AT $(1.815 ; 2.880)$ apenas realça a ordem de grandeza da média de variável DIF_alfa como um todo. Discriminando-se os dados do Anexo III, deve-se notar que algumas amostras foram feitas de forma repetida para se aumentar o volume amostral. Durante as contagens não se notaram divergências significativas dos resultados e decidiu-se colocar essas medidas repetidas no conjunto amostral de forma a se aumentar a significância dos dados obtidos. Deve-se considerar que esse viés estatístico foi utilizado, em maior número, nas experiências com amostras decapadas, para se aumentar a segurança estatística de avaliação do tratamento químico.

Nota-se que a faixa de medidas entre um valor máximo observado de 10,385 e mínimo de $-6,615$ estão centralizados em uma média de 1,815 . No entanto, esse valor não pode ser utilizado como valor médio do background, já que no seu conjunto amostral estão 
incluídas amostras supostamente contaminadas em conjunto com as decapadas. Portanto, para melhor avaliar um nível referencial de escala, deve-se utilizar o valor médio de todas as amostras decapadas (amostras CD). Esse valor tem a sua distribuição dada por $\mu=1,534 ; \sigma=2,926$. Para se estimar a faixa de significância com $5 \%$ de erro padrão de estimativa, utilizou-se o erro padrão calculado pela seguinte equação:

$$
\text { erro pad. }=\sqrt[2]{\frac{\sigma^{2}}{n}} \quad \ldots 7
$$

Onde $\sigma$ é o desvio padrão amostral e n é o número de componentes na amostra, que no caso do conjunto amostral (CD) é 122. Portanto, o erro padrão de estimativa é de $(2,926) / \sqrt{ } 122=0,265$. Multiplicando-se por 2 o erro padrão, tem-se uma faixa de significância estabelecida de 95\% para o referencial de BG para análise: 1,534 $\mathbf{5 0 . 5 3 0 .}$ Pode-se dizer que o BG está limitado de forma significativa entre os limites de 1,010 e 2,060 de contagens médias das emissões alfa em unidades de DIF_alfa para esse experimento. Portanto, todas as distribuições de contagens dos experimentos entre essas duas linhas limites foram consideradas como tecnicamente emissões de BG. 


\subsubsection{Face Superior da Placa}

Os resultados experimentais de SupSD e SupCD podem ser visualizados na Figura 20. Nota-se que as distribuições das amostras relativas à face superior, antes e após a decapagem, fundamentalmente coincidem com a região do BG.

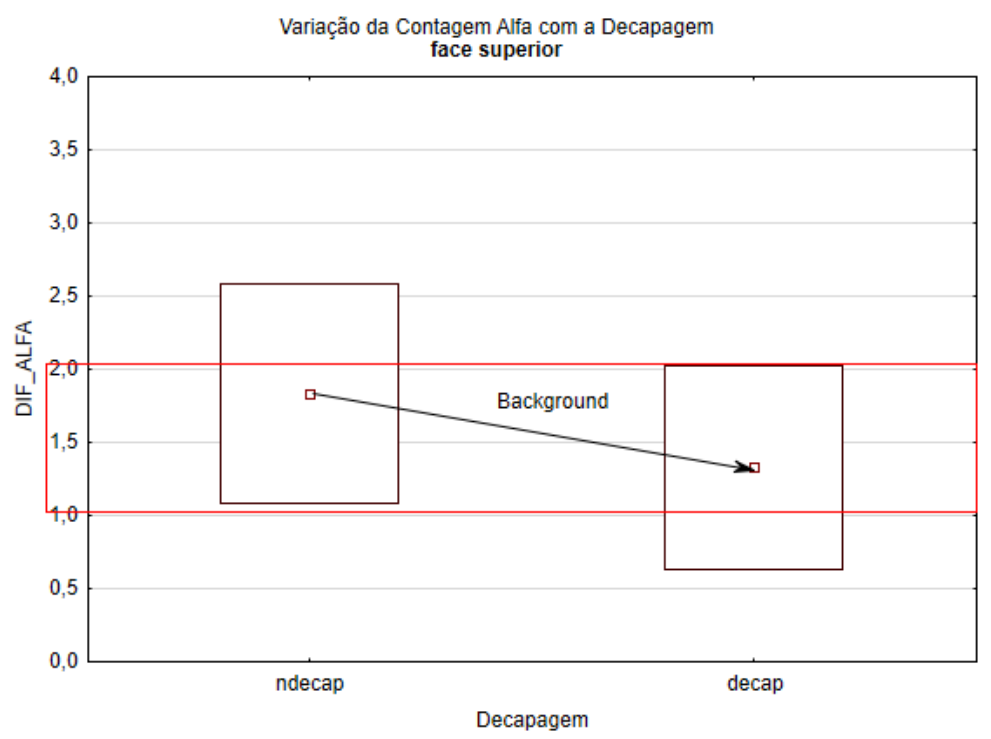

Figura 20 - Diagrama de blocos contendo a média e os limites de confiança (95\%) das contagens de emissão alfa das amostras supSD e supCD.

A média das contagens de emissões alfa da face superior, com base em DIF_alfa, revela que antes do tratamento químico das amostras havia pouca probabilidade dessas faces se contaminarem no processo de laminação das placas, onde apenas um terço da caixa de distribuição de 95\% dos dados está acima da faixa de BG. Após a decapagem, o conjunto amostral desloca-se totalmente para a região do BG. Não se espera, assim, que haja contaminação detectável por urânio residual para amostras após tratamento.

\subsubsection{Face Inferior da Placa}

$\mathrm{Na}$ Figura 21, pode-se analisar os resultados de InfSD e InfCD, que se referem as amostras da face inferior, sem e com decapagem respectivamente. Notadamente, a face inferior mostrou-se muito mais contaminada do que as amostras da face superior. 


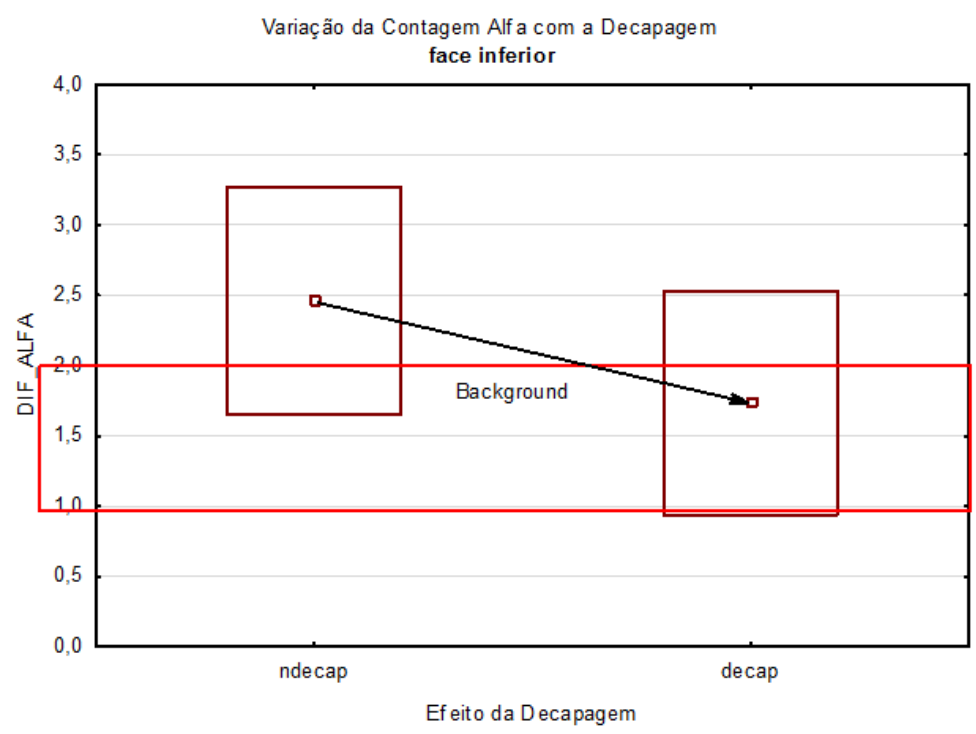

Figura 21 - Diagrama de caixas contendo a média e os limites de confiança (95\%) das contagens de emissão alfa das amostras infSD e infCD.

De acordo com os dados apresentados na Tabela 7, as amostras não tratadas na face inferior (InfSD) tem a sua média $(\mu=2,463)$ relativamente afastada da faixa superior de BG. Após o tratamento químico dessas placas, a média de DIF_alfa $(\mu=1,733)$ cai no intervalo de BG, no entanto, há dispersão ampla desses resultados com uma variabilidade que extrapola o limite superior do BG em cerca de um terço de sua caixa de dispersão e isso pode gerar possibilidade de contaminação por resíduos de urânio no elemento combustível final.

\subsubsection{Possibilidade de Contaminação}

Tendo-se em vista o resultado estatístico analisado com base na amostragem histórica ampliada, pode-se dizer que a possibilidade de se ter alguma contaminação levada para o reator com o elemento combustível seria devido ao urânio residual que resta do tratamento químico da face inferior das placas.

Fez-se então um histograma das amostras da face inferior após a decapagem (InfCD) que deram valores de DIF_alfa maior que o limite superior do BG $(2,06)$. Esse histograma está mostrado na Figura 22. 
Histograma das amostras $>2.06$ CPM

Superficie Inferior Após a Decapagem

— Distribuição Normal Esperada

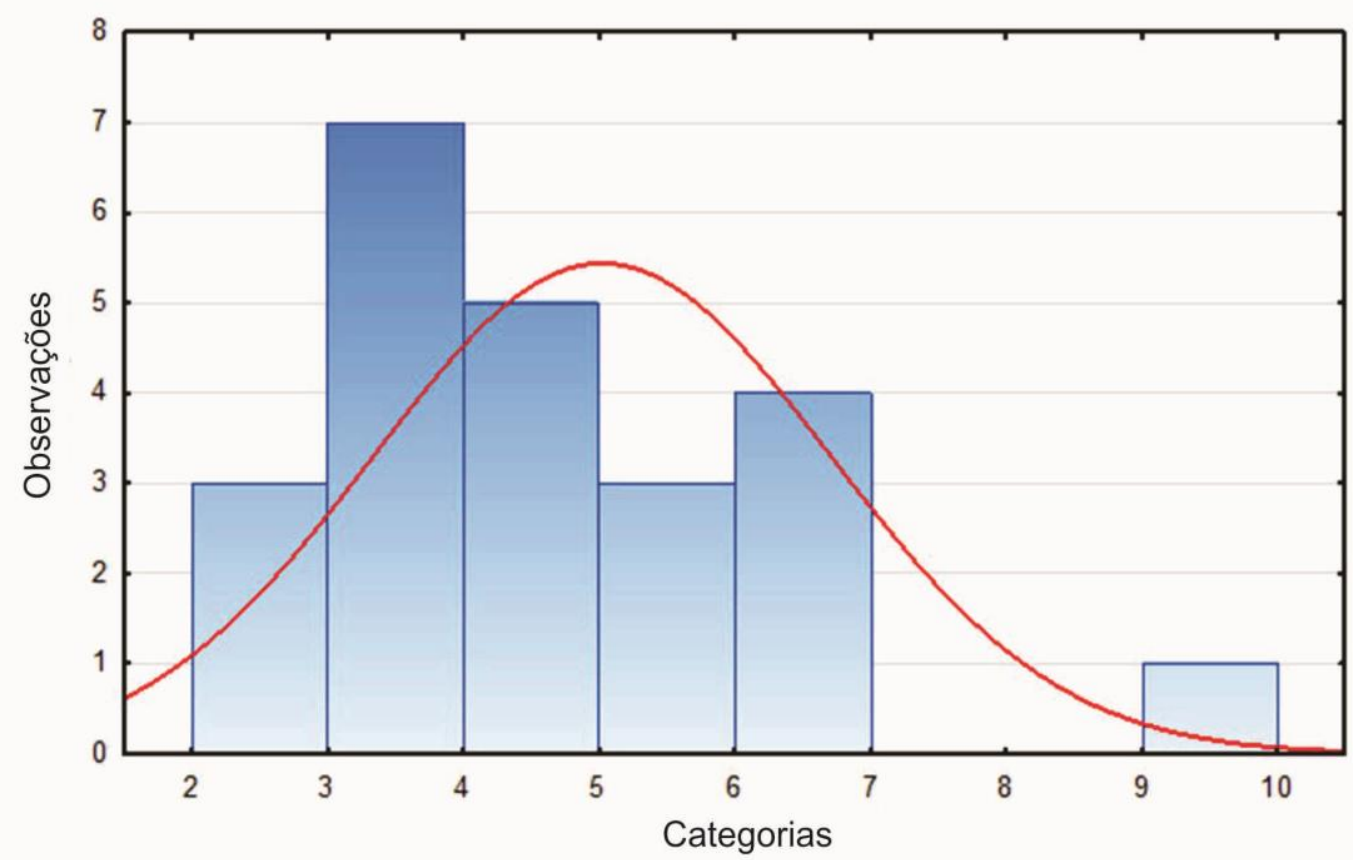

Figura 22 - Histograma de distribuição das amostras da superfície inferior que foram decapadas e que apresentaram o nivel de contagem alfa acima de 2,06.

Com base nesse histograma, tem-se o comportamento estatístico de distribuição normal dado por $5,025 \pm 0,352$. Ressalta-se que essa curva corresponde a valores medidos em amostras já decapadas, com um número total de 23 contagens. Esse número de ocorrências corresponde a 37,1\% da distribuição total de amostras infCD (62 ocorrências), fazendo-se a proporção de 23/62 tem-se a razão de 0,371. Essa é a estimativa proporcional de infCD>2,06 em relação ao conjunto amostral de InfCD. Utilizando-se a distribuição normal de todas as amostras $\operatorname{InfCD}[\mu=1,7334 ; \sigma=3,1372]$, tem-se que $\operatorname{InfCD}>2,06$ tem a probabilidade de ocorrência dada pela área superior integrada acima de 2,06 dando a probabilidade acumulada de 0,367. Como se pode ver, as estimativas da probabilidade de ocorrência de contaminação estão no nível de $37 \%$ com relação ao conjunto amostral das amostras infCD.

Portanto, pode-se dizer que o atual processo de produção de placas seguido do procedimento do tratamento químicos tem a probabilidade 0,37 (37\% de ocorrências), 
pode promover uma contaminação por urânio em um nível de 0,467 a 0,537 cpm. Esse dado representa os níveis de 95\% de significância da média de DIF_alfa [5,025 $\pm 0,352]$ para DIF_Alfa>2,06 já transformados em contagens alfa (1/10 de DIF_alfa).

Considerando-se a amostra com área de contagem de $2 \mathrm{~cm}^{2}$, esse intervalo de atividade alfa é reduzido pela metade dando a densidade de contagem por área de superfície analisada, isto é, de 0,234 a $0,269 \mathrm{cpm} / \mathrm{cm}^{2}$.

Para efeito de avaliação dos valores de contaminação em atividade radioativo como densidade de desintegração por segundo (dps) por área, chega-se a unidade $\mathrm{Bq} / \mathrm{cm}^{2}$, considera-se a seguinte equação para cálculo da atividade em $\mathrm{Bq} / \mathrm{cm}^{2}$ :

$$
\text { Atividade }^{\alpha}=\frac{\text { contagemalfa }}{\text { eficiência } .60 \mathrm{~s}}\left[\mathrm{~Bq} / \mathrm{cm}^{2}\right] \quad \ldots 8
$$

Onde contagem alfa é a faixa de variabilidade da contagem calculada $(0,234$ a $0,269 \mathrm{cpm} / \mathrm{cm}^{2}$ ). A eficiência do contador Ludlum 3030p, conforme folha de calibração do fabricante, é de $40 \%$. Esse resultado é dado em $\mathrm{cps} / \mathrm{cm}^{2}$ que por definição é igual à unidade $\mathrm{Bq} / \mathrm{cm}^{2}$. Logo, valor da atividade média calculada para esse nível de contaminação desse experimento foi de $9,72 \times 10^{-3}$ até $11,19 \times 10^{-3} \mathrm{~Bq} / \mathrm{cm}^{2}$.

Como foi considerado acima que a chance dessa contaminação de ocorrer na placa é de cerca de $37 \%$, isso equivale a dizer que esse fator pode ser multiplicado à faixa de atividade calculada acima. Dessa forma, a probabilidade de ocorrência de contaminação seria normalizada no tempo. Essa faixa de atividade por contaminação de urânio residual de forma temporal seria de $3,60 \times 10^{-3}$ a $4,14 \times 10^{-3} \mathrm{~Bq} / \mathrm{cm}^{2}$ por elemento combustível.

Considerando-se que a constante de decaimento de urânio 238 é $\lambda\left({ }^{238} \mathrm{U}\right)=4,88 \times 10^{-18} \mathrm{~s}^{-1}$ logo, pode-se calcular pela lei do decaimento a quantidade correspondente de urânio que leva a esse decaimento. De uma forma aproximada, $1 \mathrm{mg}$ de urânio 238 produz uma atividade de $12,34 \mathrm{~Bq} / \mathrm{cm}^{2}$. Portanto, estima-se que a quantidade de urânio que um elemento combustível do CCN, com área superficial total de $15540 \mathrm{~cm}^{2} \mathrm{em}$ placas

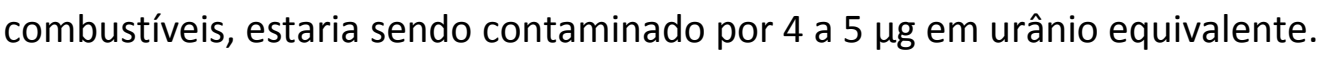


Como as medidas de contagem são efetivas para todos os isótopos de urânio e como o nível de enriquecimento no urânio utilizado no CCN é de $20 \%$ de enriquecimento de ${ }^{235} \mathrm{U}$, deve-se considerar que:

- Apenas $1 / 5$ do teor de urânio estimado nesse experimento pode gerar a contaminação efetiva durante o fissionamento nuclear, pois o isótopo ${ }^{238} \mathrm{U}$ é um isótopo pouco efetivo para se desintegrar no reator IEA-R1 por trabalhar com baixa densidade neutrônica e com nêutrons termalizados, por ter baixa seção de choque, conforme analisado no Anexo II.

- Cerca de $1 \mu \mathrm{g}{ }^{235} \mathrm{U}$ ou menos é a possibilidade de que um elemento combustível do CCN ter contaminação externa por presença de urânio residual na superfície das placas combustíveis, demonstrado estatisticamente ao longo da história de produção de elementos combustíveis no CCN.

Com base nos resultados obtidos no presente estudo, deve-se avaliar o evento de aumento da atividade da área da piscina do reator em 2006/2007. Considera-se, que aqueles resultados encontrados não pertencem à população estatística dos resultados presentes em termos de contaminação de urânio residual. Os níveis potenciais de contaminação revelados pelo presente estudo mostram que a fabricação histórica dos elementos combustíveis carreiam contaminações muito abaixo dos teores que poderiam ter causado aqueles incidentes de aumento da atividade na piscina do reator IEA-R1. Seriam esperados teores 100 vezes maior em ${ }^{235} \mathrm{U}$ do que os presentemente revelados para a produção histórica de elementos combustíveis. Constata-se que o reator IEA-R1 já operou mais de 100 elementos combustíveis oriundos dessa fabricação do CCN e somente por 4 vezes o processo de irradiação constatou atividade radioativa fora do normal, por algum fato fora da compreensão do presente estudo. Acredita-se que foram fatos esporádicos, mas que estão contemplados no nível de significância estatística de $95 \%$ de confiabilidade. 


\section{CONCLUSÕES}

Utilizando metodologia de contagem de emissões alfa associada à análise estatística com amostragem confiável de placas combustíveis produzidas pelo Centro de Combustível Nuclear do IPEN, chegaram-se aos seguintes resultados:

- A rotina presente de produção não produz contaminações mensuráveis fora do intervalo de background das contagens de radiação alfa.

- Amostras densamente contaminadas podem ser tratadas pela rotina atual de tratamento químico das placas combustíveis e produzem resultados de contagem alfa na faixa de background.

- Com base em uma amostragem estatística da produção histórica de placas combustíveis produzidas no período de 1998 a 2013, determinou-se que há uma potencial contaminação na forma de urânio residual após tratamento químico das placas. Essa contaminação é estimada em teores menores do que $1 \mu \mathrm{g}$ de ${ }^{235} \mathrm{U}$ por elemento combustível.

Face ao nível de contaminação determinado, o presente estudo mostrou que o nível de contaminação gerado é muito mais baixo do que as exigências para a própria água do reator, cujos níveis, inferiores a $50 \mu \mathrm{g} / \mathrm{L}$, são considerados satisfatórios para operação do reator IEA-R1.

No entanto, deve-se considerar que esse trabalho foi desenvolvido para um universo particular de uma fábrica de combustíveis nucleares com características próprias e que não pode ser generalizado de uma forma ampla.

O método de contagem de emissão alfa para verificação e controle de contaminação superficial de urânio em placas combustíveis mostrou-se aplicável e reprodutivo. A sensibilidade do método mostrou-se suficiente para se qualificarem placas combustíveis quanto à contaminação superficial com urânio. 


\section{SUGESTÕES PARA TRABALHOS FUTUROS}

Sugere-se, como trabalhos futuros, que sejam feitas pesquisas nas seguintes áreas:

- Fazer replicação da amostragem histórica de produção de placas combustíveis de forma a aumentar a robustez das presentes determinações de urânio residual nas placas combustíveis produzidas no CCN.

- Com a entrada em operação do reator RMB, deve-se acompanhar o perfil de atividade na piscina do reator para se determinar se as atuais práticas do CCN para produção de placas combustíveis mantem os níveis atuais adequados para operacionalidade do IEA-R1.

- Houve indicativos que a atual prática de tratamento químico das placas pode estar levando a um nível maior de contaminação por urânio residual na face inferior. Isso pode ser um indicativo de ocorrência de alguma fonte de contaminação preferencial durante o processo de fabricação da placa, bem como, de potencial inadequação da prática de tratamento químico atual. 


\section{ANEXO I - Teor de urânio na piscina do reator IEA-R1}

Controle de resíduo de urânio na água do reator IEA-R1, feito pelo CRPq junto ao CQMA/IPEN-SP.

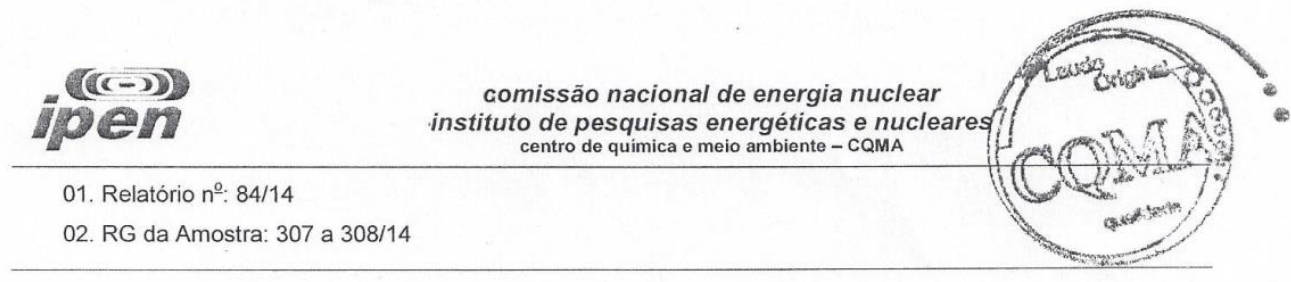

03. São Paulo, 01 de Abril de 2014.

\section{RELATÓRIO DE ANÁLISE}

04. Solicitante: $\quad$ CCN - Olair dos Santos

05. Amostra:

Água da Piscina do reator IEA-R1

06. Análise Solicitada:

Urânio

07. Informações Complementares

08. Data de Recebimento para Análise: 11/03/2014

09. Data da Realização da Análise: 27/03/2014

10. Laboratório: Laboratório de Análises Química e Ambiental - LAQA

Responsável: Marycel E. B. Cotrim; mecotrim@ipen.br; (11)3133-9305

Analista: Cleide Moreira da Silva / Marycel E. B. Cotrim

Técnica Analítica: Espectrometria de Emissão Óptica com Plasma de Argônio (ICP-OES)

11. Resultados:

\begin{tabular}{|c|c|c|}
\hline RG & Amostra & $\begin{array}{c}\text { Urânio } \\
\left(\mu \mathrm{g} \mathrm{mL}^{-1}\right)\end{array}$ \\
\hline $307 / 14$ & Piscina do reator 23/07/13 & $<0,050$ \\
\hline $308 / 14$ & Piscina do reator $27 / 07 / 13$ & $<0,050$ \\
\hline
\end{tabular}

12. Comentários:

O resultado representa a média de três (3) determinações.

13. Cláusulas de Responsabilidade:

A. Os resultados obtidos se referem somente ao material submetido ao ensaio.

B. Não se admite qualquer responsabilidade referente à exatidão da amostragem, a menos que esta tenha sido efetuada mediante

nossa própria supervisão. Salvo menção expressa, as amostras foram livremente selecionadas pelo solicitante.

C. A reprodução deste relatório está autorizada em sua forma integral. A reprodução parcial só é permitida com a autorização expressa do CQMA.

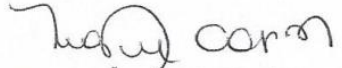

14. Dra. Marycel E. B. Cotrim - CRQ: 04121797 Responsável pelo Laboratório
15. Dr. Hélio A. Furusawa- CRQ: 04223486

Signatário Autorizado 


\section{ANEXO II - Atividade Específica dos Produtos de Fissão Gasosa no reator IEA-R1}

Memorial de Cálculo da estimativa de atividade específica dos produtos de fissão gasosa na água da piscina do reator IEA-R1 elaborado pelo Prof. Dr. Luis Antônio Albiac Terremoto em 2008 [34]. 


\section{Estimativa da Atividade Específica dos Produtos de Fissão Gasosos}

\section{I - Hipóteses gerais}

1. Concentração de $1 \mu \mathrm{gU} / \mathrm{L}$ na água do reator no início da operação

2. Composição isotópica do urânio idêntica à utilizada no combustível nuclear do reator, ou seja, $19,92 \%$ são átomos de ${ }^{235} \mathrm{U}$ e $80,08 \%$ são átomos de ${ }^{238} \mathrm{U}$

3. Operação contínua do reator a $5 \mathrm{MW}$ durante 64 horas, sendo o cálculo referente à atividade gerada ao final de todo o período

4. Temperatura média da água do reator igual a $34^{\circ} \mathrm{C}$

5. Fluxo médio de nêutrons lentos no reator igual a $3,45 \cdot 10^{13} \mathrm{n} / \mathrm{cm}^{2} . \mathrm{s}$

6. Fluxo médio de nêutrons rápidos no reator igual a $9,45 \cdot 10^{13} \mathrm{n} / \mathrm{cm}^{2} . \mathrm{s}$

7. Os produtos de fissão analisados são gama emissores gasosos habitualmente empregados no monitoramento da atividade específica da água do reator: ${ }^{133} \mathrm{Xe},{ }^{135} \mathrm{Xe}$, ${ }^{138} \mathrm{Xe} /{ }^{138} \mathrm{Cs},{ }^{85 \mathrm{~m}} \mathrm{Kr},{ }^{87} \mathrm{Kr} \mathrm{e}{ }^{88} \mathrm{Kr} /{ }^{88} \mathrm{Rb}$

8. Os produtos de fissão analisados e seus precursores não são retirados e tampouco escapam da água do reator, sendo nula a atividade específica inicial dos mesmos

9. O modelo utilizado considera cadeias de decaimento ${ }^{[1]}$ simplificadas $^{[2]}$ para os produtos de fissão analisados, nas quais precursores com meia-vida ${ }^{[3]}$ menor que 4 minutos (inferior a $0,1 \%$ do tempo total de irradiação) e estados isoméricos intermediários são desprezados

10. A fissão de um isótopo de urânio e a absorção de um nêutron por um produto de fissão são consideradas apenas se o valor médio da respectiva seção de choque ${ }^{[4-6]}$ for maior que $1 \mathrm{~b}$

\section{II - Cadeias de decaimento simplificadas e equações diferenciais correspondentes}

a) ${ }^{133} \mathrm{Xe}$

- Cadeia de decaimento simplificada

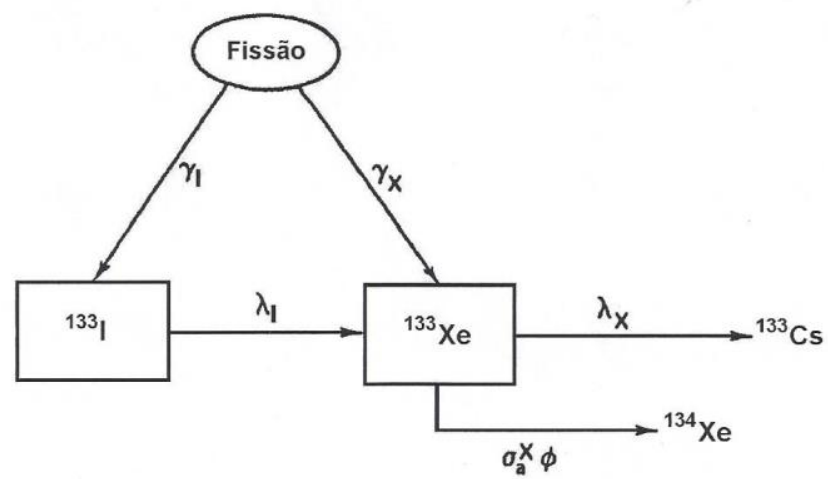


- Equações diferenciais correspondentes

$$
\begin{aligned}
& \frac{\mathrm{dI}}{\mathrm{dt}}=\gamma_{\mathrm{I}} \cdot \mathrm{N} \cdot \sigma_{\mathrm{f}} \cdot \phi-\lambda_{\mathrm{I}} \cdot \mathrm{I} \Rightarrow \mathrm{I}(\mathrm{t})=\frac{\gamma_{\mathrm{I}} \cdot \mathrm{N} \cdot \sigma_{\mathrm{f}} \cdot \phi}{\lambda_{\mathrm{I}}} \cdot\left(1-\mathrm{e}^{-\lambda_{\mathrm{I}} \mathrm{t}}\right) \Rightarrow A_{\mathrm{I}}(\mathrm{t})=\gamma_{\mathrm{I}} \cdot \mathrm{N} \cdot \sigma_{\mathrm{f}} \cdot \phi \cdot\left(1-\mathrm{e}^{-\lambda_{\mathrm{I}} \cdot \mathrm{t}}\right) \\
& \frac{\mathrm{dX}}{\mathrm{dt}}=\gamma_{\mathrm{X}} \cdot \mathrm{N} \cdot \sigma_{\mathrm{f}} \cdot \phi+\lambda_{\mathrm{I}} \cdot \mathrm{I}-\lambda_{\mathrm{X}} \cdot \mathrm{X}-\sigma_{\mathrm{a}}^{\mathrm{X}} \cdot \phi \cdot \mathrm{X} \Rightarrow \\
& \mathrm{X}(\mathrm{t})=\frac{\left(\gamma_{\mathrm{I}}+\gamma_{\mathrm{X}}\right) \cdot \mathrm{N} \cdot \sigma_{\mathrm{f}} \cdot \phi}{\lambda_{\mathrm{X}}+\sigma_{\mathrm{a}}^{\mathrm{X}} \cdot \phi} \cdot\left[1-\mathrm{e}^{-\left(\lambda_{\mathrm{X}}+\sigma_{\mathrm{a}}^{\mathrm{X}} \cdot \phi\right) \cdot \mathrm{t}}\right]+\frac{\gamma_{\mathrm{I}} \cdot \mathrm{N} \cdot \sigma_{\mathrm{f}} \cdot \phi}{\lambda_{\mathrm{X}}-\lambda_{\mathrm{I}}+\sigma_{\mathrm{a}}^{\mathrm{X}} \cdot \phi} \cdot\left[\mathrm{e}^{-\left(\lambda_{\mathrm{X}}+\sigma_{\mathrm{a}}^{\mathrm{X}} \cdot \phi\right) \cdot \mathrm{t}}-\mathrm{e}^{-\lambda_{\mathrm{I}} \cdot \mathrm{t}}\right] \Rightarrow \\
& A_{\mathrm{X}}(\mathrm{t})=\frac{\lambda_{\mathrm{X}} \cdot\left(\gamma_{\mathrm{I}}+\gamma_{\mathrm{X}}\right) \cdot \mathrm{N} \cdot \sigma_{\mathrm{f}} \cdot \phi}{\lambda_{\mathrm{X}}+\sigma_{\mathrm{a}}^{\mathrm{X}} \cdot \phi} \cdot\left[1-\mathrm{e}^{-\left(\lambda_{\mathrm{X}}+\sigma_{\mathrm{a}}^{\mathrm{X}} \cdot \phi\right) \cdot \mathrm{t}}\right]+\frac{\lambda_{\mathrm{X}} \cdot \gamma_{\mathrm{I}} \cdot \mathrm{N} \cdot \sigma_{\mathrm{f}} \cdot \phi}{\lambda_{\mathrm{X}}-\lambda_{\mathrm{I}}+\sigma_{\mathrm{a}}^{\mathrm{X}} \cdot \phi} \cdot\left[\mathrm{e}^{-\left(\lambda_{\mathrm{X}}+\sigma_{\mathrm{a}}^{\mathrm{X}} \cdot \phi\right) \cdot \mathrm{t}}-\mathrm{e}^{-\lambda_{\mathrm{I}} \cdot \mathrm{t}}\right]
\end{aligned}
$$

b) ${ }^{135} \mathrm{Xe}$

- Cadeia de decaimento simplificada

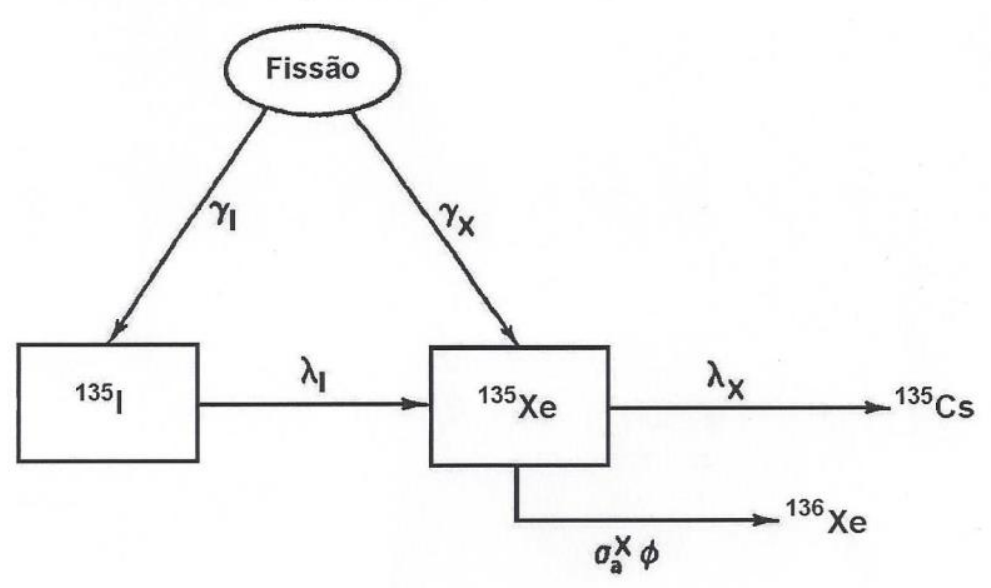

- Equações diferenciais correspondentes

$$
\begin{aligned}
& \frac{\mathrm{dI}}{\mathrm{dt}}=\gamma_{\mathrm{I}} \cdot \mathrm{N} \cdot \sigma_{\mathrm{f}} \cdot \phi-\lambda_{\mathrm{I}} \cdot \mathrm{I} \Rightarrow \mathrm{I}(\mathrm{t})=\frac{\gamma_{\mathrm{I}} \cdot \mathrm{N} \cdot \sigma_{\mathrm{f}} \cdot \phi}{\lambda_{\mathrm{I}}} \cdot\left(1-\mathrm{e}^{-\lambda_{\mathrm{I}} \mathrm{t}}\right) \Rightarrow A_{\mathrm{I}}(\mathrm{t})=\gamma_{\mathrm{I}} \cdot \mathrm{N} \cdot \sigma_{\mathrm{f}} \cdot \phi \cdot\left(1-\mathrm{e}^{-\lambda_{\mathrm{I}} \cdot \mathrm{t}}\right) \\
& \frac{\mathrm{dX}}{\mathrm{dt}}=\gamma_{\mathrm{X}} \cdot \mathrm{N} \cdot \sigma_{\mathrm{f}} \cdot \phi+\lambda_{\mathrm{I}} \cdot \mathrm{I}-\lambda_{\mathrm{X}} \cdot \mathrm{X}-\sigma_{\mathrm{a}}^{\mathrm{X}} \cdot \phi \cdot \mathrm{X} \Rightarrow \\
& \mathrm{X}(\mathrm{t})=\frac{\left(\gamma_{\mathrm{I}}+\gamma_{\mathrm{X}}\right) \cdot \mathrm{N} \cdot \sigma_{\mathrm{f}} \cdot \phi}{\lambda_{\mathrm{X}}+\sigma_{\mathrm{a}}^{\mathrm{X}} \cdot \phi} \cdot\left[1-\mathrm{e}^{-\left(\lambda_{\mathrm{X}}+\sigma_{\mathrm{a}}^{\mathrm{X}} \cdot \phi\right) \cdot \mathrm{t}}\right]+\frac{\gamma_{\mathrm{I}} \cdot \mathrm{N} \cdot \sigma_{\mathrm{f}} \cdot \phi}{\lambda_{\mathrm{X}}-\lambda_{\mathrm{I}}+\sigma_{\mathrm{a}}^{\mathrm{X}} \cdot \phi} \cdot\left[\mathrm{e}^{-\left(\lambda_{\mathrm{X}}+\sigma_{\mathrm{a}}^{\mathrm{X}} \cdot \phi\right) \cdot \mathrm{t}}-\mathrm{e}^{-\lambda_{\mathrm{I}} \mathrm{t}^{\mathrm{t}}}\right] \Rightarrow \\
& A_{\mathrm{X}}(\mathrm{t})=\frac{\lambda_{\mathrm{X}} \cdot\left(\gamma_{\mathrm{I}}+\gamma_{\mathrm{X}}\right) \cdot \mathrm{N} \cdot \sigma_{\mathrm{f}} \cdot \phi}{\lambda_{\mathrm{X}}+\sigma_{\mathrm{a}}^{\mathrm{X}} \cdot \phi} \cdot\left[1-\mathrm{e}^{-\left(\lambda_{\mathrm{X}}+\sigma_{\mathrm{a}}^{\mathrm{X}} \cdot \phi\right) \mathrm{t}}\right]+\frac{\lambda_{\mathrm{X}} \cdot \gamma_{\mathrm{I}} \cdot \mathrm{N} \cdot \sigma_{\mathrm{f}} \cdot \phi}{\lambda_{\mathrm{X}}-\lambda_{\mathrm{I}}+\sigma_{\mathrm{a}}^{\mathrm{X}} \cdot \phi} \cdot\left[\mathrm{e}^{-\left(\lambda_{\mathrm{X}}+\sigma_{\mathrm{a}}^{\mathrm{X}} \cdot \phi\right) \cdot \mathrm{t}}-\mathrm{e}^{-\lambda_{\mathrm{I}} \mathrm{I}^{\mathrm{t}}}\right]
\end{aligned}
$$


c) ${ }^{138} \mathrm{Xe} /{ }^{138} \mathrm{Cs}$

- Cadeia de decaimento simplificada

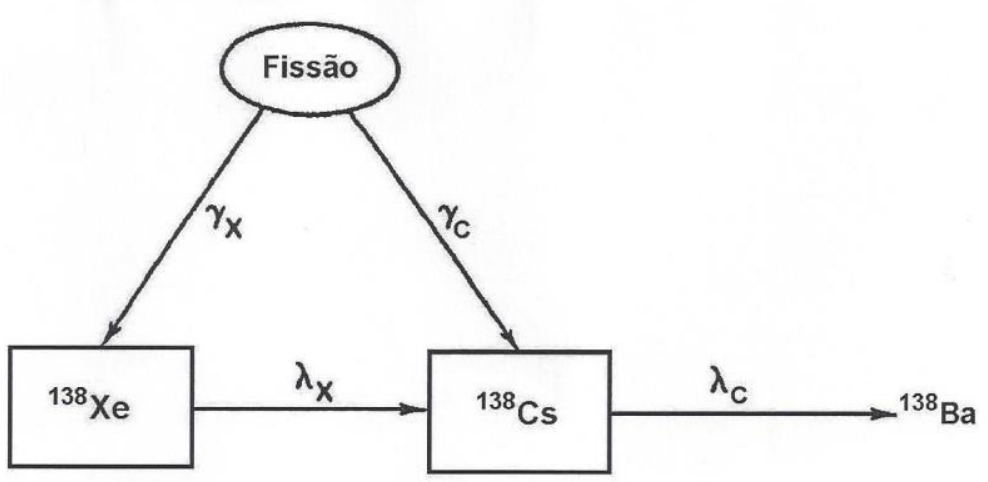

- Equações diferenciais correspondentes

$\frac{\mathrm{dX}}{\mathrm{dt}}=\gamma_{\mathrm{X}} \cdot \mathrm{N} \cdot \sigma_{\mathrm{f}} \cdot \phi-\lambda_{\mathrm{X}} \cdot \mathrm{X} \Rightarrow \mathrm{X}(\mathrm{t})=\frac{\gamma_{\mathrm{X}} \cdot \mathrm{N} \cdot \sigma_{\mathrm{f}} \cdot \phi}{\lambda_{\mathrm{X}}} \cdot\left(1-\mathrm{e}^{-\lambda_{\mathrm{X}} \cdot \mathrm{t}}\right) \Rightarrow A_{\mathrm{X}}(\mathrm{t})=\gamma_{\mathrm{X}} \cdot \mathrm{N} \cdot \sigma_{\mathrm{f}} \cdot \phi \cdot\left(1-\mathrm{e}^{-\lambda_{\mathrm{X}} \cdot \mathrm{t}}\right)$

$\frac{\mathrm{dC}}{\mathrm{dt}}=\gamma_{\mathrm{C}} \cdot \mathrm{N} \cdot \sigma_{\mathrm{f}} \cdot \phi+\lambda_{\mathrm{X}} \cdot \mathrm{X}-\lambda_{\mathrm{C}} \cdot \mathrm{C} \Rightarrow$

$\mathrm{C}(\mathrm{t})=\frac{\left(\gamma_{\mathrm{X}}+\gamma_{\mathrm{C}}\right) \cdot \mathrm{N} \cdot \sigma_{\mathrm{f}} \cdot \phi}{\lambda_{\mathrm{C}}} \cdot\left[1-\mathrm{e}^{-\lambda_{\mathrm{C}} \cdot \mathrm{t}}\right]+\frac{\gamma_{\mathrm{X}} \cdot \mathrm{N} \cdot \sigma_{\mathrm{f}} \cdot \phi}{\lambda_{\mathrm{C}}-\lambda_{\mathrm{X}}} \cdot\left[\mathrm{e}^{-\lambda_{\mathrm{C}} \cdot \mathrm{t}}-\mathrm{e}^{-\lambda_{\mathrm{X}} \cdot \mathrm{t}}\right] \Rightarrow$

$A_{C}(\mathrm{t})=\left(\gamma_{\mathrm{X}}+\gamma_{\mathrm{C}}\right) \cdot \mathrm{N} \cdot \sigma_{\mathrm{f}} \cdot \phi \cdot\left[1-\mathrm{e}^{-\lambda_{\mathrm{C}} \cdot \mathrm{t}}\right]+\frac{\lambda_{\mathrm{C}} \cdot \gamma_{\mathrm{X}} \cdot \mathrm{N} \cdot \sigma_{\mathrm{f}} \cdot \phi}{\lambda_{\mathrm{C}}-\lambda_{\mathrm{X}}} \cdot\left[\mathrm{e}^{-\lambda_{\mathrm{C}} \cdot \mathrm{t}}-\mathrm{e}^{-\lambda_{\mathrm{X}} \cdot \mathrm{t}}\right]$

d) ${ }^{85 \mathrm{~m}} \mathrm{Kr}$

- Todos os precursores deste radionuclídeo possuem meia-vida inferior a 3 minutos, de maneira que o mesmo será considerado como produzido diretamente a partir da fissão

- Equação diferencial correspondente

$\frac{\mathrm{dK}}{\mathrm{dt}}=\gamma_{\mathrm{K}} \cdot \mathrm{N} \cdot \sigma_{\mathrm{f}} \cdot \phi-\lambda_{\mathrm{K}} \cdot \mathrm{K} \Rightarrow \mathrm{X}(\mathrm{t})=\frac{\gamma_{\mathrm{K}} \cdot \mathrm{N} \cdot \sigma_{\mathrm{f}} \cdot \phi}{\lambda_{\mathrm{K}}} \cdot\left(1-\mathrm{e}^{-\lambda_{\mathrm{K}} \cdot \mathrm{t}}\right) \Rightarrow A_{\mathrm{K}}(\mathrm{t})=\gamma_{\mathrm{K}} \cdot \mathrm{N} \cdot \sigma_{\mathrm{f}} \cdot \phi \cdot\left(1-\mathrm{e}^{-\lambda_{\mathrm{K}} \cdot \mathrm{t}}\right)$

e) ${ }^{87} \mathrm{Kr}$

- Todos os precursores deste radionuclídeo possuem meia-vida inferior a 1 minuto, de maneira que o mesmo será considerado como produzido diretamente a partir da fissão

- No caso do ${ }^{87} \mathrm{Kr}$, porém, o efeito decorrente da absorção de um nêutron é relevante, sendo necessário levá-lo em conta 


$$
\begin{aligned}
& \text { - Equação diferencial correspondente } \\
& \frac{\mathrm{dK}}{\mathrm{dt}}=\gamma_{\mathrm{K}} \cdot \mathrm{N} \cdot \sigma_{\mathrm{f}} \cdot \phi-\lambda_{\mathrm{K}} \cdot \mathrm{K}-\sigma_{\mathrm{a}}^{\mathrm{K}} \cdot \phi \cdot \mathrm{K} \Rightarrow \mathrm{K}(\mathrm{t})=\frac{\gamma_{\mathrm{K}} \cdot \mathrm{N} \cdot \sigma_{\mathrm{f}} \cdot \phi}{\lambda_{\mathrm{K}}+\sigma_{\mathrm{a}}^{\mathrm{K}} \cdot \phi} \cdot\left[1-\mathrm{e}^{-\left(\lambda_{\mathrm{K}}+\sigma_{\mathrm{a}}^{\mathrm{K}} \cdot \phi\right) \cdot \mathrm{t}}\right] \Rightarrow \\
& A_{\mathrm{K}}(\mathrm{t})=\frac{\lambda_{\mathrm{K}} \cdot \gamma_{\mathrm{K}} \cdot \mathrm{N} \cdot \sigma_{\mathrm{f}} \cdot \phi}{\lambda_{\mathrm{K}}+\sigma_{\mathrm{a}}^{\mathrm{K}} \cdot \phi} \cdot\left[1-\mathrm{e}^{-\left(\lambda_{\mathrm{K}}+\sigma_{\mathrm{a}}^{\mathrm{K}} \cdot \phi\right) \cdot \mathrm{t}}\right] \\
& \text { f) }{ }^{88} \mathrm{Kr} /{ }^{88} \mathbf{R b}
\end{aligned}
$$

- Cadeia de decaimento simplificada

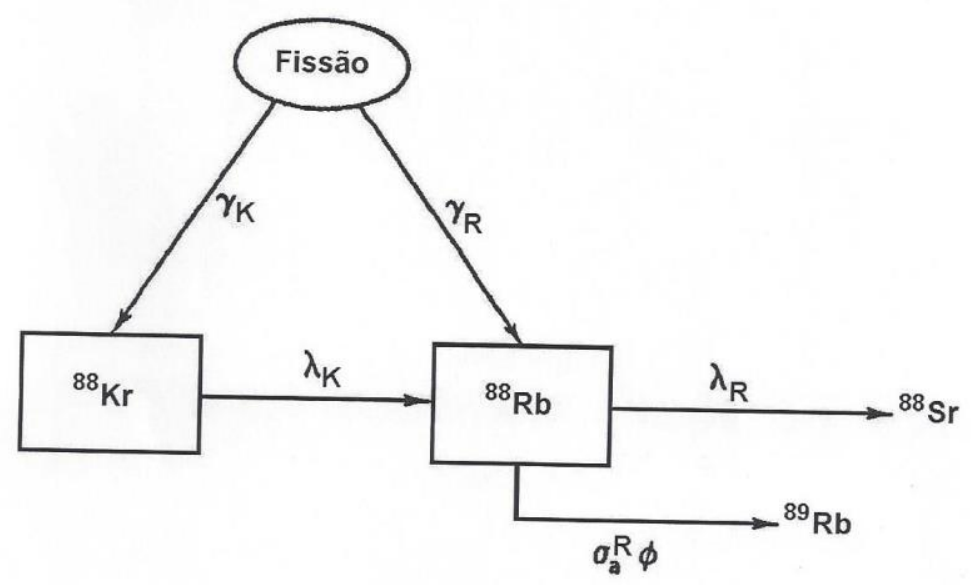

- Equações diferenciais correspondentes

$$
\begin{aligned}
& \frac{\mathrm{dK}}{\mathrm{dt}}=\gamma_{\mathrm{K}} \cdot \mathrm{N} \cdot \sigma_{\mathrm{f}} \cdot \phi-\lambda_{\mathrm{K}} \cdot \mathrm{K} \Rightarrow \mathrm{K}(\mathrm{t})=\frac{\gamma_{\mathrm{K}} \cdot \mathrm{N} \cdot \sigma_{\mathrm{f}} \cdot \phi}{\lambda_{\mathrm{K}}} \cdot\left(1-\mathrm{e}^{-\lambda_{\mathrm{K}} \cdot \mathrm{t}}\right) \Rightarrow A_{\mathrm{K}}(\mathrm{t})=\gamma_{\mathrm{K}} \cdot \mathrm{N} \cdot \sigma_{\mathrm{f}} \cdot \phi \cdot\left(1-\mathrm{e}^{-\lambda_{\mathrm{K}} \cdot \mathrm{t}}\right) \\
& \frac{\mathrm{dR}}{\mathrm{dt}}=\gamma_{\mathrm{R}} \cdot \mathrm{N} \cdot \sigma_{\mathrm{f}} \cdot \phi+\lambda_{\mathrm{K}} \cdot \mathrm{K}-\lambda_{\mathrm{R}} \cdot \mathrm{R}-\sigma_{\mathrm{a}}^{\mathrm{R}} \cdot \phi \cdot \mathrm{R} \Rightarrow \\
& \mathrm{R}(\mathrm{t})=\frac{\left(\gamma_{\mathrm{K}}+\gamma_{\mathrm{R}}\right) \cdot \mathrm{N} \cdot \sigma_{\mathrm{f}} \cdot \phi}{\lambda_{\mathrm{R}}+\sigma_{\mathrm{a}}^{\mathrm{R}} \cdot \phi} \cdot\left[1-\mathrm{e}^{-\left(\lambda_{\mathrm{R}}+\sigma_{\mathrm{a}}^{\mathrm{R}} \cdot \phi\right) \cdot \mathrm{t}}\right]+\frac{\gamma_{\mathrm{K}} \cdot \mathrm{N} \cdot \sigma_{\mathrm{f}} \cdot \phi}{\lambda_{\mathrm{R}}-\lambda_{\mathrm{K}}+\sigma_{\mathrm{a}}^{\mathrm{R}} \cdot \phi} \cdot\left[\mathrm{e}^{-\left(\lambda_{\mathrm{R}}+\sigma_{\mathrm{a}}^{\mathrm{R}} \cdot \phi\right) \cdot \mathrm{t}}-\mathrm{e}^{-\lambda_{\mathrm{K}} \cdot \mathrm{t}}\right] \Rightarrow \\
& A_{\mathrm{R}}(\mathrm{t})=\frac{\lambda_{\mathrm{R}} \cdot\left(\gamma_{\mathrm{K}}+\gamma_{\mathrm{R}}\right) \cdot \mathrm{N} \cdot \sigma_{\mathrm{f}} \cdot \phi}{\lambda_{\mathrm{R}}+\sigma_{\mathrm{a}}^{\mathrm{R}} \cdot \phi} \cdot\left[1-\mathrm{e}^{-\left(\lambda_{\mathrm{R}}+\sigma_{\mathrm{a}}^{\mathrm{R}} \cdot \phi\right) \mathrm{t}}\right]+\frac{\lambda_{\mathrm{R}} \cdot \gamma_{\mathrm{K}} \cdot \mathrm{N} \cdot \sigma_{\mathrm{f}} \cdot \phi}{\lambda_{\mathrm{R}}-\lambda_{\mathrm{K}}+\sigma_{\mathrm{a}}^{\mathrm{R}} \cdot \phi} \cdot\left[\mathrm{e}^{-\left(\lambda_{\mathrm{R}}+\sigma_{\mathrm{a}}^{\mathrm{R}} \cdot \phi\right) \cdot \mathrm{t}}-\mathrm{e}^{-\lambda_{K} \cdot \mathrm{t}}\right]
\end{aligned}
$$

- Uma vez que, na fissão do ${ }^{235} \mathrm{U}$, o rendimento dos isótopos com $\mathrm{A}=88$ na é maior do que o rendimento dos isótopos com $\mathrm{A}=87$, não foi considerada a contribuição da captura de um nêutron pelo ${ }^{87} \mathrm{Kr}$ (mencionada anteriormente) na formação do ${ }^{88} \mathrm{Kr}$ e conseqüentemente do ${ }^{88} \mathrm{Rb}$ 


\section{III - Efeitos de temperatura}

Devido ao fato de terem sido considerados os fluxos médios de nêutrons para o cerne do reator como um todo, torna-se necessário calcular as correções decorrentes dos efeitos de temperatura nas seções de choque de fissão e absorção para nêutrons lentos, conforme as seguintes equações ${ }^{[7]}$ :

$$
\begin{aligned}
& \sigma_{f l}=\frac{\sqrt{\pi}}{2} \cdot g_{f}(T) \cdot\left(\frac{T_{0}}{T}\right)^{1 / 2} \cdot \sigma_{f}\left(E_{0}\right) \\
& \sigma_{a}=\frac{\sqrt{\pi}}{2} \cdot g_{a}(T) \cdot\left(\frac{T_{0}}{T}\right)^{1 / 2} \cdot \sigma_{a}\left(E_{0}\right)
\end{aligned}
$$

onde $\mathrm{E}_{0}=0,0252 \mathrm{eV}$ e $\mathrm{T}_{0}=293,16 \mathrm{~K}\left(20^{\circ} \mathrm{C}\right)$. Os fatores de correção $\mathrm{g}_{\mathrm{f}}(\mathrm{T})$ são bem conhecidos e tabelados para ${ }^{235} \mathrm{U}$. Dentre os produtos de fissão, os fatores de correção $\mathrm{g}_{\mathrm{a}}(\mathrm{T})$ são tabelados ${ }^{[7]}$ apenas para ${ }^{135} \mathrm{Xe}$, sendo aproximadamente iguais a 1,17 na faixa de temperatura em torno de $30{ }^{\circ} \mathrm{C}$. Para os demais, quando necessário, será adotado o valor unitário.

\section{IV - Valores dos parâmetros}

$1 \mu \mathrm{gU} / \mathrm{L} \Rightarrow \mathrm{N}_{235}=5,05311.10^{11}$ átomos $/ \mathrm{cm}^{3} ; \mathrm{N}_{238}=2,03139.10^{12}$ átomos $/ \mathrm{cm}^{3}$

$\mathrm{t}=64$ horas $\Rightarrow \mathrm{t}=230400 \mathrm{~s}$

$\mathrm{T}=34{ }^{\circ} \mathrm{C} \Rightarrow \mathrm{T}=307,16 \mathrm{~K}$

$\phi_{1}=3,45 \cdot 10^{13} \mathrm{n} / \mathrm{cm}^{2} . \mathrm{s}$

$\phi_{\mathrm{r}}=9,45 \cdot 10^{13} \mathrm{n} / \mathrm{cm}^{2} . \mathrm{s}$

${ }^{235} \mathrm{U} \Rightarrow$ nêutrons lentos: $\sigma_{\mathrm{f}}\left(\mathrm{E}_{0}\right)=577 \mathrm{~b} ; \mathrm{g}_{\mathrm{f}}(\mathrm{T})=0,9639 ; \sigma_{\mathrm{fl}}=504,52 \mathrm{~b}$ nêutrons rápidos: $\sigma_{\mathrm{fr}}=1,40 \mathrm{~b}$

${ }^{133} \mathrm{Xe} \Rightarrow \lambda_{\mathrm{I}}=9,25677.10^{-6} 1 / \mathrm{s} ; \lambda_{\mathrm{X}}=1,51655.10^{-6} 1 / \mathrm{s}$ nêutrons lentos: $\gamma_{\mathrm{II}}=6,7003 \% ; \gamma_{\mathrm{XI}}=2,8.10^{-3} \% ; \sigma_{\mathrm{a}}^{\mathrm{X}}\left(\mathrm{E}_{0}\right)=190 \mathrm{~b} ; \sigma_{\mathrm{a}}^{\mathrm{X}}=172,36 \mathrm{~b}$ nêutrons rápidos: $\gamma_{\mathrm{Ir}}=6,6202 \% ; \gamma_{\mathrm{Xr}}=6,2.10^{-3} \%$; absorção muito baixa

${ }^{135} \mathrm{Xe} \Rightarrow \lambda_{\mathrm{I}}=2,91287 \cdot 10^{-5} 1 / \mathrm{s} ; \lambda_{\mathrm{X}}=2,12049.10^{-5} 1 / \mathrm{s}$ nêutrons lentos: $\gamma_{\mathrm{II}}=6,3056 \% ; \gamma_{\mathrm{Xl}}=0,2427 \% ; \sigma_{\mathrm{a}}^{\mathrm{X}}\left(\mathrm{E}_{0}\right)=2,65.10^{6} \mathrm{~b} ; \mathrm{g}_{\mathrm{a}}(\mathrm{T})=$ 1,$1672 ; \sigma_{\mathrm{a}}^{\mathrm{X}}=2,80.10^{6} \mathrm{~b}$

nêutrons rápidos: $\gamma_{\mathrm{lr}}=6,0270 \% ; \gamma_{\mathrm{Xr}}=0,3229 \%$; absorção muito baixa

${ }^{138} \mathrm{Xe} /{ }^{138} \mathrm{Cs} \Rightarrow \lambda_{\mathrm{X}}=8,19323 \cdot 10^{-4} 1 / \mathrm{s} ; \lambda_{\mathrm{C}}=3,58772.10^{-4} 1 / \mathrm{s}$

nêutrons lentos: $\gamma_{\mathrm{XI}}=6,4371 \% ; \gamma_{\mathrm{Cl}}=0,2795 \%$

nêutrons rápidos: $\gamma_{\mathrm{Xr}}=6,0422 \% ; \gamma_{\mathrm{Cr}}=0,4626 \%$ 


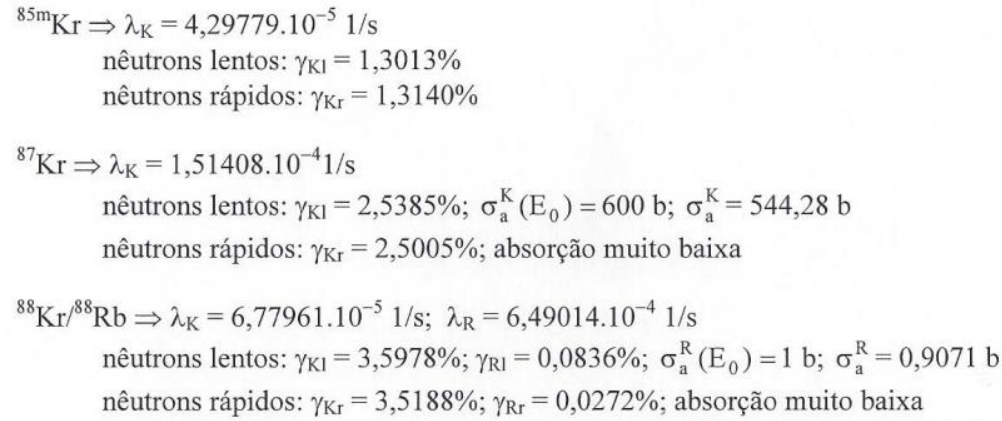

Não será considerada a contribuição das fissões em átomos de ${ }^{238} \mathrm{U}$ por nêutrons rápidos, pois a seção de choque média é inferior a $1 \mathrm{~b}$.

\section{V-Resultados}

Substituindo os valores dos parâmetros nas soluções das equações diferenciais correspondentes, são obtidos os seguintes resultados para a atividade específica:

$$
\begin{aligned}
&{ }^{133} \mathrm{Xe} \Rightarrow 106,875 \mathrm{~Bq} / \mathrm{cm}^{3}=106875 \mathrm{~Bq} / \mathrm{L}=2,89 \mu \mathrm{Ci} / \mathrm{L} \\
&{ }^{135} \mathrm{Xe} \Rightarrow 107,655 \mathrm{~Bq} / \mathrm{cm}^{3}=107655 \mathrm{~Bq} / \mathrm{L}=2,91 \mu \mathrm{Ci} / \mathrm{L} \\
&{ }^{138} \mathrm{Xe} \Rightarrow 570,209 \mathrm{~Bq} / \mathrm{cm}^{3}=570209 \mathrm{~Bq} / \mathrm{L}=15,41 \mu \mathrm{Ci} / \mathrm{L} \\
&{ }^{138} \mathrm{Cs} \Rightarrow 595,102 \mathrm{~Bq} / \mathrm{cm}^{3}=595102 \mathrm{~Bq} / \mathrm{L}=16,08 \mu \mathrm{Ci} / \mathrm{L} \\
&{ }^{85 m} \mathrm{Kr} \Rightarrow 115,327 \mathrm{~Bq} / \mathrm{cm}^{3}=115327 \mathrm{~Bq} / \mathrm{L}=3,12 \mu \mathrm{Ci} / \mathrm{L} \\
&{ }^{87} \mathrm{Kr} \Rightarrow 224,916 \mathrm{~Bq} / \mathrm{cm}^{3}=224916 \mathrm{~Bq} / \mathrm{L}=6,08 \mu \mathrm{Ci} / \mathrm{L} \\
&{ }^{88} \mathrm{Kr} \Rightarrow 318,794 \mathrm{~Bq} / \mathrm{cm}^{3}=318794 \mathrm{~Bq} / \mathrm{L}=8,62 \mu \mathrm{Ci} / \mathrm{L} \\
&{ }^{88} \mathrm{Rb} \Rightarrow 326,165 \mathrm{~Bq} / \mathrm{cm}^{3}=326165 \mathrm{~Bq} / \mathrm{L}=8,82 \mu \mathrm{Ci} / \mathrm{L}
\end{aligned}
$$

\section{VI - Comentários gerais}

1) É recomendável que os cálculos apresentados nesse informe técnico sejam repetidos utilizando o programa ${ }^{[8]}$ ORIGEN 2 , pois o mesmo emprega valores mais precisos para as seções de choque

2) A realização de comparações diretas com medidas usualmente empregadas para monitoramento do nível de atividade na água de refrigeração do reator, cujos resultados são geralmente apresentados em contagens por segundo (cps), somente é possível mediante todo um longo e cuidadoso trabalho de calibração ${ }^{[9]}$, tanto em energia quanto (e principalmente) em eficiência, do sistema de espectrometria gama onde tais medidas são efetuadas

3) Os valores relativamente baixos obtidos para as atividades eram esperados, tendo em vista a concentração de urânio que foi irradiada $(1 \mu \mathrm{g} / \mathrm{L})$ 


\section{VII - Referências bibliográficas}

[1] JNDC Nuclear Data Library of Fission Products, Japan Atomic Energy Research Institute - JAERI 1287, Tokai-mura - Naka-gun - Ibaraki-ken (October/1983).

[2] J. J. Duderstadt and L. J. Hamilton, Nuclear Reactor Analysis, John Wiley \& Sons Inc., New York (1976).

[3] U. Reus and W. Westmeier, Atomic Data and Nuclear Data Tables 29, 193 - 406 (1983).

[4] I. Kaplan, Nuclear Physics, Addison-Wesley Publishing Company Inc., Reading (1977).

[5] R. L. Murray, Nuclear Energy, Pergamon Press, Oxford (1993).

[6] D. J. Bennet and J. R. Thomson, The Elements of Nuclear Power, Longman Scientific \& Technical, London (1989).

[7] J. R. Lamarsh, Introduction to Nuclear Reactor Theory, Addison-Wesley Publishing Company Inc., Reading (1972).

[8] A. G. Croff, Nuclear Technology 62, 335 - 352 (1983).

[9] G. F. Knoll, Radiation Detection and Measurement, John Wiley \& Sons Inc., New York (1989) 


\section{ANEXO III - Amostragem histórica ampliada - dados}

Tabela de dados contendo os resultados da amostragem histórica ampliada, considerando os valores da contagem de emissões alfas feitas no aparelho Ludlum 3030P, aumentando o nível de resolução em CPM em 100\%.

As siglas utilizadas foram:

1. DEC_ND - Medidas realizadas antes e após a decapagem química alcalina): NDecap = não decapada (antes da decapagem); Dec = decapada (após a decapagem)

2. SUP_INF - Superfície da placa superior (SUP) e inferior (INF) - a superfície superior é aquela que entrou em contato com o cilindro superior de laminação no primeiro passe.

3. Alfa - contagem das emissões alfa em minutos no contador Ludlum 3030p

4. DIF_ALFA - é a diferença entre o valor obtido e o valor médio do BG entre as medidas.

\begin{tabular}{|c|c|c|c|c|c|}
\hline AMOSTRA & DATA & DEC_ND & SUP_INF & $\begin{array}{c}\text { ContagemAlfa } \\
\text { (CPM) }\end{array}$ & DIF_ALFA \\
\hline Si032A & $18 / 12 / 138: 13$ & ndecap & SUP & 48 & 7,3846 \\
\hline Si032B & $18 / 12 / 138: 20$ & ndecap & INF & 49 & 8,3846 \\
\hline Si044A & $18 / 12 / 138: 29$ & ndecap & SUP & 45 & 4,3846 \\
\hline Si044B & $18 / 12 / 138: 36$ & ndecap & INF & 42 & 1,3846 \\
\hline Si049A & $18 / 12 / 138: 43$ & ndecap & SUP & 42 & 1,3846 \\
\hline Si049B & $18 / 12 / 138: 49$ & ndecap & INF & 43 & 2,3846 \\
\hline Si070A & $18 / 12 / 138: 58$ & ndecap & SUP & 40 & $-0,6154$ \\
\hline Si070B & $18 / 12 / 139: 04$ & ndecap & INF & 43 & 2,3846 \\
\hline Si107A & $18 / 12 / 139: 11$ & ndecap & SUP & 42 & 1,3846 \\
\hline Si107B & $18 / 12 / 139: 17$ & ndecap & INF & 39 & $-1,6154$ \\
\hline Si109A & $18 / 12 / 139: 30$ & ndecap & SUP & 43 & 2,3846 \\
\hline Si109B & $18 / 12 / 139: 36$ & ndecap & INF & 45 & 4,3846 \\
\hline Si121A & $18 / 12 / 139: 45$ & ndecap & SUP & 45 & 4,3846 \\
\hline Si121B & $18 / 12 / 139: 51$ & ndecap & INF & 41 & 0,3846 \\
\hline Si176A & $18 / 12 / 139: 58$ & ndecap & SUP & 43 & 2,3846 \\
\hline Si176B & $18 / 12 / 13$ 10:03 & ndecap & INF & 42 & 1,3846 \\
\hline Si176A & $18 / 12 / 13$ 10:09 & ndecap & SUP & 44 & 3,3846 \\
\hline Si176B & $18 / 12 / 13 ~ 10: 16$ & ndecap & INF & 42 & 1,3846 \\
\hline
\end{tabular}




\begin{tabular}{|c|c|c|c|c|c|}
\hline Si200A & $18 / 12 / 1310: 22$ & ndecap & SUP & 43 & 2,3846 \\
\hline Si200B & $18 / 12 / 1310: 28$ & ndecap & INF & 42 & 1,3846 \\
\hline 21 incr $A$ & $18 / 12 / 13$ 10:39 & ndecap & SUP & 46 & 5,3846 \\
\hline 21 incr B & $18 / 12 / 13$ 10:45 & ndecap & INF & 45 & 4,3846 \\
\hline Si0233B & 18/12/13 11:08 & ndecap & INF & 40 & $-0,6154$ \\
\hline Si0234A & $18 / 12 / 1311: 14$ & ndecap & SUP & 47 & 6,3846 \\
\hline Si0234B & $18 / 12 / 1311: 20$ & ndecap & INF & 51 & 10,3846 \\
\hline Si0235A & $18 / 12 / 1311: 29$ & ndecap & SUP & 46 & 5,3846 \\
\hline Si0235B & $18 / 12 / 1311: 34$ & ndecap & INF & 44 & 3,3846 \\
\hline Si0246A & $18 / 12 / 1311: 41$ & ndecap & SUP & 40 & $-0,6154$ \\
\hline Si0246B & $18 / 12 / 1311: 47$ & ndecap & INF & 44 & 3,3846 \\
\hline Si0262A & $18 / 12 / 1311: 53$ & ndecap & SUP & 43 & 2,3846 \\
\hline Si0262B & $18 / 12 / 1311: 59$ & ndecap & INF & 42 & 1,3846 \\
\hline Si0264A & $18 / 12 / 1312: 07$ & ndecap & SUP & 41 & 0,3846 \\
\hline Si0264B & $18 / 12 / 1312: 13$ & ndecap & INF & 42 & 1,3846 \\
\hline Si0272A & $18 / 12 / 1312: 19$ & ndecap & SUP & 44 & 3,3846 \\
\hline Si0272B & $18 / 12 / 1312: 26$ & ndecap & INF & 44 & 3,3846 \\
\hline Si0285A & $18 / 12 / 1312: 32$ & ndecap & SUP & 43 & 2,3846 \\
\hline Si0285B & $18 / 12 / 1312: 37$ & ndecap & INF & 40 & $-0,6154$ \\
\hline Si0287A & $18 / 12 / 1312: 44$ & ndecap & SUP & 47 & 6,3846 \\
\hline Si0287B & $18 / 12 / 1312: 54$ & ndecap & INF & 43 & 2,3846 \\
\hline Si0333A & $18 / 12 / 1313: 00$ & ndecap & SUP & 44 & 3,3846 \\
\hline Si0333B & 18/12/13 13:06 & ndecap & INF & 43 & 2,3846 \\
\hline Si200A & $19 / 12 / 13$ 10:12 & ndecap & SUP & 44 & 3,3846 \\
\hline Si295A & $19 / 12 / 1310: 23$ & ndecap & SUP & 46 & 5,3846 \\
\hline Si295A & $19 / 12 / 13$ 10:28 & ndecap & SUP & 42 & 1,3846 \\
\hline Si295A & $19 / 12 / 13$ 10:42 & ndecap & SUP & 47 & 1,3846 \\
\hline $\mathrm{Si} 295 \mathrm{~B}$ & $19 / 12 / 13$ 10:48 & ndecap & INF & 47 & 6,3846 \\
\hline Si290A & 19/12/13 11:01 & ndecap & SUP & 34 & 6,3846 \\
\hline Si290B & $19 / 12 / 13$ 11:08 & ndecap & INF & 43 & $-6,6154$ \\
\hline Si410A & 19/12/13 11:15 & ndecap & SUP & 45 & 2,3846 \\
\hline Si410B & $19 / 12 / 1311: 20$ & ndecap & INF & 43 & 4,3846 \\
\hline Si458A & $19 / 12 / 1311: 27$ & ndecap & SUP & 40 & 2,3846 \\
\hline Si458B & $19 / 12 / 1311: 33$ & ndecap & INF & 44 & $-0,6154$ \\
\hline Si472A & $19 / 12 / 1311: 40$ & ndecap & SUP & 41 & 3,3846 \\
\hline Si472B & $19 / 12 / 1311: 53$ & ndecap & INF & 40 & 0,3846 \\
\hline Si483A & 19/12/13 12:04 & ndecap & SUP & 41 & 0,3846 \\
\hline Si483B & $19 / 12 / 1312: 10$ & ndecap & INF & 43 & 2,3846 \\
\hline Si490A & $19 / 12 / 1312: 16$ & ndecap & SUP & 39 & $-1,6154$ \\
\hline Si490B & $19 / 12 / 1312: 22$ & ndecap & INF & 43 & 2,3846 \\
\hline Si506A & $19 / 12 / 1312: 28$ & ndecap & SUP & 42 & 1,3846 \\
\hline Si506B & $19 / 12 / 1312: 34$ & ndecap & INF & 41 & 0,3846 \\
\hline Si533A & $19 / 12 / 13 \quad 12: 40$ & ndecap & SUP & 42 & 1,3846 \\
\hline
\end{tabular}




\begin{tabular}{|c|c|c|c|c|c|}
\hline Si533B & $19 / 12 / 1312: 46$ & ndecap & INF & 46 & 5,3846 \\
\hline Si564A & $19 / 12 / 1312: 52$ & ndecap & SUP & 39 & $-1,6154$ \\
\hline Si564B & $19 / 12 / 1312: 57$ & ndecap & INF & 40 & $-0,6154$ \\
\hline Si585A & 20/12/13 9:49 & ndecap & SUP & 37 & $-3,6154$ \\
\hline Si585B & 20/12/13 9:55 & ndecap & INF & 43 & 2,3846 \\
\hline Si601A & 20/12/13 10:01 & ndecap & SUP & 39 & $-1,6154$ \\
\hline Si601B & 20/12/13 10:07 & ndecap & INF & 43 & 2,3846 \\
\hline Si606A & 20/12/13 10:13 & ndecap & SUP & 45 & 4,3846 \\
\hline Si606B & $20 / 12 / 13$ 10:20 & ndecap & INF & 46 & 5,3846 \\
\hline Si613A & $20 / 12 / 1310: 26$ & ndecap & SUP & 37 & $-3,6154$ \\
\hline Si613B & 20/12/13 10:31 & ndecap & INF & 43 & 2,3846 \\
\hline Si651A & $20 / 12 / 13$ 10:43 & ndecap & SUP & 43 & 2,3846 \\
\hline Si651B & 20/12/13 10:49 & ndecap & INF & 40 & $-0,6154$ \\
\hline Si682A & 20/12/13 11:01 & ndecap & SUP & 39 & $-1,6154$ \\
\hline Si682B & $20 / 12 / 13$ 11:06 & ndecap & INF & 42 & 1,3846 \\
\hline Si683A & 20/12/13 11:13 & ndecap & SUP & 39 & $-1,6154$ \\
\hline Si683B & 20/12/13 11:19 & ndecap & INF & 42 & 1,3846 \\
\hline Si701A & $20 / 12 / 1311: 25$ & ndecap & SUP & 46 & 5,3846 \\
\hline Si701B & 20/12/13 11:32 & ndecap & INF & 43 & 2,3846 \\
\hline Si734A & $20 / 12 / 1311: 56$ & ndecap & SUP & 41 & 0,3846 \\
\hline Si734B & $20 / 12 / 13$ 12:04 & ndecap & INF & 43 & 2,3846 \\
\hline Si752A & 20/12/13 12:10 & ndecap & SUP & 41 & 0,3846 \\
\hline Si752B & 20/12/13 12:15 & ndecap & INF & 43 & 2,3846 \\
\hline Si754A & $26 / 12 / 1312: 42$ & ndecap & SUP & 40 & $-0,6154$ \\
\hline Si754A & $26 / 12 / 13 \quad 12: 42$ & decap & SUP & 40 & $-1,1053$ \\
\hline Si754B & $26 / 12 / 13$ 12:49 & ndecap & INF & 42 & 1,3846 \\
\hline Si754B & $26 / 12 / 1312: 49$ & decap & INF & 42 & 0,8947 \\
\hline Si793A & $26 / 12 / 1312: 55$ & ndecap & SUP & 40 & $-0,6154$ \\
\hline Si793A & $26 / 12 / 1312: 55$ & decap & SUP & 40 & $-1,1053$ \\
\hline Si793B & $26 / 12 / 13$ 13:01 & ndecap & INF & 47 & 6,3846 \\
\hline Si793B & 26/12/13 13:01 & decap & INF & 47 & 5,8947 \\
\hline Si808A & 26/12/13 13:10 & ndecap & SUP & 40 & $-0,6154$ \\
\hline Si808A & $26 / 12 / 1313: 10$ & decap & SUP & 40 & $-1,1053$ \\
\hline Si808B & 26/12/13 13:16 & ndecap & INF & 43 & 2,3846 \\
\hline Si808B & 26/12/13 13:16 & decap & INF & 43 & 1,8947 \\
\hline Si827A & $26 / 12 / 13$ 15:02 & ndecap & SUP & 37 & $-3,6154$ \\
\hline Si827A & $26 / 12 / 13$ 15:02 & decap & SUP & 37 & $-4,1053$ \\
\hline Si827B & $26 / 12 / 13$ 15:08 & ndecap & INF & 48 & 7,3846 \\
\hline Si827B & $26 / 12 / 13$ 15:08 & decap & INF & 48 & 6,8947 \\
\hline Si829A & $26 / 12 / 13$ 15:14 & ndecap & SUP & 42 & 1,3846 \\
\hline Si829A & $26 / 12 / 13$ 15:14 & decap & SUP & 42 & 0,8947 \\
\hline Si829B & $26 / 12 / 13$ 15:20 & ndecap & INF & 42 & 1,3846 \\
\hline Si829B & $26 / 12 / 13$ 15:20 & decap & INF & 42 & 0,8947 \\
\hline
\end{tabular}




\begin{tabular}{|c|c|c|c|c|c|}
\hline Si863A & $26 / 12 / 1315: 26$ & ndecap & SUP & 43 & 2,3846 \\
\hline Si863A & $26 / 12 / 13$ 15:26 & decap & SUP & 43 & 1,8947 \\
\hline Si863B & $26 / 12 / 13$ 15:31 & ndecap & INF & 42 & 1,3846 \\
\hline Si863B & $26 / 12 / 13$ 15:31 & decap & INF & 42 & 0,8947 \\
\hline Si928A & $26 / 12 / 13$ 15:38 & ndecap & SUP & 46 & 5,3846 \\
\hline Si928A & $26 / 12 / 13$ 15:38 & decap & SUP & 46 & 4,8947 \\
\hline Si928B & $26 / 12 / 13$ 15:43 & ndecap & INF & 46 & 5,3846 \\
\hline Si928B & $26 / 12 / 13$ 15:43 & decap & INF & 46 & 4,8947 \\
\hline Si931A & $26 / 12 / 13$ 15:55 & ndecap & SUP & 43 & 2,3846 \\
\hline Si931A & $26 / 12 / 13$ 15:55 & decap & SUP & 43 & 1,8947 \\
\hline Si931B & 26/12/13 16:01 & ndecap & INF & 48 & 7,3846 \\
\hline Si931B & $26 / 12 / 13$ 16:01 & decap & INF & 48 & 6,8947 \\
\hline Si936A & $26 / 12 / 13$ 16:08 & ndecap & SUP & 42 & 1,3846 \\
\hline Si936A & $26 / 12 / 13$ 16:08 & decap & SUP & 42 & 0,8947 \\
\hline Si936B & $26 / 12 / 13$ 16:14 & ndecap & INF & 39 & $-1,6154$ \\
\hline Si936B & $26 / 12 / 13$ 16:14 & decap & INF & 39 & $-2,1053$ \\
\hline Si004A & $26 / 12 / 1316: 20$ & ndecap & SUP & 40 & $-0,6154$ \\
\hline Si004A & $26 / 12 / 1316: 20$ & decap & SUP & 40 & $-1,1053$ \\
\hline Si004B & $26 / 12 / 1316: 26$ & ndecap & INF & 46 & 5,3846 \\
\hline Si004B & $26 / 12 / 1316: 26$ & decap & INF & 46 & 4,8947 \\
\hline Si032A & $26 / 12 / 13$ 18:15 & decap & SUP & 42 & 0,8947 \\
\hline Si032B & $26 / 12 / 13$ 18:21 & decap & INF & 43 & 1,8947 \\
\hline Si044A & $26 / 12 / 1318: 27$ & decap & SUP & 40 & $-1,1053$ \\
\hline Si044B & $26 / 12 / 13$ 18:33 & decap & INF & 42 & 0,8947 \\
\hline Si049A & $26 / 12 / 13$ 18:39 & decap & SUP & 41 & $-0,1053$ \\
\hline Si049B & $26 / 12 / 13$ 18:45 & decap & INF & 38 & $-3,1053$ \\
\hline Si070A & $26 / 12 / 13$ 18:56 & decap & SUP & 46 & 4,8947 \\
\hline Si070B & 26/12/13 19:02 & decap & INF & 41 & $-0,1053$ \\
\hline Si107A & 26/12/13 19:08 & decap & SUP & 40 & $-1,1053$ \\
\hline Si107B & $26 / 12 / 13$ 19:14 & decap & INF & 40 & $-1,1053$ \\
\hline Si109A & 27/12/13 7:07 & decap & SUP & 43 & 1,8947 \\
\hline Si109B & 27/12/13 7:13 & decap & INF & 45 & 3,8947 \\
\hline Si121A & $27 / 12 / 137: 33$ & decap & SUP & 43 & 1,8947 \\
\hline Si121B & 27/12/13 7:39 & decap & INF & 41 & $-0,1053$ \\
\hline Si176A & 27/12/13 7:54 & decap & SUP & 45 & 3,8947 \\
\hline Si176B & 27/12/13 8:00 & decap & INF & 42 & 0,8947 \\
\hline Si196A & 27/12/13 8:06 & decap & SUP & 41 & $-0,1053$ \\
\hline Si196B & 27/12/13 8:12 & decap & INF & 43 & 1,8947 \\
\hline Si200A & 27/12/13 8:18 & decap & SUP & 44 & 2,8947 \\
\hline Si200B & 27/12/13 8:23 & decap & INF & 43 & 1,8947 \\
\hline Si233A & 27/12/13 8:44 & decap & SUP & 43 & 1,8947 \\
\hline Si233B & 27/12/13 8:49 & decap & INF & 48 & 6,8947 \\
\hline Si234A & $27 / 12 / 138: 56$ & decap & SUP & 42 & 0,8947 \\
\hline
\end{tabular}




\begin{tabular}{|c|c|c|c|c|c|}
\hline Si234B & 27/12/13 9:01 & decap & INF & 36 & $-5,1053$ \\
\hline Si235A & 27/12/13 9:09 & decap & SUP & 39 & $-2,1053$ \\
\hline Si235B & 27/12/13 9:16 & decap & INF & 37 & $-4,1053$ \\
\hline Si246A & $27 / 12 / 13$ 9:22 & decap & SUP & 43 & 1,8947 \\
\hline Si246B & 27/12/13 9:28 & decap & INF & 41 & $-0,1053$ \\
\hline Si262A & 27/12/13 9:34 & decap & SUP & 37 & $-4,1053$ \\
\hline Si262B & 27/12/13 9:40 & decap & INF & 45 & 3,8947 \\
\hline Si264A & 27/12/13 9:58 & decap & SUP & 42 & 0,8947 \\
\hline Si264B & $27 / 12 / 13$ 10:04 & decap & INF & 46 & 4,8947 \\
\hline Si272A & $27 / 12 / 13$ 10:10 & decap & SUP & 44 & 2,8947 \\
\hline Si272B & $27 / 12 / 13$ 10:16 & decap & INF & 39 & $-2,1053$ \\
\hline Si285A & $27 / 12 / 13$ 10:22 & decap & SUP & 45 & 3,8947 \\
\hline Si285B & $27 / 12 / 13$ 10:28 & decap & INF & 45 & 3,8947 \\
\hline Si287A & $27 / 12 / 13$ 10:34 & decap & SUP & 43 & 1,8947 \\
\hline Si287B & $27 / 12 / 13$ 10:40 & decap & INF & 42 & 0,8947 \\
\hline Si333A & $27 / 12 / 13$ 10:47 & decap & SUP & 41 & $-0,1053$ \\
\hline Si333B & $27 / 12 / 13$ 10:54 & decap & INF & 42 & 0,8947 \\
\hline Si295A & $27 / 12 / 13$ 11:07 & decap & SUP & 46 & 4,8947 \\
\hline Si295B & 27/12/13 11:12 & decap & INF & 40 & $-1,1053$ \\
\hline Si295B & $27 / 12 / 1311: 18$ & decap & INF & 43 & 1,8947 \\
\hline Si290B & $27 / 12 / 13$ 11:24 & decap & INF & 42 & 0,8947 \\
\hline Si410A & $27 / 12 / 1311: 30$ & decap & SUP & 43 & 1,8947 \\
\hline Si410B & $27 / 12 / 13$ 11:36 & decap & INF & 39 & $-2,1053$ \\
\hline Si458A & $27 / 12 / 13$ 11:42 & decap & SUP & 46 & 4,8947 \\
\hline Si458B & $27 / 12 / 13$ 11:48 & decap & INF & 44 & 2,8947 \\
\hline Si472A & $27 / 12 / 13$ 11:55 & decap & SUP & 38 & $-3,1053$ \\
\hline Si472B & $27 / 12 / 13$ 12:00 & decap & INF & 44 & 2,8947 \\
\hline Si483A & $27 / 12 / 1312: 21$ & decap & SUP & 44 & 2,8947 \\
\hline Si483B & $27 / 12 / 1312: 26$ & decap & INF & 38 & $-3,1053$ \\
\hline Si490A & $27 / 12 / 1312: 33$ & decap & SUP & 39 & $-2,1053$ \\
\hline Si490B & $27 / 12 / 1312: 39$ & decap & INF & 45 & 3,8947 \\
\hline Si506A & $27 / 12 / 13 \quad 12: 45$ & decap & SUP & 42 & 0,8947 \\
\hline Si506B & $27 / 12 / 1312: 50$ & decap & INF & 43 & 1,8947 \\
\hline Si533A & $27 / 12 / 1312: 57$ & decap & SUP & 42 & 0,8947 \\
\hline Si533B & $27 / 12 / 13$ 13:03 & decap & INF & 43 & 1,8947 \\
\hline Si564A & 27/12/13 13:09 & decap & SUP & 41 & $-0,1053$ \\
\hline Si564B & $27 / 12 / 13$ 13:14 & decap & INF & 47 & 5,8947 \\
\hline Si564A & $27 / 12 / 13$ 14:49 & decap & SUP & 45 & 3,8947 \\
\hline Si585A & $27 / 12 / 1314: 58$ & decap & SUP & 49 & 7,8947 \\
\hline Si585B & $27 / 12 / 13$ 15:05 & decap & INF & 43 & 1,8947 \\
\hline Si601A & $27 / 12 / 13$ 15:18 & decap & SUP & 44 & 2,8947 \\
\hline Si601B & $27 / 12 / 13$ 15:27 & decap & INF & 42 & 0,8947 \\
\hline Si606A & $27 / 12 / 13$ 15:35 & decap & SUP & 41 & $-0,1053$ \\
\hline
\end{tabular}




\begin{tabular}{|c|c|c|c|c|c|}
\hline Si606B & 27/12/13 15:41 & decap & INF & 41 & $-0,1053$ \\
\hline Si613A & 27/12/13 15:49 & decap & SUP & 49 & 7,8947 \\
\hline Si613B & 27/12/13 15:55 & decap & INF & 40 & $-1,1053$ \\
\hline Si651A & $27 / 12 / 13$ 16:01 & decap & SUP & 42 & 0,8947 \\
\hline Si651B & 27/12/13 16:07 & decap & INF & 46 & 4,8947 \\
\hline Si682A & $27 / 12 / 13$ 16:32 & decap & SUP & 41 & $-0,1053$ \\
\hline Si682B & $27 / 12 / 13$ 16:39 & decap & INF & 45 & 3,8947 \\
\hline Si683A & $27 / 12 / 13$ 16:45 & decap & SUP & 45 & 3,8947 \\
\hline Si683B & $27 / 12 / 1316: 51$ & decap & INF & 48 & 6,8947 \\
\hline Si701A & 27/12/13 17:03 & decap & SUP & 37 & $-4,1053$ \\
\hline Si701B & 27/12/13 17:09 & decap & INF & 46 & 4,8947 \\
\hline Si734A & 27/12/13 17:16 & decap & SUP & 40 & $-1,1053$ \\
\hline Si734B & $27 / 12 / 13$ 17:21 & decap & INF & 51 & 9,8947 \\
\hline Si734B & 27/12/13 17:28 & decap & INF & 39 & $-2,1053$ \\
\hline Si752A & $27 / 12 / 13$ 17:34 & decap & SUP & 47 & 5,8947 \\
\hline Si752B & $27 / 12 / 13$ 17:40 & decap & INF & 45 & 3,8947 \\
\hline Si754A & 27/12/13 17:53 & decap & SUP & 47 & 5,8947 \\
\hline Si754B & $27 / 12 / 13$ 17:58 & decap & INF & 43 & 1,8947 \\
\hline Si793A & $27 / 12 / 13$ 18:06 & decap & SUP & 43 & 1,8947 \\
\hline Si793B & 27/12/13 18:13 & decap & INF & 41 & $-0,1053$ \\
\hline Si808A & $27 / 12 / 13$ 18:20 & decap & SUP & 45 & 3,8947 \\
\hline Si808B & $27 / 12 / 1318: 26$ & decap & INF & 45 & 3,8947 \\
\hline Si827A & $27 / 12 / 13$ 18:32 & decap & SUP & 42 & 0,8947 \\
\hline Si827B & 27/12/13 18:39 & decap & INF & 39 & $-2,1053$ \\
\hline Si829A & $27 / 12 / 13$ 18:45 & decap & SUP & 43 & 1,8947 \\
\hline Si829B & 27/12/13 18:51 & decap & INF & 44 & 2,8947 \\
\hline Si863A & 27/12/13 19:04 & decap & SUP & 43 & 1,8947 \\
\hline Si863B & 27/12/13 19:10 & decap & INF & 42 & 0,8947 \\
\hline Si928A & 27/12/13 19:16 & decap & SUP & 43 & 1,8947 \\
\hline Si928B & $27 / 12 / 13$ 19:23 & decap & INF & 42 & 0,8947 \\
\hline Si931A & 27/12/13 19:29 & decap & SUP & 40 & $-1,1053$ \\
\hline Si931b & 27/12/13 19:35 & decap & INF & 47 & 5,8947 \\
\hline Si936a & 27/12/13 19:41 & decap & SUP & 43 & 1,8947 \\
\hline Si936B & 27/12/13 19:46 & decap & INF & 38 & $-3,1053$ \\
\hline Si004A & 27/12/13 19:52 & decap & SUP & 39 & $-2,1053$ \\
\hline Si004B & 27/12/13 19:57 & decap & INF & 39 & $-2,1053$ \\
\hline
\end{tabular}




\section{ANEXO IV - Esfregaço em placas combustíveis antes do tratamento químico}

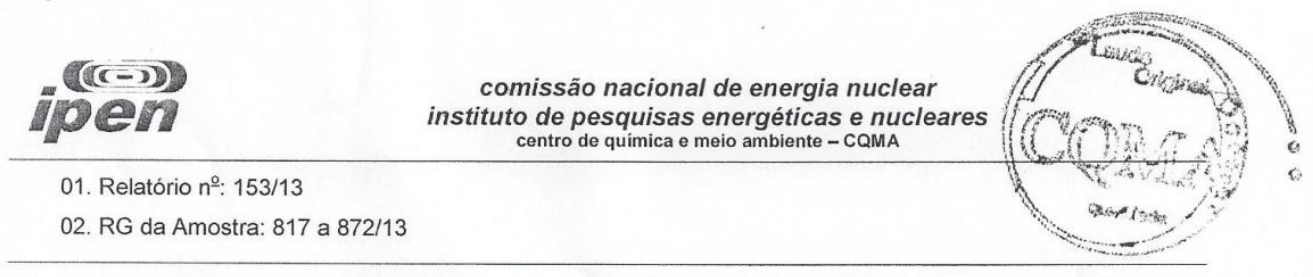

03. São Paulo, 22 de Maio de 2013.

\section{RELATÓRIO DE ANÁLISE}
04. Solicitante:
05. Amostra:
06. Análise Solicitada:
$\mathrm{CCN}$ - Olair dos Santos
07. Informações Complementares
Esfregaço das placas combustíveis
08. Data de Recebimento para Análise:
Urânio
09. Data da Realização da Análise:
$10 / 05 / 2013$
10. Laboratório:
Laboratório de Análises Química e Ambiental - LAQA
Responsável: Marycel E. B. Cotrim; mecotrim@ipen.br; (11)3133-9305
Analista: Alder S. A. Pereira
Técnica Analítica: Espectrometria de Emissão Óptica com Plasma de Argônio (ICP-OES)

11. Resultados:

\begin{tabular}{|c|c|c|}
\hline RG & Amostra & $\underset{\left(\mu g \cdot g^{-1}\right)}{U}$ \\
\hline $817 / 13$ & Placa 814 lado A/B & $<6,00$ \\
\hline $818 / 13$ & Placa 853 lado A/B & $<6,00$ \\
\hline $819 / 13$ & Placa 854 lado A/B & $<6,00$ \\
\hline $820 / 13$ & Placa 855 lado A/B & $<6,00$ \\
\hline $821 / 13$ & Placa 857 lado A/B & $<6,00$ \\
\hline $822 / 13$ & Placa 858 lado A/B & $<6,00$ \\
\hline $823 / 13$ & Placa 859 lado A/B & $<6,00$ \\
\hline $824 / 13$ & Placa 860 lado $\mathrm{A} / \mathrm{B}$ & $<6,00$ \\
\hline $825 / 13$ & Placa 861 lado A/B & $<6,00$ \\
\hline $826 / 13$ & Placa 862 lado A/B & $<6,00$ \\
\hline $827 / 13$ & Placa 863 lado A/B & $<6,00$ \\
\hline $828 / 13$ & Placa 864 lado A/B & $<6,00$ \\
\hline $829 / 13$ & Placa 865 lado A/B & $<6,00$ \\
\hline $830 / 13$ & Placa 866 lado A/B & $<6,00$ \\
\hline $831 / 13$ & Placa 867 lado A/B & $<6,00$ \\
\hline $832 / 13$ & Placa 868 lado A/B & $<6,00$ \\
\hline $833 / 13$ & Placa 869 lado A/B & $<6,00$ \\
\hline $834 / 13$ & Placa 870 lado $A / B$ & $<6,00$ \\
\hline $835 / 13$ & Placa 871 lado $A / B$ & $<6,00$ \\
\hline $836 / 13$ & Placa 872 lado $A / B$ & $<6,00$ \\
\hline $837 / 13$ & Placa 873 lado A/B & $<6,00$ \\
\hline $838 / 13$ & Placa 874 lado $\mathrm{A} / \mathrm{B}$ & $<6,00$ \\
\hline $839 / 13$ & Placa 875 lado A/B & $<6,00$ \\
\hline $840 / 13$ & Placa 876 lado A/B & $<6,00$ \\
\hline $841 / 13$ & Placa 877 lado $A / B$ & $<6,00$ \\
\hline $842 / 13$ & Placa 878 lado A/B & $<6,00$ \\
\hline $843 / 13$ & Placa 879 lado A/B & $<6,00$ \\
\hline $844 / 13$ & Placa 880 lado $A / B$ & $<6,00$ \\
\hline $845 / 13$ & Placa 881 lado A/B & $<6,00$ \\
\hline
\end{tabular}


comissão nacional de energia nuclear

instituto de pesquisas energéticas e nucleares

centro de quimica e meio ambiente - CQMA

01. Relatório n: $153 / 13$

02. RG da Amostra: 817 a $872 / 13$

\begin{tabular}{|c|c|c|}
\hline RG & Amostra & $\begin{array}{c}U \\
\left(\mu \mathrm{g} \cdot \mathrm{g}^{-1}\right.\end{array}$ \\
\hline $846 / 13$ & Placa 883 lado A/B & $<6,00$ \\
\hline $847 / 13$ & Placa 885 lado A/B & $<6,00$ \\
\hline $848 / 13$ & Placa 886 lado A/B & $<6,00$ \\
\hline $849 / 13$ & Placa 887 lado A/B & $<6,00$ \\
\hline $850 / 13$ & Placa 888 lado A/B & $<6,00$ \\
\hline $851 / 13$ & Placa 890 lado A/B & $<6,00$ \\
\hline $852 / 13$ & Placa 891 lado A/B & $<6,00$ \\
\hline $853 / 13$ & Placa 892 lado A/B & $<6,00$ \\
\hline $854 / 13$ & Placa 893 lado A/B & $<6,00$ \\
\hline $855 / 13$ & Placa 894 lado A/B & $<6,00$ \\
\hline $856 / 13$ & Placa 895 lado A/B & $<6,00$ \\
\hline $857 / 13$ & Placa 913 lado A/B & $<6,00$ \\
\hline $858 / 13$ & Placa 914 lado A/B & $<6,00$ \\
\hline $859 / 13$ & Placa 915 lado A/B & $<6,00$ \\
\hline $860 / 13$ & Placa 916 lado A/B & $<6,00$ \\
\hline $861 / 13$ & Placa 917 lado A/B & $<6,00$ \\
\hline $862 / 13$ & Placa 918 lado A/B & $<6,00$ \\
\hline $863 / 13$ & Placa 919 lado A/B & $<6,00$ \\
\hline $864 / 13$ & Placa 920 lado A/B & $<6,00$ \\
\hline $865 / 13$ & Placa 921 lado A/B & $<6,00$ \\
\hline $866 / 13$ & Placa 922 lado A/B & $<6,00$ \\
\hline $867 / 13$ & Placa 923 lado A/B & $<6,00$ \\
\hline $868 / 13$ & Placa 924 lado A/B & $<6,00$ \\
\hline $869 / 13$ & Placa 925 lado A/B & $<6,00$ \\
\hline $870 / 13$ & Placa 926 lado A/B & $<6,00$ \\
\hline $871 / 13$ & Placa 927 lado A/B & $<6,00$ \\
\hline $872 / 13$ & Placa 929 lado A/B & $<6,00$ \\
\hline & & \\
\hline
\end{tabular}

12. Comentários:

0 resultado refere-se à lixiviação dos filtros com $\mathrm{HNO}_{1}$ 1:1 (v:v).

13. Cláusulas de Responsabilidade:

A. Os resultados obtidos se referem somente ao material submetido ao ensaio.

B. Não se admite qualquer responsabilidade referente à exatidão da amostragem, a menos que esta tenha sido efetuada mediante

nossa própria supervisão. Salvo menção expressa, as amostras foram livremente selecionadas pelo solicitante,

C. A reprodução deste relatório está autorizada em sua forma integral. A reprodução parcial só é permitida com a autorização expressa do CQMA.

Tuchel Cornon

14. Dra. Marycèl'E. B. Cotrim - CRQ: 04121797 Responsável pelo Laboratório
Aldo fanar jace

15. Dr. Hélio A. Furusawa - CRQ: 04223486 Signatário Autorizado 


\section{REFERÊNCIAS BIBLIOGRÁFICAS}

1. IEA-SP, Reator de Pesquisas. 1958, Instituto de Energia Atômica: São Paulo.

2. Pasqualeto, H., Níveis de radiação na superfície livre da piscina do reator IEA-R1, in Instituto de Enegia Atômica. 1978, Universidade de São Paulo: São Paulo.

3. Vieira, E. and M. Durazzo. Estudo parametrico da deformação de placas combustiveis com núcleos de dispersão. in 19.Cbecimat. 2010. Campos do Jordão, SP, Brazil: CBECIMAT.

4. Cunningham, J.E. and E.J. Boyle, MTR-Type fuel Elements, in Peaceful uses of atomic energy: proceedings of the international conference chemical (Geneva 820Aug 1955): Reactor technology and chemical processing, U. Nations, Editor. 1956: New York (N.Y.). p. 203-207.

5. Kaufman, A.R., Nuclear reactor fuel elements, metallurgy and fabrication. 1962, New York: Interscience.

6. Saliba-Silva, A.M., et al., Research Reactor Fuel Fabrication to Produce Radioisotopes. Radioisotopes-Applications in Physical Sciences: InTech, 2011.

7. Saliba-Silva, A.M., et al., Fabrication of U3Si2 powder for fuels used in IEA-R1 nuclear research reactor. Materials Science Forum, 2008. 591: p. 194-199.

8. Travelli, A., Current status of the RERTR Program in: Development Fabrication and Application of Reduced-enriched Fuels for Research and Test Reactor: Procedings, in RERTR Meeting 1980, A.N.L. RERTR, Editor. 1980, ANL/DOE: Argonne.

9. Binford, F.T. and W.R. Knight, The use of U3O8-Al Cermet Fuel in Research Reactors. Trans. Amer. Nucl. Soc., 1977. 27.

10. Travelli, A., et al., Reduced-Enrichment Research and Test Reactors Program. Trans. Amer. Nucl. Soc., 1978. 30.

11. Schwartz, J.P., Enchiment Reduction in Research and Test Reactors. Trans. Amer. Nucl. Soc., 1978. 30.

12. Snelgrove, J.L., et al., Near-term Reduced Enrichment Conversions of Plate-Type Research and Test Reactors. Trans. Amer. Nucl. Soc., 1978. 30.

13. Stahl, D., J.E. Cuningham, and W.C. Francis, Development of advanced highuranium density reduced enrichment plate type fuels. trans. Amer. Nucl. Soc., 1978. 30.

14. Gietzen, A.J. and G.B. West, Low enrichment U-ZrH fuel for Triga and plate type reactors. Trans. Amer. Nucl. Soc., 1978. 30.

15. Capochi, J.D.T., S.H.L. Cintra, and E.F. Gentile, Estudo experimental de fabricação de elementos combustíveis planos contendo núcleos de cermets. Metalurgia, 1968. 24.

16. Capochi, J.D.T., S.H.L. Cintra, and E. Gentile, Estudo de fabricação de elementos combustíveis planos com núcleos de cermets de 65\% U308-35\%Al revestidos com alumínio. Metalurgia, 1968. 24.

17. Cintra, S.H.L., et al., Análise de variáveis do processo de fabricação de placas combustíveis com núcleos de dispersões Al-U308. Metalurgia, 1970. 26.

18. Souza Santos, T.D., H.M. Haydt, and C.T. Freitas, Fabricação de elementos combustíveis para o reator Argonauta do Instituto de Energia Nuclear. Metalurgia, 1965. 21. 
19. Souza Santos, T.D., H.M. Haydt, and C.T. Freitas, Principais características metalúrgicas dos elementos combustíveis produzidos para o reator Argonauta do Instituto de Energia Nuclear. Metalurgia, 1965. 21.

20. Souza, J.A.B.d., Procedimento de fabricação de elementos combustível a base de dispersão com alta concentração de urânio, in Instituto de Pesquisas Energéticas e Nucleares. 2011, Universidade de São Paulo: São Paulo.

21. Kim, Y.S. and G.L. Hofman, Interdiffusion in U3Si-Al, U3Si2-Al, and USi-Al dispersion fuels during irradiation. Journal of Nuclear Materials, 2011. 410(1-3): p. 1-9.

22. Park, J., et al., Effect of Si and Zr on the interdiffusion of U-Mo alloy and Al. Journal of Nuclear Materials, 2008. 374(3): p. 422-430.

23. Ryu, H.J., Y.S. Kim, and G.L. Hofman, Characterization of the interaction products in U-Mo/Al dispersion fuel from in-pile and out-pile tests, in 2006 RERTR Meeting, A.N.L. RERTR, Editor. 2006.

24. Ryu, H., et al., Heats of formation of $(U, M o) A / 3$ and $U(A l, S i) 3$ sw. Journal of Nuclear Materials, 2006. 358(1): p. 52-56.

25. Hofman, G.L., et al., Progress in development of low enriched U-Mo dispersion fuels, in Internacional Meeting on Research Reactor Fuel Manegement, 2002. 2002.

26. Hofman, G.L., et al. Initial assessment of radiation behavior of very-high-density LEU fuels. in 1999 International Meeting RERTR. 1999. Budapest, Hungary: RERTR.

27. Hofman, G.L. and M.K. Meyer. Design of high density gamma-phase uranium alloys for LEU dispersion fuel applications. in The 1998 International Reduced Enrichment for Test Reactor Conference. 1998. Sao Paulo, Brazil: RERTR.

28. Hofman, G.L., A short note on high density dispersion fuel. 1996, Argonne National Laboratory.

29. Durazzo, M., Corrosão de Pacas Combustíveis tipo MTR Contendo Núcleos de Cermets U3O8-Al, in Instituto de Pesquisas Energéticas e Nucleares - IPEN/USP. 1986, Universidade de São Paulo: São Paulo.

30. Comunicação-Privativa, Dr. Adimir dos Santos e Dr. Benedito sobre o conteúdo de urânio livre no Reator IEA-R1. 2014: CEN/IPEN.

31. Loveland, W., D.J. Moririssey, and G.T. Seaborg, Modern Nuclear Chemistry. 2006, New Jersey, EUA: John Willey \& Sons.

32. Tasaka, K., et al. JNDC Nuclear Data Library of Fission Products. 1983.

33. Verkoijen, A.H.M. and J.W. Vries, Experience with MTR fuel at the HOR reactor. Kerntechnik, 2004. 69(3): p. 88-91.

34. Comunicação-Privativa, Dr. Terremonto, L.A.A. Urânio na água do reator IEA-R1 (acidente 2006). 2008.

35. Firestone, R.B., et al., Table of Isotopes - CD Rom Edition, N.P.D.o.t.U.D.o. Energy, Editor. 1996, Wiley Interscience.

36. Keech, P., J. Noel, and D. Shoesmith, The electrochemical reduction of hydrogen peroxide on uranium dioxide under intermediate $\mathrm{pH}$ to acidic conditions. Electrochimica Acta, 2008. 53(18): p. 5675-5683. 